\title{
Les commencements de la technologie
}

Jacques Guillerme et Jan Sebestik

\section{OpenEdition}

Journals

Édition électronique

URL : http://journals.openedition.org/dht/1226

DOI : $10.4000 /$ dht. 1226

ISSN : 1775-4194

Éditeur :

Centre d'histoire des techniques et de l'environnement du Cnam (CDHTE-Cnam), Société des élèves du CDHTE-Cnam

Édition imprimée

Date de publication : 1 décembre 2007

Pagination : 49-122

ISBN : 978-2-9530779-0-2

ISSN : 0417-8726

\section{Référence électronique}

Jacques Guillerme et Jan Sebestik, «Les commencements de la technologie », Documents pour I'histoire des techniques [En ligne], 14 | $2^{\mathrm{e}}$ semestre 2007, mis en ligne le 30 décembre 2010, consulté le 08 septembre 2020. URL : http://journals.openedition.org/dht/1226 ; DOI : https://doi.org/10.4000/ dht. 1226

(c) Tous droits réservés 


\section{Les commencements de la technologie}

\section{Jacques Guillerme}

Chef de travaux à la Faculté de médecine de Besançon, Institut d'Histoire des Sciences.

Jan Sebestik

Attaché de recherches au CNRS, Institut d'Histoire des Sciences.

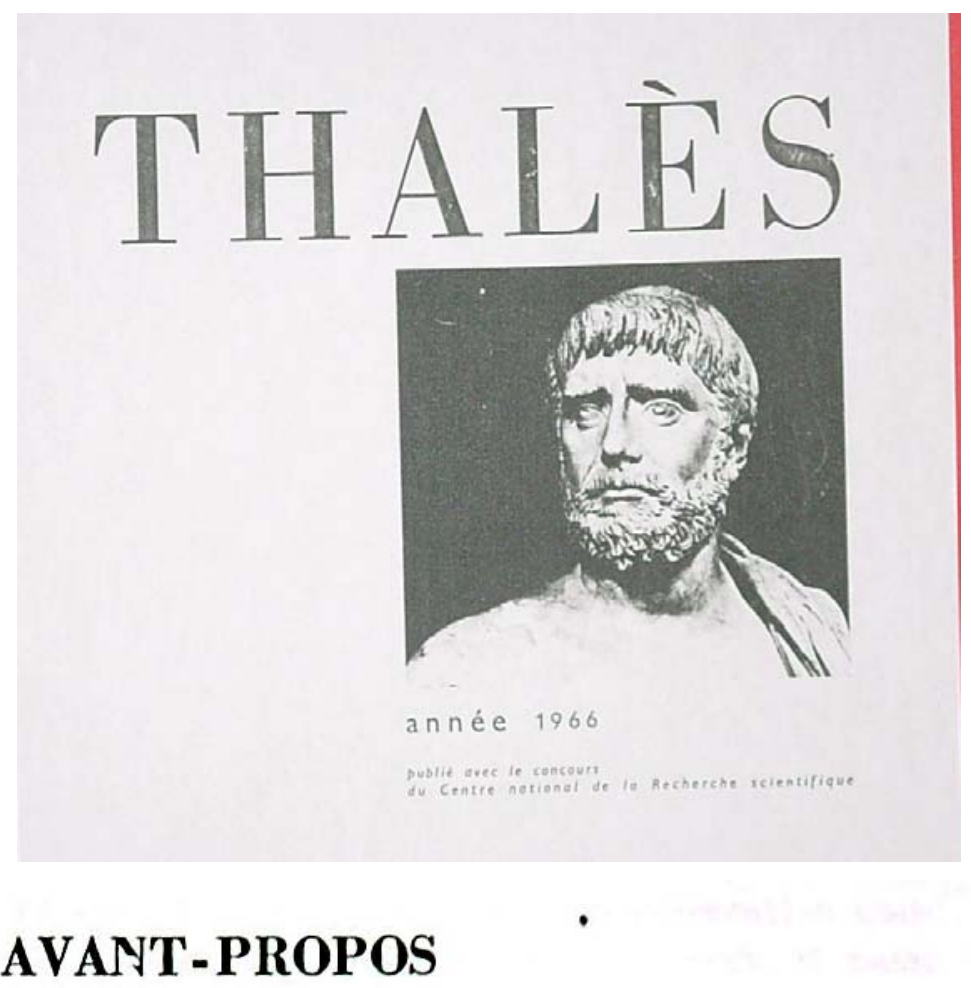

Le précédent numéro de Thalès contenail, sous le tilre "Du développement d l'évolulion an $X I X^{\mathrm{e}}$ siècle ", l'exposé des résullats d'un travail de séminaire rédigé en équipe el assumé dans son ensemble par ses qualre signalaires.

Le présenl numéro expose les résullals d'un nouveau travail colleclif, poursuivi à l'Institut d'hisloire des sciences durant les années universilaires 1963-64 et 1964-65. Mais, celle fois, le nombre des chercheurs ou éludiants ayant participé a l'exploralion de la question élail trop élevé pour qu'un mode de rédaction collectif pûl être adoplé. C'est la raison pour laquelle j'ai demandé à deux des chercheurs ayant participé aux travaux du Séminaire, MM. Guillerme el Sebeslik, de bien vouloir en présenter les résullals. J'ai relu leur texle el je les remercie bien vivement de leur travail de mise au point. M. Morère qui a participé activement, lui aussi, aux travaux du Séminaire a rédigé une nole complémentaire. La bibliographie générale est l'œuvre de MM. Guillerme el Sebestik. Enfin, il me plait de nommer ici celles el ceux qui ont, en dehors de mon collegue Gilberl Simondon, professeur de psychologie d la Sorbonne, el de M. Roger Hahn, professeur d l'Universilé de Berkeley, apporlé leur concours aux recherches et aux discussions : Mmes ou Mlles Chevroton, Conry, Legée, Renaull, Salomon-Bayet; MM. Balibar, Brunelle, Hamamdjian, Jacques, Loraux, Mac Keon, Piquemal el Rashed.

Georges Ganguilhem. 
Ce travail n'est pas à proprement parler une contribution à l'histoire des techniques. Il ne s'agit pas ici d'explorer l'histoire des procédés techniques eux-mêmes, de reprendre à notre compte le travail entrepris précisément sous la dénomination IIislory of technology par Derry et Williams ou par Singer. La technologie est prise ici d'abord, dans le sens qui détermine globalement son champ, comme un discours sur les techniques, et l'histoire qui en est tentée ici est celle d'une discipline scientifique, ou tout au moins du projet de traitement. scientifique, ayant pour objet les opérations techniques.

Mais il ne s'agit pas non plus de remonter, comme l'a fait Alfred Espinas, aux origines de la technologie. Notre recherche se propose de saisir ses commencements : son objectif principal est de détecter l'introduction du mot, la définition du concept et l'entrée de la discipline dans l'univers scientifique, de déterminer le moment qui l'instaure en introduisant ainsi une coupure dans l'apparente continuité de l'évolution historique. Le titre "Commencements de la technologie "vise donc la constilution du discours sur les opérations techniques comme discours de type scientifique.

La discipline elle-même se situe sur un plan réflexif par rapport à l'activité opératoire technique. Aussi, son histoire est celle d'une réflexion, d'une méta-technieł; bien qu'elle ait un objet propre - la maturation d'un discours empirique et sa mutation conformément aux exigences d'un discours scientifique - cette histoire au second plan doit constamment avoir présente à l'esprit la référence à la technique elle-même. Si le discours se déroule et se transforme dans le temps, c'est en fonction des tensions et des modifications structurelles de l'activité technique humaine, de ses implications et prolongements. L'histoire de la méta-technie suppose une histoire de la technie elle-mème.

Dans ce sens, l'histoire de la technologie n'a jamais été tentée, ni en France, ni en pays anglo-saxons. Elle le fut à deux reprises en Allemagne : en 1872, par Karl Karmarsch et récemment, en 1964, par Albrecht Timm (1). Issu de recherches collectives, notre travail recoupe en partie un tout récent ouvrage d'Ulrich Troitzsch consacré à la pensée technologique chez les caméralistes allemands du $\mathrm{xvII}^{\mathrm{e}}$ et $\mathrm{xvIII}^{\mathrm{e}}$ siècles (2). Timm a bien souligné la muta-

(1) K. Капмавsсн, Geschichle der Technologie seil der Mitle des achlzchnten Jahrhunderls, Munchen, 1872 (rééd. New York, 1965). - А. Тıмм, Kleine Geschichle der Technologie Stuttgart, 1964. - Notre historique coincide, quant à la matière traitée, avec la $1^{\circ}$ partie de 1'Histoire de Karmarsch ( Geschichte der technologischen Wissenschaft $\triangleright$ ) et avec le Ior chapitre de l'ouvrage de Timm (a Zur Wissenschaftsgeschichte s).

(2) U. Troiтzsch, Ansälze technologischen Denkens bei den Kameralislen des 17 - und 18. Jahrhunderls. Berlin, 1966. 
tion du discours sur les arts qu'a instituée la nouvelle discipline. Il a prêté attenlion au problème de sa définition et de son unité conceptuelle. Par lá, nous rejoignons son propos. Le nôtre en différe par une liaison plus étroile qu'il tente d'établir entre les arts et les sciences, par la documentation nouvelle, en particulier française, inconnue de Timm et de Karmarsch, et aussi par la trajectoire globale du discours sur les techniques que nous avons essayé de dessiner.

Sans qu'il y ait une coupure nette dans nolre exposé, nous nous sommes arrêtés vers le milieu du xix ${ }^{e}$ siècle. Mais cette limite approximative correspond à la fois à une évanescence et à une dispersion du discours technologique. La mulliplication saturante de ses produits provoque son éclatement en savoirs techniques spécialisés et parcellaires. La technologic, c'est alors les aventures, dans l'industrie, de la science appliquée.

Le terme de tcchnologie ne s'est acclimaté qu'avec difficultè dans la langue française. Si sa signification paraît quelque peu fixée aujourd'hui, ce n'est qu'après une longue suite de mutations diversement fécondes. On l'a entendu dans l'acception antique de terminologie des divisions du savoir (1); il a désigné la langue des arts, et ce n'est que tardivement qu'on le voit utilisé, assez timidement d'abord, dans le sens consacré en 1706 par le Phillips Dictionary : " $\Lambda$ Description of Arts, especially Mechanical n. Enoncé bref, mais précis, qui est généralisé en 1728 dans la Logica de Wolff sous ces termes : "Scientia arlium et operum artis $n(2)$. En français, le mot apparait, furtivement, pour la premièrc fois, semble-t-il, dans l'article Calalogue de l'Encyclopédie; il y désigne unc branche particulière de la division du savoir, celle qui se rapporte á la lotalité des arts (3). Mais ce néologisme ne fait pas partic du fonds termi-

(J) \& Quid est Technologia ? Est doctrina praccognoscenda, de affectionibus, ordine \& divisione disciplinarum =(p. 27), Cf. également le titre du livre 11 : . Liber secundus exhibens l.eclinologiam, id est Doctrinam de propriela tibus, \& numéro disciplinarum ". Telles sont les définitions de Alsted. Le terme qui répondrait le micux au sens de technologie, tel qu'il est envisagé ici, serait clrez cet auteur, celui de Mechanologia : . Encyclopediae liber vigesimus octavus exhlibens Mechanologiam generalem... Finis artibus mechanicis propositus est supplere defectum aliguem in vita humana (p. 1861). Artifices mechanici inducunt formam, naturae imilatione... (p. 1862), Johannis-Henrici Alsledii Encyclopediae, Herborn, 1630. - La première édition est de l'609, a Herborn; il y eut une réédilion à Lyon, en 1649 .

(2) Philosophia ralionalis sive logica, Discours préliminaire (III, De partibus philoso-' phiae). Cr. ci-dessous, $\mathrm{p}$. 29.

(3) : Cét article [Calalogue] a été fnit par M. David l'atné, un des libraires associés pour $l$ 'Encycloṕédic, sur un des manuscrits légués par feu $M$. Girard à $M$. Le Breton, son imprimeur et son nmi. Ce manuscrit est intitulé : Bibliotheque générale ou essai de litteralurc universelle ". La division bibliographique du savoir proposée par Girard comprend la théologie, la nomologie, l'historiographie, la philosophic, la philologic et la technologie. Celle-ci se rapporle au bonlicur de a tout âtre sensible et intelligent ... il est naturel que l'lomme ne néglige rien de tout ce qu'il croit être propre á le rendre heureux. C'cst par ce désir du bien-être, \& par la nécessité de pourvoir à ses besoins réels ou imaginaires, que son industrie a été excitée ; qu'en étudiant ce qui platt aux sens comme ce qui orne l'espril, il a donné naissance aux arts. Ce qui les regarde fait le sixième \& le dernier chef de ce système sous le titre de Technologie $n$. Celle lechnologie se divise en six parlies: arts civiques, ncadémiques, gymnastiques, plastiques, nutrilifs el mystériques. Parmi les disciplines classécs sous ces rubriques, la réunion de certaines d'entre elles (arts pécuniaires, la mécanique et les arts plastiques) cons- 
nologique de Diderol (on ne le trouve pas dans l'article $A r l$ ), el le projet proprement technologique de l'Encyclopédie ignore l'initialive d'un leltré qui s'est. préoccupé de nomenclature bibliographique.

La plupart des définitions proposées ensuile par les écrivains technologurs ne différeront guère de l'énoncé de Wolff, sinon pour privilégier tel aspect. des opérations industrielles, ou mettre en lumière leur finalité sociale. Cette définilion wolffienne définit un projet, mais ne suffit pas à fonder un enseignrment ou une nouvelle discipline. Cependant, c'est du côté de l'enseignement. qu'il nous faut mener nolre enquête si nous espérons gagner quelqque cerlitude, c'est en étudiant les leçons de ceux qui les premiers professèrent expressis verbis la technologie que nous pouvons nous former une idée de ce yue fut l'essence du projet technologique. Cet enseignement, on le trouve d'abord donne i Göllingen dans les années 1770 par Johann Beckmann. II s'esl. clairement. expliqué sur ses intentions, et si elles ne furent pas entièrement rénlisér's dans ses leçons, elles n'en ont pas moins fondé une discipline particuliere dont la constitution et le destin sont dignes de recherches. Sans doulc, Irenverons-nous le corpus et les visées de la technologie beckmanienne présentes, profressés, développés ailleurs sous d'autres dénominations, de même que ses ingrédients apparaissent constitués avant lui. Mais c'est leur réunion en un édifice thèrorique cohérent qui nous intéresse ici, comme science de l'application des savoirs aux besoins de la société. Et nous verrons qu'elle n'a pu pleinement se réaliser que du jour où les sciences de la nature eurent formé leur langue et celle de la vérification, si bien que l'on peut se demander si technologie ne serait pas le. nom donné à une trajectoire nécessaire de la culture occidenlale.

La naturalisation universitaire de la technologie fut, a bien des égards, révolutionnaire; elle supposait une valorisation et une thćorisation des arts mécaniques relativement aux arts libéraux qui n'a pu s'affirmer que lenlement, en Italie d'abord, puis en Angleterre, enfin en France et en pays germanique. Il n'est pas interdil de penser qu'elle aurait été plus lente à s'affirmer si le projet technologique n'avait trouvé un modèle partiel dans ce genre littéraire que sont les instructions pour l'art de la guerre, après que scra banalisée l'artillerie.

L'analogie apparaît aisément entre les problèmes des ingènieurs mililaires, dès la fin du $\mathrm{xvi}^{\mathrm{e}}$ siècle, et la gouverne des grandes manufactures à l'àge indus-

Lituera la technologic au sens moderne. Girard désigne par arls plastiques - ceux qui travaillent la matière pour en faire des ouvrages de consistance. La différente faşon de la manier fait ou des manufncturiers ou des manouvriers. Les manufachuricrs forment, c'est-i1-dire gu'ils donnent à ce qu'ils emploient, un nouvel etre par la fusion, la composition on le tissu. L.es manoumiers adaplent, simplement, c'est-ì-dire qu'ils font les ouvrages en coupant, laillant, joignant, \& les malérinux dont ils se servent. Sur ce dernier point de vile l'inspirntion baconienne semble patente (vide in/ra, p. 8). C'èst à M. Deforge que nous devons d'avoir eu notre attention altirée sur cet importanl texle. - La division de Girarl a été reprise en 1789 par M. Leclenc dans l'A brégé des diudes de l'homme fait, en laveur de l'homme do former, dédié anx neprésenlanls de la Nalion. 
triel. Il s'agit dans les deux cas, de coordonner les gestes plus ou moins spécialisés d'une multitude d'individus avec le ménage d'énergies considérables - ici l'artilleric, là des moteurs hydrauliques puis thermiques - en vue d'un effet bien défini, tout en s'assurant de la meilleure économic dq moyens. Dans les deux cas, il s'agit-d'organiser des forces - qu'elles soient productrices ou destructrices - relativement aux aspirations d'un prince, ou d'un groupe financier, en fonction des ressources du territoire dominé. Enfin dans les deux cas, les agents d'exécution et de maitrise sont instruits hors du cercle traditionnel de l'apprentissage corporatif.

Les armées fondamentalement mercenaires du $x_{v} \|^{\mathbf{e}}$ siècle, "formées de plusieurs Nations "(1) rameulaient des hommes d'origine el de talents très divers dont les tâches se technicisèrent progressivement. Le panache des belles aclions et les prouesses de l'héroïsme individuel conserveront certes un preslige soigneusement enlretenu; la taclique n'en deviendra pas moins en quelque façon une technologic, à mesure que s'accroiltra la puissance de feu et que s'affinera la précision des tirs. Le chef de guerre devra apprendre la langue de l'ingénieur. Celui-ci, cependant, ordonne à plusicurs corps de métier ; il doit en connaître les habiletés et leurs limites (2). Dans la " paix la plus profonde " comme dans le feu du combat, l'heureuse coordination des forces individuelles en vuc d'unc action colleclive suppose donc une circulation fluide de l'information entre les individus, d'où l'invention d'une symbolique intellectuelle pour projeter et combiner les plans d'opération, d'où encore le recours à un schématisme géométrique des puissances et à une normalisation des matériels, d'où enfin une pédagogie par le dessin immédiatement intelligible à des agents de langue, d'extraction et de culture différenles. Tout cela, qui s'accorde bien avec la formalisation d'un savoir technique exotérique, est tout le contraire de l'habileté technique acquise dans le monde corporalif telle que la caractérise M. Gilbert Simondon : "initiatique et exclusive ; c'est en s'élevant à l'intérieur d'une communauté déjà toüte imprégnée des schèmes d'un travail déterminé que l'enfant acquiert ses inluitions de base "(3).

Le mercénariat militaire préfigure à plus d'un égard, l'organisation sociale du $\mathrm{x}_{1 x^{\mathrm{e}}}$ siècle; il crée, avant la lettre, un prolétariat dont l'instruction techni-

(1) * J'eus la Joye d'entendre le bruit des Conquestes de V.M. ... Ce lut pour moy une salisfaction incroyable de les entendre d'une Arméc composéc de la pluspart des Nations de l' liurope ", Allain Manesson Maldet, Les travaux de Mars on l'Arl de la guerre, Paris, l6s5. Cel ouvrage dì au a Maistre de Mathématiques des Pages de la petite Ecurie p, se recommande par plus de quatre cents planches en taille douce, signe de l'inlérêt porté à l'enseignement par l'image par ce * cy-devant Ingénicur \& Sergent Minjor d'Artillerie au Portugnl.

(2) : Il est de plus nécessaire d'établir un ordre uniforme dans toutes les places que l'on fortifiera, qui instruise \& en sépare les fonctions de ceux qui en sont chargés \& qu'on règle \& distribue les emplois sclon la nécessité des ouvrages \& la capacité d'un chacun, afin de n'y employer que les gens utiles \& nécessaires... *, Le Direclcupr général des forlificalions, par M. de Vauban, Ingénieur général de France..., La Haye, 1685.

Le modèle militaire sera mainles fois inyoqué dans l'industrie. Cr. Dupıs dans sa leçon cle cloture du 26 mars 1825 au Conservatoire des arts et métiers : Les avantages que l'art de la guerre doit aux habitudes d'ordre, de régularité, d'uniformilé qu'il impose à toutes ses opérations peuvent être également produites dans les arts civils... . Discours el leģons..., Paris, 1825, p. 347.

(3) G. Simondon, Du mode d'exislence des objels lechnigues, Paris, 1958, p. 90. 
que, mème élémentaire, brise le cercle étroit de l'ésotérisme corporalif. $\Lambda$ un niveau de savoir plus élevé, la diffusion de traités à l'usage des officiers, rédigés en langue vulgaire, assortis de figures intelligibles expliquant les disposilifs techniques et tactiques, ruine l'image un peu fabuleuse de l'ingénieur inspiré de la Renaissance. Celui-ci dont la dignité et le prestige furent initialement liés à la prouesse technique avait figure de héros qui, à l'instar d'Amplion, ordonne charismatiquement aux forces de la nature. L'institutionalisation d'une pédagogie de la technique militaire va renverser radicalemenl. celte image. Sera ingénicur l'individu qui accomplit son essence grâce aux forces, conformément aux lois naturclles; e'est désormais l'homme qui trouve les bonnes formes. Non plus unique ; on peut le tuer, prendre sa place, puisque la bonne méthode créatrice de honnes formes cesse d'ètre domaine ésolérique, devient objet d'enseignement.

Du jour oú la castramétation (1) devient une application de la stalique el que la balistique introduil la dynamique et ses calculs dans la science des colonels, nous entendons prophétiser la technologie industrirlle, de mème que: la stratégie préfigurc les sciences camérales.

Le prestige accordé par les grands aux choses militaires a conféré sa dignité à la science de l'ingénicur militaire (doublet pléonastique au demeurant, jusqu'à des temps récents). Dans des emplois civils le même homme jouissait. autrefois d'une considération bien inférieure, tanl était enraciné parmi la plupart des doctes et des mondains le préjugé contre les praticiens. Il faudra, en France, attendre la Restauration pour que soit communément estimée - voire surestimée - la condition de l'ingénieur civil. Deux siècles durant les " mechaniciens" durent inlassablement argumenter contre l'impérialisme des "arts libéraux n, et répéter en quelque sorte la polémique de Léonard en faveur de la dignité du peintre comparée à celle du poète. L'Italic, au demcurant, avait. produit tôt une abondante littérature technique et le personnage de l'ingénieurartiste jouissait dans la lumière de la Renaissance toscane d'un prestige assuré. Il se trouve qu'en France ou en $A$ ngleterre les ingénicurs furent moins inspirés

(1) Caslrametatio, Dal is legermeling, Beschreven door Simon Stcvin..., Rotterdam, 1617 ; souvent relié avec la Nieuue Maniere van Slerclebou, door Spilshlussen, ígi 7 ; réél. Leydlen, 1633. - Trad. franç. La Castramélation Nouvelle Manière de Fortificalion par Escluses, Leideil et Rotterdam, 1618. - Trad. all., Franckfurl, 1631.

Il convient de rappeler ici cetle figure importante qui a réuni les talents de mathématicien, de pliysicien, d'ingénieur militaire el d'ingénieur civil. Son mérile est communément. obsorbé dans la gloire d'avoir construit des chariots à voile! En fait, on lui doil d'insignes réalisations dans le domaine des arts mécaniques, qu'il s'agisse de moulins, d'écluses ou de machinerie hydraulique.

La polyvalence de l'ingénieur militaire s'affirme avec éclat î la fin dil xvillo sičcle ; clle s'incarne dans l'idéologie polylechnicienne et il faudra attendre le second liers du Xixe siecli pour que l'ingénieur civil s'arrache à celte détermination. La rncinc militaire de l'arl ur I'ingénicur esl affirmée avec vigueur, en 1796, par l'officier du génie Mares, quand il écril. que e les fonctions de l'ingénicur... ont reçu de la part des gouvernemens le caractère pullic que leur importance rendoit indispensnble au bon emploi de ses connoissances. Mais ce caractére public a cu pour premier objet les fonctions de la guerre *. Lq sauveraineté de l'ingénieur ne peut que tendre ì s'exercer sur la société ontière : "L'art de l'ingénicur est celui d'appliquer aux besoins de la société, suivant les régles de la théorie et de l'expérience, la combinaison des différens élémens de l'existence pliysique et politique de celte société ". Quclqurs idées sur l'arl el les devoirs de l'ingénieur, Cologne, an V1, pp. 1 et 2. 
qu'un Francesce di Giorgio ou un Alberti, surtout que l'altente d'art était en romparaison anemique, quc les structures sociales staient, moins propices à l'affirmalion de grands génies sagaces en toutes sorles de travaux et de spéculations.

Cepenrlaut, c'est. d'Angleterre que vint le branle en faveur des arts mécaniquues, au moment, de la première révolution inclustrielle, qui privilégia l'ordre quantilatif dans la production (1). C'est l'époque de la forlune de Bacon et de ses idées. Premier d'une lignée de commissaires politiques du scientisme qui hanlent jusefu'aujourd'hui les enlours des laboratoires, il exerça par son oeuves et son action politique, une influence décisive dans la psychomachic des arts.

Pour eslimer it sa juste mesure la réforme baconienne, il n'est pas inutile de remonler dans le temps et de préciser anparavant les allitudes médiévales a l'égard du lravail et do la technique. M. de Gandillac a monlré, dans un récent arlicle (2), quelle vileur certains cleres du xince sicele accorderent aux "arts méchaniques n. Il se réfère à Lulle pour des raisons il la fois pédagogiques et. éronomiquess ; ce dernier réhabilite le travail, "sans référence it une théologic (presıjue: inconnue au moyen âge) qui invoquait, l'exemple de Jésus charpentier, de. Paul fabricant, de tentes, pour magnifier celte lormierung par laquelle la matiere brule se trouve teclıniquement élaboréc, lransformée en ouvrage propremenl. humain ". Il y a encore lieu de se référer aux mystiques rhénans tels jue lickhart et. Tauler qui, un demi-siècle plus tard, criliquent l'excès de l'olium monastiugue, sans toutcfois faire l'apologrie des fruits matériels du travail. "Il leur semble: seulement que la condition normale de l'homo vialor implique un operari in mundo el que les prètendus contemplatifs qui, dis ici-bas, venlent faire l'annre, font, trop sonvent la bèle n. La fidélité scolaslique au classement frarlit innel des modes de vie défini par Aristole, qui silue la quète laborieuse du profit bien au-dessous du loisir contemplatif el apres la vie politigue et militaire, "'n pas empéché los hommes du moyen-äge, moines, souvernins et inlendauls des grands domaines, d'accomplir une profonde technicisation de l'univers chrölien qui a nécessairement préparé la naturalisation de l'ingénieur. On en peul, percevoir l'écho dans les sávanles encyclopédies médiévales „ui fonl une place aux sciences "poétieques n (3), puis dans le prestige dont jouiront. les ingénicurs toscans, bien que ceux-ci aient souvent conçu leurs machines dans un espace plus onirique que réel et ne puissent être donc résolument tenus pour des technologues dont la mission est, au sens du $\mathrm{XIX}^{\mathrm{e}}$ siècle, de définir et de calculer l'espace optimum de déploiement d'une technique.

(1) (:f. J.U. Nib, La maissance de la cinilisation induslriclle, Paris, 1954, pp. 14 el 44.

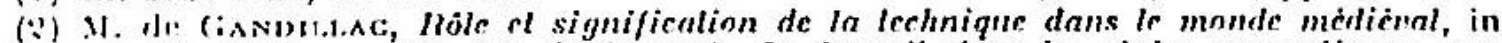
biouline. $" 17$, 1964, p. 136. Cr. égnlement, Le travnil dans les rigles monasliques, par

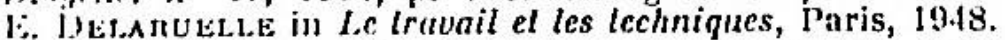

(3) Cr. Vincent de Beauvais qui composa vers 1220, avec l'npprobation de Louis $1 \mathrm{X}$, la plus importante encyclopédic médiévale jamais écrite. Sur ce sujet, cf. A.L. Gabrier, The crlucalional ideas of Vincent de Beauvais, 1956. - L' Encyclopaediae, seu Orbis disciplinarum, lam sacrurum quam prophanarum, Epislemon de P. Scsltcuus, Bale, I559, recomnil dans la Nécanique eutre autres parties : "Nanganaria, Mechanopoclice, Organopoctice, ... , p. 71 . 
La pensèe de Bacon s'affirme à une époque oi des inventions lechniqun's récentes ont radicalement modifiè la condition humaine. Comme a Tommaso Campanella (1), rien ne lui apparail plus important que certaines decouvorles qui ont pour nom imprimeric, artilleric, aimant; " aucun empire, aucune secte, aucun astre ", prétend-il, n'ont exercé un plus grand pouvoir, une plus grande influence dans les affaires lumaines que les changements qui en risultèrent (2). La nalure n'est pas ingrate; l'homme peul et doit désormais degan'r sa puissance de fécondité par une application constante aux sciencers ill ill arts. Il rêve de réunir dans une commune espérance enquêteurs attenlifs, rallailteurs de trucs et voyeurs d'arcenes. Il faul faire confiance à l'ingeninsilé de: l'homme, combinateur de forces et de formes; de son aclivilé incessantr. collégiale de préférence, destinée à épuiser toutes les transformations possilıes du monde physique, sortiront de nouvelles productions, matérielles el inlellex:tuelles, un nouvel homme, une nature autre. L'homme baconien s'exercaul. it une ardente venalio des secrels nalurels, accomplit les propositions dejji formulées par Saint-Thomas (3) el s'instilue a ministre et interprite de la nalure" (-1): il se transforme en transformant le monde qu'il enrichit d'une " nature fac:tice v (5) ; celle-ci, à vrai dire, n'est selon Bacon que le troisieme ét al de la nature, après celle des especces et celle des monstres (6). "Dans les chose's arlificielles, la nature prend les ordres de l'homme et lravaille sous son auturiti. ... par les soins et le ministère humains se manifeste une nouvelle face des choses, un autre univers ou théàtre des choses " (7). Bacon dispule aux humanistes le droit au dévoilement, à la traduction, à la conversion; el ce qu'il privilègie:


les injonctions de la malhesis, c'est qu'elles lui semblent moins fécenules, unuus

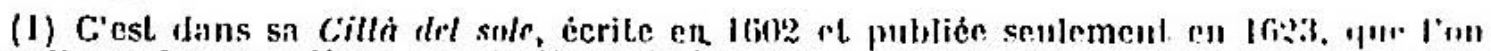

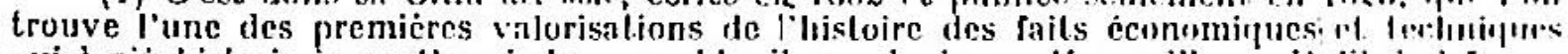




bugi, gran segno dell' union del montor.


un pamphlet en faveur des mudernes, réfutaul l'idée d'une régression de la civilisalion : In Apologie or Declaration of the Pouber and Providence of God in the Goumernment of thr tworld, consisling in an Examinalion and Censure of the common Error touching Nolurr's prrprlumi \& thiversal Decay). Le thème csl déjì exposé en 1608 par Simon Stevin qui propllélise l'avinement attendı du Wijsentijl, l'Age des sages.

(3) * Ars est ministra naturae ", St-Thomas. Cependant, Ia nature questionnéc de I3acoin offrira une plus grancle puissance de fécondilé; clicz. le Docteur angélique, comme cliez. Aristole, l'art est destiné à suppléer aux déficiences de la nalure - in illis in quibus mntura teficil ".

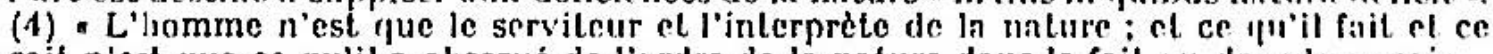
qu'il sait n'est que ce ru'il a observé de l'urdre de la nature daus le fail tuil raus la prensio.... La chatne des causes ne peul dére par aucune force relachée ni rompue, et l'on ne peut commander à la naluro qu'en lui obéssint. Ces deux objols jumeaux, la conmaissance ret Ir: pouvoir de l'linmme, se conjuguent rédlement on un seul *. Instauralio magnrt, in fine. i:f. cgalement, Nousm Orgunum, nphorisme I.

(5) Les commentaleurs tardifs de Bacon ont. semble-l-il, reslireinl Ie rinamp la la

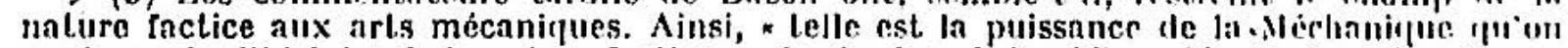
peut appeler l'histoire de la nature factice... "ill dnalyse de la philosophic du chancelirr Buron, Amsterdam, 1755 , p. 195. - Les objets artificicls (res arte/aclac) forment une dis ision spie. ciale également dans la classification de Dalgarno.

(6) Parasceve ad hisloriam naluralem el experimenlalem. The New Organm, licl. F.ll. Anderson, Indianapolis, 1960, p. 273.

(7) Ibid., p. 273. 
expressives, c'est qu'il reconnait comme primordiale la puissance informante des éléments, plus riche de produits leurs combinaisons innombrables : a Entre les arts particuliers, il faut préférer ceux qui extraient, modifient et préparent les corps naturels et la substance des choses, comme l'agriculture, l'art culinaire, la chimic, la teinture, la verreric, l'émaillerie, la sucreric, la fabrication de la poudre, la pyrotechnic, la papeterie el d'autres productions semblables... n Il y a chez cel liomme un avidité gourmande pour les malières, une atterdion presque ' anxieuse pour leur engendrement. Il relègue en seconde position " ccux des arts qui consistent principalement dans le mouvement délicat des mains ou d'instruments... tels que le tissage, la charpenteric, l'archilecture, la construction des moulins, des horloges et autres arts semblables, quoi qu'il ne faille aucunement les négliger ". Ils importent, en effet, parce qu'ils sont l'occasion et le siège de phénomènes " relatifs à l'altération des corps nalurels, el parce qu'ils apportent des enseignements précis touchant au mouvement local, ce qui est une alfaire de grand intérêt, à plusieurs points de vue "(1). C'est. donc dans la production des matières et dans la mise en ceuvre d'une nature transmutable que s'enracine le programme baconien. Espérance point folle, qui ne manquait pas d'encouragements, alors que l'ingéniosité des céramistes ou les premiers traités techniques, comme celui d'Agricola, multiplient des exemples de réussile. Ils devaient être assez convaincants, puisqu'à la source de l'induction baconionne, on a pu supposer non sans vraisemblance, des méditations sur la technique (2). Certes, on a critiqué l'écart trop tendu, pour nous, entre son ambition de dominer la totalilé du savoir et l'empirisme de sa méthodologie ; mais on oublie, en revanche, que de nombreux traits de son monde idéal, sont aujourd'hui incarnés dans le nòtre, comme allant de soi, cependant que certaines de ses vues les plus déroutanles traduisent simplement l'état récl de la société dans laquelle il vivait (3). En fait, il prélude à la pensée technologique

(1) Ibid, p. 278. On pcul reconnaitre la postérité de Bacon dans la chimie de l'Encyclopédie, extractrice et combinatrice de qualités. Au contraire de la pliysique mécaniste, énoneiatrice de vérilés abstrailes, elle prétend aller au corur des choses et surprendre la * vie de la nature . On connnil í cel egard les critiques de Diderol formulèes dans son Interprèlalion de la nature: "La cliose du mathémnticien n'a pas plus d'existence dans la nature que celle du joueur * (in CEuvres philosophiques, éd. P. Vernic̀re, Paris, 1956, pp. 179-80). Cf. également, les remarģues de Buffon : a l'idée de ramener l'explication des pliénomènes à des principes mécanif(ues est grande et belle. Mais ce n'est qu'un projet, el ... il n'est pas fondé . (in Gowres, él. Flourens, Paris, 1855, L. I, p. 152). T'our lui, "Loules les idées des arts onl leur modele dans les productions de la nature * (Ibid., p. 15). Un courant vivace de la p philosophie " jacobine hérite de toules ces conviclions et les investit dans les projets d'éducalion technigue; ee que l'on perçoil bien dans ces propos de Masuyer: * je venx que toules les malières des arts, sortant brutes des mains de la nature, subissent successivement entre les mains des éleves, el sous l'reil de leurs maltres, tous les procédés, tontes les opérations qui les appliquent aux usnges de la société ; je veux que la theorie et la prolique se domnent la main, s'éclairent mulucllement, amenent rapidement tous les arts au degré de perfection tont ils sont susceptibles; je veux enfin, par les efforts combinćs de tous les maftres, par leurs observations réunies et constamment suivies, arracher de la nature ces voiles dont jusifu'ici elle a couverl ses secrets, pour l'offrir aux adorations des hommes dans toule sa nutlité, dans toute sa mnjesté o, Discours sur l'organisation de l'instruclion publique el de l'éducation nationale en France, 1793.

(2) P'our une nltentive réévaluation moderne de l'euvre de Bacon, voir Jan PAтоcKa, Arislolcles, jeho predchudei a dedicove, 1064, Praguc, pp. 288-301.

(3) Ibid., p. 293. 
du $x_{n i I^{e}}$ siècle, il préfigure la description, souvent rapsodique, des arts et des métiers, qu'il importera d'examiner avec un ceil de naturaliste et d'ordonner idéalement dans une classification taxinomique. La confrontation qu'il appelle ouvre l'activité technique de type corporaliste, en exhibe les modalités, facilitera les échanges d'ingéniosités. Ce lui est encore un mérite d'avoir pressenti la programmation politique de l'industrie et la pédagogie conséquente. Mais il n'a pas vu - qui songerait à lui en faire honnêtement grief - que la technique et la pédagogie du nouvel ordre seront fondées sur un type de science auquel il tourne le dos. D'autres fêtes le sollicilaient, entre la maison de Salomon et le métabolisme universel de la matière.

En dépil du caractère quelque peu fanlaslique de son univers, en raison plutôt du messianisme de ses discours, Bacon entraine ses lecteurs dans un grand élan contagieux vers la culture scientilique. Conlagion qui sera endémique. Par instants, Comenius répète Bacon (I) ; Descarles mème, dans un passage: célèbre, semble lui répondre; mais chez lui, les ressorls de la nouvelle science forment une armature conceptuelle, scule capable d'en assurer le mudelage technique (2). Le message baconien sera surtout revendiqué par le fidéisme techniciste de l'Encyclopédie (3) et, à sa suite, par maints technologues. Il est à peine utile d'ajouler que sa mémoire est vénérée par les Anglo-Saxons et quelques marxistes.

Les tâches du fabricant trouvent avec Bacon une nouvelle dignité et par là, il prépare la civilisation technologique. En omettant, toutefois, cette: motion essentielle, le délour conceptuel par lequel le geste technique se trouve déduit d'une théorie préalablement constituée. Il y a dans la pensée de Bacon une myopie spéculative qu'il semble de bon ton de censurer. Cependant, c'esL l'image même du rôle de l'ingénieur qui est profondément changée. Ses inventions ne seront plus seulement l'auxiliairc des desseins belliqueux, ni un art

(1) Homo autem polest agere vol non agere; et agere hoc vel illud, sic vel sic; el censere ac emendare opera sua, in infinitum. Unde tanta operum humanorum exsurgit, tum varietas, tum multitudo, ut quasi novus Mundus viderhur . Cf. J.A. Comenus, Tuo pansophical works, P'rague, 1951 (Praecognita, p. 36).

(2) Les " notions générales touchant la physique... m'ont fail voir qu'il est possible de parvenir à des connaissances qui soient fort utiles à la vie, et qu'au lieu de cette philosophie spéculative qu'on enseigne dans les écoles, on en peut trouver une pratique, par laquelle, connaissant la force el leg actions du feu, de l'eau, de l'air, des astres, des cieux el de tous les autres corps qui nous environnent, aussi distinctemeni que nous connaissons les divers métiers de nos artisans, nous les pourrions employer en même façon à lous les usages auxquels ils sont propres, el ainsi nous rendre comme maltre el possesseur de la nalure ", Discours de la méthode, $6^{\circ}$ partic (Ed. de la Pléiade, Paris, 1952, p. 168). - Entre Bacon et Descarless, le concept de nalure cliange complètement de sens : la nature baconienne, loute proclie encore de l'homme par la fascination qu'elle exerce sur ses sens est le siège de puissances obscures dont il faut arracher les secrets ; la nature cartésienne, étendue, homogène, pure de toule force cachée - la nature n'est pas a quelque Déesse, ou quelque aulre sorte de puissance imaginaire - - est transparente dans une géométrie qui lui imprime son ordre. L'homme est désormais séparé de la nature; de serviteur et inlerprête. il est promu mattre é possesseur. Son activité opératoire, dorénavant souveraine s'exerce dans un domaine illimité, assimilé à l'espace technique. Si, chez. Bacon, la nalure cst le modele pour la technique, chez. Descartes c'est la technique qui devient modéle pour la nature.

(3) Ce. l'article Arl dans lequel Diderot répète mot pour mol des formules baconiennes. Cr. également, de jugement tiré de la premiêre livraison du Journal oeconomique, dalée de janvier $1751:$ a le fond de la Nature est si varié \& si inépuisable que l'on ne peul trop exciter l'industrie à donner à ses productions toutes les lormes dont elle esl susceptible , p. 12́. 
d'ćtonner à l'usage des cours princières. Elles apparaîtront comme un moyen économique et légilime d'améliorer la condition humaine (1). A l'idée de progrès scientifigne s'unil, désormais la vue de l'utilité et du confort, qui plus est, du conforl. accessible au grand nombre, grâce ì des falbrications bien réglées; la pensée technologique se déploie d'abord dans la commodité reproduclible des ohjels, dans une ébauche de normalisation des ustensiles. Cette intention de consacrer le génic inventif de l'homme à l'extension du bien-ètre se trouve clairement. aroué daus quantité de lextes de l'époque post-haconienne. Ainsi, dans la seconde charle conslitutive de la Royal Society : "Les "fellows n doivent s'emplower it faire progresser sous la juridiction de l'expéricnee, les sciences de: la nil ure et des arts utiles pour la gloire de Dieu le créateur et le profit de la race humaine ". Termes analogues a une exhortalion de Boyle qui invite ses colligurs it contribuer par leurs talents a la "gloire du grand auteur de la nature .1. all confort de l'espèce humaine " (2). De l.clles intentions supposaient assuriment. une réforme pédagogique el la contratiction portée sans ménagement combre les habiludes scolastiques. Bacon ful des premiers à former le projel d'un collige universel voué à l'enseignement el l'avancement de loules les scinces. Projel qui recevra l'adhésion de Comenius dans la préface du tome II des Opera didactica omnia, et qui trouvera sous Cromwell une amorce de réalisailion ì Jurham. Le nom de Comenius doil être souligné ici ; il affirme à la suile de Campanella (3) le primat de la chose sur le mot dans la pédagodie (4). Sis vues furent. accueillies avec sympathie en Angleterre, notamment parmi les

(1) (at ıui ressort explicitement du programme trncí dans la Nonuelle Allanlirie. Sa fin



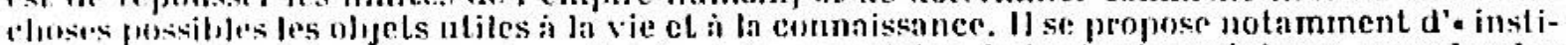
lure ant compaguie qui examineroit i fond les proprictez de toules les crétures, pour la plus grande gloire de leur Auleur \& l'utilité du Genre humain... il ful dil que de douze en douze alls il parliroil de ce Royaume deux Vnissenux dnos chacun desquels il y auroil trois confrires de la .1 aison de Salomon... avec ordre de nous rapporter toul ce qu'ils auroient remarque ... l'ubserver principalement Loul ce qui regarde les sciences, les Arts, Ies munufaclures $\&$ les iinventinus nouvelles de loul l'Univers \& de se charger a leur retour de loule sorte de Livres,

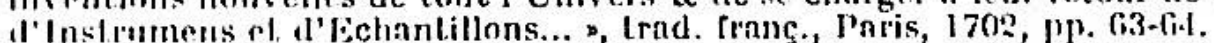


la philosuplia: laturelle, les arts mécaniques el l'agronomie, en necord avec les principes de tul' nousulle collaboration philosophique, qui n'honore le savoir que s'il esl utile à la praliulu. ". Jid. Birch, L,oudres, 1744,1 , p. 20 .

(a) Campanella inslitutionalise dans sa cilé idén]e l'enseignement par l'image murale

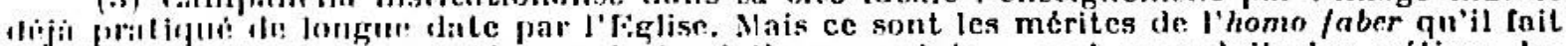
Wrientenle. Sur le mur intéricur de di sixième enceinte a sont reproduits les métiers, les unablines, lus cutils, en usage dans les diverses nations. A côlé d'eux les portrails de leurs insenteurs. L, mur extérieur est clécoré par les portrails de ceux qui, par leur intelligence, par leur génic, leuss travaux ont doté l'humanilé de quelque progrès * (F.d. Zévaès, 1950); aitusi, se trouvent préfigurés les programmes des célébrations révolulionnaires qui déploiéront l'espril de: Ia fête encyclopédique dans l'espace architeclural de la cilé. Mis ces représ'ulations ne seront pas que le cénotaphe du génie humain; clles auront une destination pédagogiquer: "II y a dans la Cité du Soleil des professeurs qui sont clungés denseign $r$ le


i jeitr, appremuent. sans peine, el comme en se jouanl ces diverses sciences el même l'histoire ile ces sciencess (l bid., p. 45).

(4) Les idées pédagogiques de Comenius qui demande ln participalion active de l'élève el unt connaissance fondén sur les rapports directs et inluitifs avec les objets ont inspiré les fomlateurs des Realschulen allemands qui seront si imporlantes pour lin diffusion des connaissances f.celınologịues. Cf. A. J'ıмм, Kl. gessh. Technol., pp. 33-39 el U. Troitzscil, Ansälze lechnol. Jenkens..., pp. IA2-IA!. 
puritains. Le besoin de recueillir sur le continent toutes sortes d'informal ions - a l'instar des observateurs de l'utopie baconienne - celui de les comparer en vue d'améliorer le confort se manifeste dès les années 16:30. Ainsi John J)ury notait en 1631 (Purpose and Plalform of my Journey inlo Germany) son intention de collecler les inventions et de réunir les procédés el pratiques de toutes les sciences ; et il insiste d'ailleurs sur l'opportunilé de recueillir plus particulièrement ce qui intéresse la santí, mais aussi l'accroissement des riclesses par' les industries mécaniques et les échanges commerciaux, sur terre cl par iner, dans la guerre comme dans la paix. La même intention parait dans la correspondance de Henry Justil qui écrira en 1667 a Daniel Huct en ces termes: "S'il y a quelque chose dans votre province... qui soit commode et qui puisst: contribuer aux aises de la vie, je vous prie de $m$ 'en faire part. Je fais un recuril de tout ce qui se trouve en chaque pays el qui n'existe point dans un autre "(1).

A l'instar de Comenius, le Poméranien Samucl Hartlieb, devenu Hartlib it Londres, s'était épris de rassembler dans une commune tolérance les diversess sectes chrétiennes dont, les rudes dissensions avairnt déchiré l'liurope ; tout comme le savant morave, il accordait le plus grand prix à l'éducation techniquus et aux vues de l'empirisme ulilitaire. Son influence qui ful considerable: illustre bien l'heureuse mobilité des esprits dans la république des lettres, celle tolérance indifférente aux origines qui contrastait si cruellement parfois avec les fanatismes religieux. Le premier séjour indiscutable de. Hartlib en Angleterre se situe en 1628; on peut mesurer son crédit a la dédicace que Hillon lui fit, en 1644 , de son traité sur l'éducation (2), et celle de l'Advice de Sir IVilliam Petty publić à Londres en 1648. C'est un ami de Hartlib, le puritain Ifezeliah, Woodward qui aide a la conversion des esprits vers l'enseignement ulilitaire "in touch with Life " que délivreront les "Dissenting Academies ". L'enseirnument scientifique trouve encore des soutiens dans l'II umble Molion to the Parliamenl of England concerning the Adurancement of Learning rédigee en 16.19 par John Hall ou dans l'Academiarum Examen publié peu après par Jolın Welsster qui revendique en faveur de la " science jamais assez appréciée de la pyrotechnie ou chimie ". Ainsi s'amorce au xvıe siècle un courant de curiosité pour les arts pratiques et leur pédagogic, qui ne sera pas sans effel à long lerme. De son propre mouvement l'éducation technologique inspire une technologie de l'éducation.

En France, l'empirisme utilitariste cut, semble-l-il, un peu plus de peine it s'affirmer. Sans doute, les signes d'impatience à l'égard de la tradition scolistique ne manqquent-ils pas au $x{ }^{e}{ }^{e}$ siècle. Il y a des exemples fameux dans toules les mémoires; mais c'est surtout Bernard Palissy qu'il Caut rappeler ici, dout.

(1) Cité par H. Bnown, Scienlific Organisations in lhe Seventecnlh centur!l Franre, Ballimore, 1934, p. 175. Huet annonce au meme correspondant en 1686, I'alsandon de son projet de livre sur les commodités de ln vie.

(2) Hartetb est l'auteur d'une utopic publiéc a Londres en 16.11, A Description of the famous Kingdom of Macaria dans laquelle il exprime sous le voile de lexulisme sis virs rélormatrices. On Lrouve par ailleurs dans l'Advice of William Pclly to Mr Samurl Ilorllit for the Aduancement of some particuliar Parls of Learning de 1648, le projel d'un gl!mnusimm mechanicum, qui serait un collège d'artisans conçu en vue du progrès des manufactures. 
les opinions appartiennent à l'univers baconien. Mème défiance à l'égard de la spéculation théorique, même reférence enthousiaste à la pratique; dès 1580, il met en garde son lecteur contre la culture absiraite : " (J'ai) désir de l'adverlir que tu le donnes garde de essuyer ton esprit de sciences escriptes aux cabinets par une théorique imaginative on crochelée de quelque livre escript par imagination de ceux qui n'ont rien practiqué ". El tout aussitòt, il vante l'expérience inluilive, sans aucunement prévoir la rationalité de l'expérimentalion : " (je) te donne gaarde de croire les opinions de ceux gui disent \& soutiennent que théorique a engendré la praclique. Ceux qui enseignent telle doctrine prennent argument mal fondé, disans qu'il faut imaginer \& figurer la chose que l'on veul faire en son esprit, devant que mettre la main à la besogne " (1). Tout comme Bacon, il cède à l'ivresse que procure la réactivité presque vivante de la matière quand on la tourmente, et il récuse la fécondité de l'imagination théorique, à dire vrai assez infirme ou inefficiente en son temps. Si Palissy se cantonne dans un empirisme provisoirement efficace, on trouve, en revanche, chez Sully et surtoul Montchretien des vues systématiques sur l'organisalion économique de la nation entière : "L'art politic dépend médiatement de l'oeconomic "aflirme Antoyne de Montchrestien dans son Traiclé de l'économie politique, dédiè en 1615 au Roy el la Reyne mère du Roy (2). Il les conjure d'user de leur puissance pour enrichir le pays : "On peut réduire à trois moyens principaux la principale gloire de vostre règne et l'accroissement de la richesse de vos peuples : Au réglement et augmentalion des artifices $\&$ manufactures, qui maintenant sont en vogue parmi nous, ou peuvent y estre mises à l'advenir ; A l'entretien de la navigation, laquelle decheut à veüe d'eil... Au restablissement du commerce qui s'en va périssant de jour en jour en ce royaume..." (3). Ces monitions ne seront guère entendues d'une Cour obsédée de soucis politiques pressants. Le propos de Montchrestien est d'ailleurs presque unique en France, à cette époque (4). C'est qu'il en a pris l'inspiration en Angleterrc, où il avait dû fuir pour échapper aux suites judiciaires d'un duel. L'Anglelerre était acquise à une mentalité protestante tolérante, comme l'a soutenu Max Weber, à une religion de l'entreprise. La France demeurera, au conlraire, dominée par une spiritualité de fond catholique, accueillante de

(1) Discours admirables..., Paris, 1589. - Advertissement aux Lecteurs, n.p.

(2) Ed. Funck-Brentano, Paris, 1889, p. 27.

(3) Ibidl., p. 38.

(4) II fait signaler toulefois, a la meme époque, la publication de quelques ouvrages trchniquues d'un mérite inégal. A côlé de dispositiłs ingénieux, parfois rénalisnbles et réalisés, ils exljibent des allégories de la puissance mécanique et des rêveries machinales. Dans l'édition par G. PASCALI (Lyon, 1582), du Thealre des instrumens malhemaliques el méchaniques de J. Besson (Lyon, 1578), un " prolemio = de F. Benonldo loue également le plaisir que son thétitre procure au regard, el l'utilité de ses machines : * suo Theatro d'una falica immensa ; si ripieno egli é di varij instrumenti \& Machine tanto a guardare giocondissime, quanto utijissime ad oprarle o $(A \mathrm{ij})$. Autre ouvrage notable, celui de Salomon de Caus qui publie en 1615, Les haisons des /orces mouvanles avec diverses Machines tanl ulilles que plaisantes auxquelles sonl adjoints plusieurs desseings de groles el fontaines, Francfort. 11 prélend se distinguer de ses prédécesseure qui * ont mis en lumière quelques Machines par eux inventées sur le de ses predect mais peu d'icelles peuvent avoir aucun effect, \& ont crea, que par une nultiplication de rodes denles les dites machines auroient effect, selon leur pensée... " (Epistre au Lecteur, n.p.). 
plus à l'absolulisme du monarque. La prospérité familiale y apparaitra plus rarement comme le signe de l'élection divine, et les sources d'enrichissement autres que foncières y jouiront longtemps d'une moindre considleration. Tout ce qui sera janséniste souffrira mal l'excès des soins temporels; dans son désir de réformer l'" homme intérieur n, Jansénius ne dénoncera-t-il pas, ct le dernier Pascal après lui, la vaine activité de l'intelligence finie coupable de détourner le vrai chrétien de la contemplation des vérités éternelles. Cippendanl, à l'utilitarisme anglais font écho divers libelles en faveur des arts mécanirgurs e.t, de leur enseignement. Propos qui se noue dès 1624 avec Emeric Cruce : "L L $\cdot s$ liummes qualifiez ou pour la noblesse de leur race, ou pour la subtilité de leur esprit devroient plustost s'occuper aux sciences, et surtoul à celles qui ragardent l'utilité de la vie, assavoir la Médecine el les Mathématiques " (1). Oii l'on ruit cette dernière discipline entendue dans son acception la plus exlensive, c'est-adire tout à la fois, la règle et l'impression de celte régle dans les produits de l'art. Ce que proclamera explicitement Desargues en 1647 : "J'avoue franchemenl que je n'eus jamais goust à l'étude ou recherche, ny de la Physique, "y de la Geometric, sinon en tant qu'elles peuvent servir à l'esprit, d'un moven d'arriver à quelque sorle de connoissance, des causes prochaines des effels des choses qui se puissenl réduire en acle effectif, au bien \& commodité de la vie qui soit en usage pour l'entretien ou conservation de la sanlé... " (2).

Une " domestication " des puissances naturelles, une organisation des commodités раг l'application raisonnée des habiletès géométriques nouvellement acquises, tel sera le souci de nombreux chercheurs qui songeront parfois à un enseignement technique. Mathématiser la pratique des arts, faire descendr dans la routine des métiers un peu de ce bel ordre rationnel que l'on se plaisait à dessiner dans la figure du monde, telle sera l'espérance de toute une lignée d'ingénieurs qui, d'Errard (3) à Bélidor et aux premiers polytechniciens, soutiennent en France des projets pédagogiques distincts de ce qui sera déliveé en Allematgne sous le nom de technologie. Ces ingénieurs étaient militaires; leur influence fut décisive sur la pédagogic des sciences appliquées. On ne saurail trop insister sur le rôle de ces hommes souvent engagés dans des guerres de posilion. Divant une artillerie de plus en plus puissante, ils prirent pleinement conscience de ce que l'effet de la fortification est directement lié à la précision rles calculs el a la correction des levés lopographiques. Ils ont vécu el éprouvé la puissance du

(1) Em. Cruce, Le Cinée d'estal sur les occurences de ec lemps, aux Monarques el Potenlats de ce Monde, s.I., 1624, p. 46. Dans un autre passige, Cruce dit des arts méchinieues qu'ils a ne cèdent guère en invention ou subtilité aux aris libérnux, \& en utilitè les surpassent . Lid., p. 42. - Il vante par ailleurs le a Dénombrement des personnes el des liens tris utiles . En rapprochant dans une meme altention les arts el la statistique, Cruce anticipe sur la formulation du projet technologique beckmanien.

(2) a Reconnoissance de Monsieur Jesargues = dans la Maniere universelle de Pracliquer la Perspective par le pelil pied comme le Gécométral, par A. Bosse, I'uris, litit7.

(3) - J'ay osé entreprendre ce que lous les Ingenieurs iusques it present ti ont voulu ou osé, au moins n'en paroist-il rien par aucun escrit traictant de cette science : Cir les discours des choses mechaniques ne meritent point ee Titre ; n'estant icy yuestion des lraicts, yui i quelqu'un pourroient réussir à l'adventure; mais des démonstrations géométriques, qui donnent à tous asseurance infaillible... " La Forlificalion, reduile en arl el demontre, ['ar I. Errard de Bar-le-Duc, Patis, 1600. 
calcul et du dessin. Leur expérience fut déterminante pour la mathématisation des arts, et ils ne participèrent guère au mode de pensée technologique qui se déploie dans le repérage et la classification des procédés et des produits des * orls.

On connaît un projet tardif de Descarles, formé en 1648, visant à instituer des écoles professionnelles : " pour perfectionner les Arts... laire batir dans le collige royal \& dans d'autres lieux qu'on auroil consacrés au Public, diverses grandes salles pour les arlisans... joindre ì chaque salle un cab̧inet rempli de tous les instrumens méchaniques necessaires ou utiles aux Ars... faire des fonds suf lisants, non seulement pour fournir aux dépenses que demanderoient les expériences, mais encore pour entretenir des Maîlres ou Prolesseurs... habiles en Mathématiques et en Physique afin de pouvoir répondre à toutes les questions des Artisans, leur rendre raison de toutes choses, et leur donner du jour pour faire de nouvelles découvertes dans les Arts n (1).

Descarles réclamait donc des écoles d'arts et méliers qui fussenl soumises à la raison des géomètres. Si le projet ne vit d'abord pas le jour dans sa netle simplicité, du moins des programmes d'inspiration voisine connurent-ils un début de réalisation. Colbert ordonnera en 1675 à l'Académie des sciences de préparer des descriptions des arts qui répondent indirectement au vœu cartésien. Le 19 juin, Claude Perrault apporte l'ordre d'« examiner les moyens de faire un traicté des méchaniques avec une description exacte de toutes les machines utiles à tous les arts \& mestiers dont on se sert à présent en France et en loute l'Europe. Et Sa Majesté veut que ce traicté soit d'utilité \& puisse estre entendu et practiqué facilement par toutes sorles de personnes... " (2). Ces descriptions demanderont une longue patience et ne verront le jour qu'assez tard et partiellement, si bien qu'en l'an VII, l'Institut national concevra encore un Programme pour la continualion de la descriplion des arls, technologiquement plus élaboré, mais qui demeurera sans lendemain (3).

Selon les vœux du pouvoir, le traité des mécaniques devait en 1675 être " entendu \& practiqué facilement par toutes sortes de personnes $n$; il s'agissait avant toul d'éclairer les hommes de métier ; mais les gentilshommes sont implicitement inclus dans cet intérêt. En 1687, le Traité du choix el de la méthode des éludes de l'abbé Fleury renferme des suggestions proprement technologiques ; l'honnête homme doit se ménager les " commodités de la vie \#, grâce à sa connais-

(1) A. BAtt.tet, La vie de Monsieur Des-Carles, 1691, l. 11, pp. 433-34. La création d'un enseignement prolessionnel fut réclamée par la suile, sans grand suecès. En 1763, Henning Calvơr souhaitait encore que l'on construislt dans le Harz a une école de mathématiques où seraient instruits dans leur jeunesse les têtes les plus capables et les plus éveillées de ceux qui veulent devenir mineurs ou charpentiers. On leur enseignerail dans leur jeunesse pendant les heures qu'ils peuvent distraire à leur travail protessionnel déjà avancé; dans les fondements de la géométrie, de la trigonométrie, de la statique et de la mécanique... en tant que sciences... . Acla historico-rhronologico-mechanica circa mclalurgiam in Hercynia superiori; Oder... Nachricht des Maschinenwesens. Le projel ressemble ì beaucoup d'égards de celui dé Descarles.

(2) Cité par A. Birembaut, P. Costanel, S. Delonmes, La correspondance LeibnizFontenelle et les relations de Leibniz avec l'Académic royale des sciences, in Revue d'hisloire des sciences, $1960, \mathrm{XIX}, 2$, p. 119.

(3) Vide infra, p. 34. 
sance des "arts utiles", tandis que les "machines ingénieuses " ne lui seront plus impénétrables (1).

Ces machines ingénieuses, on les exhibe de plus en plus; elles cessent d'ètre confinées dans les ateliers ou réservées à la dilection particulière de quelques princes ravis d'étonner. On en répète les images dans les "théstres de maclijnes "; s'ils présentent des effets surprenants, ils figurent surtout la faltriģue des machines qui sont, elles-mêmes les sujets d'une dramalurgie fantast iepe ders forces mouvanles. Les estampes des thétres se purgeront erertes en quellyues décennies du maniérisme graphique qui transportait la machime daus l'espace des glorifications hérö̈ques; elles gagneront en froide perfection formelle, dans le temps mème oi les cabinels se peuplent de morlites qui fonc: inument réellement, en petit, du moins.

On a conservé fe calalogue d'une exposition de modèles ouverte i Pari-, en 1683, qui révèle bien l'inlérêt qu'un nouveau public d'entrepreneurs ou de mondains pouvail prendre a l'explication des machines el des "forces mouvantes" (2). La maquetle entre dans les cabinets ouverts jusqu'alors aux scules bizarreries de la nalure et aux automales, c'est-i-dire aux objets fondament atlement exoliques. La technique machinale efficace apparait digne de curiosite comme le furent les " gailardises d'optiejue ", les pyrotechnies, les "gentilles inventions net loules les machinations ludiques. L'esprit du thèatre de machiturs se réfugiera en définitive, ì l'àge baroque, dans les machines de théitre, ì misure que l'expérience des mécaniciens sera requise par l'organisalion manufactu-

(1) " $A$ mesure que l'age avanceroil... on feroil en sorte de les instruire prassatblement des arts, qui regardent la comodité de la vie, leur faisant voir travialler, \& leur explingu:ant chaque chose avec grand soin... $*$, Trailé..., p. 185.

(2) Explicalion des modeles des machines el jorces moumanles que l'on esposi à Paris dans la rio de la Harpe, vis d vis Saint-Cosme, Paris, 1683. Le texte anomyme de la l'rílar" contient toutes surtes de monitions à l'égard de la a diversité des Jesprits iqui se rencontrent dans le Public $n$; on y prétend que l's explication des machines et forces mourantes doil it re considérée comme une affaire sérieuse, importanle \& trìs utile... " l. Fesplication alurdu l:ı question controversée de la dimension optimnle des machines a L'on objecle qu'il col pussible gu'une Anchine fasse son effet en petit, \& non pas lors gu'clle sern d'un" grandeur plus considérable... " (p. 2; vide in/ra, p. 17). Le rédacteur fail nllusion aux énergies motrices non

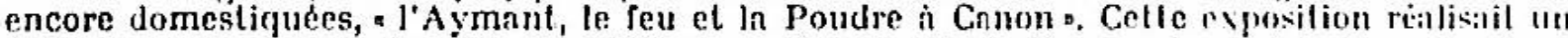
veru de lluygens qui écrivait en lfiti7 que "Pour les inventions qui eonsislenl rol pratipue comme des maclines utiles..., el parce que l'intelligence de celles que l'oul voil dombe souvent ocension et moyen d'en inventer d'autres comme aussi de perfectionuer ers premiires. il seroit bon de faire construire des modelles de toutes les machines utiles qui sont en usage comme de différens moulins, de pompes el autres inventions pour élévalion des eaux, de celles qui servent it mouvoir de grandes pesnnteurs, et nutres qu'on emploie dians disers mestiers, lesquels modelles l'on arrangeroit dans tme chambre, av'cc l'éclnircissemenl nécessatire par escrit ajouté a celles qui en ont besoin o. M. P. Biremnaut a identifié, dans th irticle rícent, I'initinteur de l'exposition avec J.B. PICot, fourrier ordinaire des logis. Rev. d'hist. des sc., av.-juin 1967, pp. $141 \mathrm{sq}$.

Cotle idée de confectionner des marpuetles nnimées s'explique en partie par l'immiturité des techniques de dessin industriel qui ne permeltaient pas de elairement remire comple des déplacements des pièces. Quand, en 1670, Colbert ordonne de procéder à des enquêtes dans les manufactures, il a en vue la construction de maquettes: "Le roi désirant faire mell re dans ga bibliothèque des modeles des machines les plus curjeuses, les intéressés en la manufacture de rubans établie à Chevreuse feront voir au sieur Niquet les nousenux métiers sur lesplurls se font plusieurs rubans it la fois, et lui laisser prendre sur les dits métiers les mesures tout il aura besoin .. Lelle du 2!) juin 1670, citce par J. Proust, Diderol al l'Fncyclopédic, l'aris, 1962, p. 183. 
rière (1). Il s'en faut cependant de beaucoup que le machinisme industriel ait accompli de ce moment des progrès décisifs. L'histoire du monde machinal semble d'abord se pulvériser en d'innombrables transitions dont le repérage est aussi difficile qu'elle est apparemment désordonnée. Pourtant, la distance est considérable entre le machinisme du débul du siècle des lumières et celui de l'ère manufacturière, entre la " lechnologie n de l'Académic des sciences et celle qui sera mise en ơuvre par les ingénieurs de l'Ecole centrale des arts et manufaclures. Une mise en parallèle s'impose entre deux types d'organisation machinale qui nous aidera à reconnaître les trajets historiquement efficaces de la pensée technologique et à en marquer les coupures décisives.

Tout d'abord, le contrat de l'inventeur avec la société est radicalement altéré car le procès de l'invention est bouleversé, cessant d'être affaire de simple intuition artistique. L'imagination des configuralions et des mouvements sera assujettie au $\mathrm{XIX}^{\mathrm{e}}$ siècle aux règles imprescriptibles d'une cinématique achevéc. La réticulation mathématique de l'espace multiplie à l'infini les choix possibles de configuration, et diversifie les opérations, mais asservit, en vertu du calcul, tout modelage partiel à la considération de la totalité de l'organisme machinal. Quant aux forces, l'ancien ingénieur les sollicitait intuitivement, au lieu que l'ingénicur du $\mathrm{xIx}^{\mathrm{e}}$ siècle est en possession des règles qui procèdent d'une connaissance scientifique des énergies de la matière et des lois de leurs transformations.

Si les anciens constructeurs de machines ne se désintéressaient pas de l'estime de l'effet, leurs calculs à ce sujet nous apparaissent bien infimes. Longtemps, ils ne purent les fonder que sur la considération des lois du levier, et sur ses applications statiques. Les lois du mouvement, la dynamique du choc,

(1) Le projet du spectacle total de Leibniz, réunissant en un seul lieu parc d'attraclions, salles des jeux, représentations théatrales, instruments, démonstrations et explications scientifiques, inventions, maquettes, modeles, reproductions, objets contrefails, monde de l'illusion, donne l'idée de cetle multiplicité des résenux de représentations dans laquelle se reconnali la société de l'âge baroque : "Les représentations seroient par exemple des Lanlernes Magiques (on pourroil commencer par lii), des vols, des météores contrefaits, toules sortes de merveilles optiques; une représentation du ciel et des astres; cometes ; globe comme de Goltorp ou Jena ; feux d'artifices, jets d'eau, vaisseaux d'estrange forme; Mandragores et autres plantes rares. ... Machine Royal de cours de chevaux artificiels... Fortifications faites, élevécs, de bois, ... un maistre de forlification expliqueroit l'usage de toul. Guerre contrefaile... Thếtre anatomique. Jardin des simples. Laboratoire suivront. Car oulre les représentations publiques, il y aurn des particulicres, comme des petiles machines de Nombres, et autres tablenux, medailles, bibliotheque. Nouvelles experiences d'eau, air, vuide. Pour les représentalions grandes serviroil aussi in machine de Mons. Guericke... On y feroit l'operation de transfusion el infusion... Des representations des muscles, nerfs, os, item machine representant le corps humain. Insecles de Mons. Schwammerdam... On y pourroit à la fin etablir des Academies d'Exercices et des colleges pour la jeunesse, peut estre la pourroit on joindre au college des 4 nations. Comedies des modes, différentes de chaque pays... Comedies des mestiers, une pour chaque mestier, qui representeroit leur adresses, fourberies, plaisanteries, chefs d'cuvre, loix et modes particulieres ridicules... L'experience de casser un verre en criant... Faire voir l'egalité des battements des pendules. ... L'usage de cette entreprise seroit plus grand qu'on ne se pourroit imaginer... ce seroit un bureau general d'adresse pour les invenleurs... Drole de pensé, touchant une nouvelle sorle de represenlalions (texte daté de septembre 1675), in Technische Schiflen, ed. E. Gerland, Leipzig, 1906, pp. 246-52 et in Nouvelle Revue /rançaise, oct. 1958 , intr. et notes de Y. Belaval. 
les modalités du frottement ne pénétrèrent que bien lentement (1) la théorie des mécaniciens qui s'accommodaient de correctifs tout empiriques, tout comme

(1) La question des proportions des maclines a été discutée par Galilée en relation avec la résistance de leurs éléments. On connatt sa thèse qui affirme catégoriquement quion in peut accroltre la dimension totale d'un dispositif sans en modifier les proportions. II la déve. loppe par l'organe de Salviali dans ses Discorsi... inlorno a due nuove scienze : "... con Lulte cid il solo esser materiale fa che la macchina maggiore, fabricala dell'istessa materia e cor l'istesse proporzioni de la minore, in tutte l'altre condizioni risponderi con giusta simmetri: alla minore, fuor che nella robustezza e resistenza contro alle violente insasioni ; ma quante piii sari grande, tanto a proporzione sari debole... Perd, Sig. Sagredo, revochi pur l'opinion che teneva, e forse insieme con molti altri che nella mecanica lian fatto studio, che le machine e le fabbriclie composte delle medesime mnterie, con puntuale osservanza delle medesime pro. porzioni tra le loro parti, debban esser egualmente, o, per dir meglio, proporzionalmente disposte al resistere ed al cedere alle invasioni ed impeti esterni, per clie si pud geometrica. mente dimostrare sempre le maggiori essere a proporzione men resistenti clic ie minori ; si clit ultimamente non solo di tulte le macchine e fabbriche artifiziali, ma delle naturali ancora, si: un lermine necessariamente ascritto, oltre al quale nè l'arte nè la natura possa trapassare trapassar, dico, con osservar sempre l'istesse proporzioni con l'identită della maleria. $L$. Opere, tome Vill, p. 51, Florence, 1933.

On sail que Galilée développe dans le second dialogue une théorie de la résistance is l: rupture d'une poutre, inaugurant une série de recherches fondamentales pour toute thécori de la construction, qui seront poursuivies par Bélidor, et surtout Coulomb el Navier.

Le problème du passage de la maquetle à la machine réelle, c'est-î-dire celui du calcu de la dimension des parties relativement à la dimension d'un organisme machinal entier n'es en aucune façon réductible à des considérations de résistance. Il y entre cncore la considération des frottements qui, en l'absence d'une théorie achevée, rend douteuse l'estimation a prior de l'effet d'une machine, ou encore de sa dimension optimale en vue de tel rendement. l.: difficulté de la question a été pressentie par divers auteurs, notamment le Pére Valebranche e Diderot. C'est dans la Recherche de la vérité (VI, J, iv) que le premier note la distance qu sépare la mécanique théorique de la pratique machinale : " dans les mécaniques on supposı que les roues el les leviers sont parfaitement durs et semblables ì des lignes et it des cercle: mathématiques sans pesanteur et sans frottement. ; ou plutot on ne considere pas assez teut pesanteur, leur frottement, leur matière, ni le rapport que ces choses ont entre elles ; que l: dureté ou la grandeur augmente la pesanteur, que la pesanteur augmente le froticment que le frottement diminue la force, qu'elle rompt ou use en peu de temps la machine, $r$ qu'ainsi ce qui réussit presque toujours en petit ne réussit presque jamais en grand . ("'es dans l'arlicle Arl que Diderol traile de l'optimum de dimensions des machines : ${ }^{\circ}$ il y a reliti vement aux dimensions d'une machine, un point, s'il est permis de parler ainsi, un termı oì elle ne produit plus d'cffel, il y en a un autre au delà ou en deçí duquel elle ne protuit pas le plus grand effel dont son mécanisme était capable. Toute machine a, selon la manière di dire des géomètres, un maximum de dimensions ^. Or, selon Diderot, l'optimum, la n dimen sion véritable et absolue one ressortit pas au seul calcul, c'est, dit-il a il la gèmétrie expéri mentale et manouvrière de plusicurs siécles, aidée de la gèométrie intellectuelle la plus déliế à donner une solution approchée de ces problèmes; et je suis convaincu qu'il est impossibl d'obtenir quelque chose de satisfaisant lii-dessus de ces géométries séparées, et très difficili de ces géométries réunies * (éd. J. Asséznt, p. 367-8).

La difficulté de constituer une theorie genérale des machines explique la per sistance de types d'ingénieurs représentés par Walt ou Smeaton. Dans son Introdur - tion a la mécanique induslriclle, Poncelet pourra encore écrire en 1829, quin un espac immense sépare la Mécanique enseignée dans nos écoles, de ses applicalions, mèm les plus usuelles el les plus simples. Tantôt la compressibilité ou la flexilitité natu relles des corps, tantâ leur inertie el les résistances, de loute espèce, qu'ils opposent aI mouvement el ii l'action des forces, viennent, sinon démentir completement, du moins morli fier tellement les déductions théoriques, que les résultats diffèrent souvent du simple au yua druple ou au quintuple ". Il stigmatise les méfails intellectuels des n idées incomplètes... su l’équilibre alısolu, sur te mouvement idéal des corps ou parfaitement durs ou parfaitemen élastiques, ou sur les machines simples qui ne sont, en effet, que yles êtres géomél riques, 1 forme extéricure étant la seule chose qui leur reste, car a les principales difficultés ne résiden pas tant dans la démonstralion des principes généraux de l'équilibre ct du mouvemenl mais bien dans la conception physique des phénomènes physiques $n$ (p. xiv). - Quant au pro blème de l'estimation du rendement d'une machine motrice, il a reçu un commencement d trailement theorique, en 1737, dans le mémoire de Piтot inlitule Régles pour connoilre l'cfle qu'on doil espérer d'une machinc. Ce problème sera également examiné par L. Eulen en 1 \% (vide infra, p. 25). La recherche des moyens à disposer en vue d'oblenir avec une puissanc donnée tel effet désiré constituera un arlicle fondamental du programme technologique idés de Hassenfontz (vide infra, p. 48). 
ils soumeltaient à des réglages intuitifs les " jeux " et les adhérences des pièces mobiles.

L'ingénieur moderne, pour sa part, peut dans une certaine mesure conditionner ses projets selon la graduation de tout un système de lolérances bien calibrées. $\Lambda$ ces spécificalions dimensionnelles, répond encore pour lưi un tableau de spécifications proprement malérielles, beaucoup plus riches, et diversifiées, mais bięn micux normalisées que l'univers des anciens matériaux lechniques. Il est vrai qu'à cet enrichissement des composants répond une diversification et une extension des milieux plysico-chimiques qui entrent au contact des organes mécaniques.

En définitive, si le mécanicien d'autrefois est en mesure de oonstruire une machine efficiente, il est bien éloigné de pouvoir prédire avec une bonne approximation son efficacilé. L'ingénieur du $\mathrm{xIx}^{\mathrm{e}}$ siècle pourra, en revanche, projeter toules sortes de dispositifs par application de règles qui, si elles n'embrassent pas la totalité des déterminations possibles, constiluent un système normatif hiérarchisé permeltant de prédire l'effel du dispositif dans des limiles connues d'approximation. Une telle démarche inlègre les théories qui rendent raison des déperditions énergétiques inhérentes aux structures machinales; elles permelient en conséquence de les réduire et de calculer au terme des ajustements le rentemenl pralique de la machine. En d'aulres termes, l'ingénieur du xix ${ }^{e}$ siècle est, au contraire de son prédécesseur, apte à déterminer par le calcul, entre plusieurs projets, celui qui produira tel effet dans telles conditions techniques données. Il accomplit par la combinaison des formes, des malieres el des forces les conditions de l'oplimalisalion. La valeur économique de la machine est inséparable de cette optimalisation technique, bien qu'clle doive ètre encore référée aux struclures socio-économiques contemporaines. En fail, cettc estimation est toujours conjecturale, puisque la machine qui est immergée dans un ensemble économique, ne prend toute sa valeur que par son pouvoir d'adaptation à cette struclure qu'elle contribue à réaliser. Bien plus, l'insertion de la machine dans la vie sociale a pour effet. d'injecter des propriètés machinales dans l'organisme social même donl les crises seront désormais liées à l'ordre de la production. Une autre conséquence apparaît cependant dans la société a technologiquen, c'est la multiplication de produits stéréotypés, nés des machines qui engendre l'obligation presque morale de la consommation.

La machine n'a d'abord servi qu'à amplifier la puissance de la main ; ce n'est qu'ensuite qu'elle a permis de crécr des opérations techniquement et économiquement inconcevables par la seule pralique manuelle. La division du travail qui dépossède l'ouvrier d'une puissance informatrice continue, est concomitante d'un grand débit d'énergies physiques et chimiques incomparables et incommensurables aux forces humaines. Le xix siècle verra donc s'instaurer un mode de produclion spécifiquement machinal qui modifiera peu à peu l'environnement humain. L'homme se concentre dans les machinofactures et se regroupe dans des cités usinières; le paysage traditionnel est bouleversé, dans le temps même où se déplace la finalité des gestes techniques. Ce qui 
comptera désormais, ce seront les interactions économiçues de t. lles on tell. unilés de production; des interférences se produiront à l'échelle des nations . la pensée technologique se déploiera, à son niveau supéricur, comme la tolalis. tion des organes lechniques d'une société entière.

Cette problématique de l'insertion de la machine dans la société se dév. loppera durant le xvinle siècle à l'horizon des sciences camérales. A un nive: plus spécifiquement technique, on voit alors se déplacer et s'enchevêtrer 1 ligne de partage entre deux attitudes qui se combaltront dans l'Encyclopéd et jusqu'à l'Ecole polytechnique : d'une part, la recension des procédés el I pratique intuitive ; de l'autre, la rationalisation malhématicienne. Les empir ques avaient l'avantage de la priorité dans la construction des machines; i furent patiemment catéchisés par les géomètres dont les écrits laissent volor tiers percer quelque agacement au sujet des machines conçues dans la sulf sance de la seule pralique. C'est La Hire qui concède en 1695 que "s'il s'. trouvé quelques ouvriers qui ayent réüssi dans des entreprises assez considér: bles par la seule pratique, on ne peut pas dire qu'ils ne scussent rien de mécan: que \& qu'il vaut bien mieux travailler comme au hasard... " (1). C'est. Fontenell qui, faisant l'éloge du Père Sébastien Truchet, rappelle que " la géomètrie aabsolument nécessaire pour la théorie de la mécanique. Que le génie le plu heureux pour une certaine adresse d'exécution, pour l'invention même, ne s. flatte pas d'être en droit d'ignorer et de mépriser les principes de théorie, qui "n sauroient que trop bien se venger " (2). A quoi fail écho Bèlidor dans so: Archileclure hydraulique : "Il faut convenir qu'il se trouve des Praticiens q" trouvent dans la supériorité de son génie des ressources merveilleuses, \& qu' général c'est aux personnes de ce caraclère que l'on est redevoble de ce qu'il y : de plus heureusement imaginé dans les Arts ". Mais la réussite n'est alors que 1. signe de la participation à un schématisme géométrique opératoire, lien com mun de la société : "lorsqu'on est capable de méditer un projet \& de captir.. long-temps son attention sur une même chose pour en développer toutes 1 . faces, afin de ne se déterminer qu'en faveur du parti le plus avanlageux cette manière de penser est une vraye théorie â laquelle on doit le succès qui en est la suite; alors sans le sçavoir, on imite les géomètres, on en a l'esprit $\mathcal{S}$ l. vưes, puisqu'on cherche à parvenir au même but... n. Cette fécondité instinctiw. a, bien entendu, ses limites : "Il se rencontre souvent des cas ou les puissaner: dont on doit considérer l'action, renferment des rapports si compliqués, qu'i!

(1) Trailé de mécanique oú l'on explique tout ce qui est néccssairc dans la pralique des Arts. e les proprieles des corps pesanls lesquelles onl un plus grand usage dans la phylsique, Paris. 1695, p. 4 .

(2) Eloge du P. Sébasticn Truchel, Carme, in Guures, éd. 1792, Paris, l. VIII, p. 311.

En 1853, un polylechnicien, A.J. de Monléferrier dénoncern encore dans un long articl." sur * l'importance actuelle des sciences mécaniques... la fausse idée de la supériorité de l: pratique sur la théoric $\gg$. Revue progressive, $\mathrm{n}^{\circ} 1, \mathrm{p}$. 5 . 
n'est pas possible de les appercevoir sans le secours d'une théorie fort délicatc... Il est des choses essentielles à sçavoir que l'expérience n'apprend pas..." (1).

Avec tous ceux qui cherchent résolument dans les mathématiques des moyens de perfectionner les arts, il entend déterminer par le calcul les meilleurs profils de construction et la bonne figure des machines; on lui est redevable des premiers traités proprement scientifiques pour l'ingénieur qui conserveront durablement leur prestige aux yeux des praticiens (2). Non seulement, il propose des dispositifs nouveaux, mais encore démontre-t-il " géométriquement plusieurs parties essentielles qui n'avoient été jusqu'à présent mises en usage que par pratique ». Cetle approbation de son supérieur Gittard pourrait ettre étendue à ses cuvres d'hydraulique dans lesquelles il analyse, tant du point de vue cinématique que dynamique, maintes machines exislanles ; il en démontre les organes et les liaisons dans de belles planches où la vue perspective est souvent accompagnée de plans géométraux et de schémas cinématiques. Comparativement, maintes planches de l'Encyclopédie sont pauvrement narratives et anecdotiques ; c'est bien plutòt Monge et Prony qu'il annonce. Certes, tout n'esl pas irréprochable chez Bélidor, certains passages sont un peu hâtifs, il y a les erreurs sur les roues à auget, parfois les genres sont mêlés; mais enfin, ses trailés marquent positivement l'èlaboration d'une science de l'ingénieur construclcur, c'est-à-dire un " homme universel " qui connaît, les raisons numériques des puissances, imagine et projette les configurations, s'est enfin assimilé la " matière machinale ", comme dit Fontenclle (3).

La théorie des mouvements avait retenu l'attention des mécaniciens du $\mathrm{xvil}^{\mathrm{e}}$ siècle ; c'est en démontrant que l'isochronisme des oscillations se produit sur la cycloïde, ct, non sur le cercle, (4) que Huyghens énonce les conditions d'un découpage métrique du temps, et définit les propriétés de l'instrument capable de résoudre ce problème théorique. C'est une exigence de précision technique qui permettra d'indiquer avec justesse par des repères matériels la solution de ce problème ; c'est par l'acquisition de la précision que se distingue le disposilif techniquement achevé, celui dont l'action permet la mesure d'autres actions, et institue la possibilité d'étendre indéfiniment l'application du calcul aux machines. Il appartiendra aux savants mécaniciens du xvır ${ }^{\mathrm{e}}$ siècle de traiter les grosses machines avec l'attention des savants instrumentalistes et. de graduer la hiérarchie des approximations dans la définition des formes. Mais l'impérialisme du calcul ne se déploiera pas sans peine. La contagion

(1) Archilechure hydraulique ou l'art de conduire, d'élever el de ménager les eaux pour les differens besoins de la vie, par M. Belinon..., Paris, 1737. Préface, $\mathrm{b}$ ij.

(2) Paul Louis Courier, du temps qu'il était ingénicur militaire en Italie, demandait encore qu'on lui envoyat " son Bélidor *, c'est-ł̀-dire La science des ingénieurs, ulile compendium pour toutes sorles d'ouvrages. L'Archileclure hydraulique fut traduite en allemand en 17.10 î la diligence de $\mathrm{C}$. Wolff qui rédigea à celte occasion une intéressante préface (vide in/ra, p. 23) et Navier réédilera les deux principaux ouvrages de Bélidor en 1816 et 1819.

(3) Vide infra, page 24.

(4) Cr. A. Koyne, Du monde de l'à peu près à l'univers de la précision, in Critique, no 28, 1948. Réimpr., Eludes d'hisloire de la pensie philosophique, 1961, p. 329. 
subreptice de la précision échappe pour une brenne part à l'historien qui "ne dispose que de discours isolés et d'exposés doctrinaux dont il est difficile w. mesurer le retentissement dans la république des sciences. Tout au plus, ponvons-nous distinguer qualitativement des parlis pris théoriques. Il y a lieu, 'n outre, de discerner ce qui est du domaine de l'assemblage cinématique dans l:ı coneption de disposilifs transformateurs de mouvement et ce qui procède d'um. intention d'optimaliser l'aménagement des forces. Le calcul des formes ' ' viu. du meilleur rendement énergétique ne se présentera que tardivement à l'esprit des machinistes, faute de théoric suffisante, alors que le découpage astucieus des dispositifs, objet possible de l'intuition, apparaitra beaucoup plus tót comme le principe même du génie mécanicien. Tel est le sentiment de Condorcil. quand il fait l'éloge de Vaucanson. Pour nous dire son idée parliculiere du mécanicien, il dit d'abord ce qu'il n'est pas : a ce n'est point un géomitre quii. approfondissant la théorie du mouvement et l'ordre des phénomenes, cric drprincipes nouveaux de mécanique ou découvre dans la nature des lois inconnues; ce n'est pas le physicien géomètre qui, joignant la science de l'observiation et de l'expérience à celle du calcul, fait de ces connaissances une application utile à la construction des machines ou aux travaux des arts " (1). Son affaire n'est donc pas ce que nous appelons la mécanique rationnelle, encorr moins une thermodynamique; ces sciences seront certes impliquées dans toul." machine satisfaisante, mais le propre même de l'ingénicur mécanicien, selon Condorcet, est plutôt la conception spatiale et cinématique d'unc pluralité de: liaisons, une différenciation organisée de l'étendue : "Le génie dans celte parti. des sciences, consiste principalement à imaginer et à disposer dans l'espace les différents mécanismes qui doivent produire un effet donne, et qui sersent it régler à distribucr, à diriger la force motrice " (2). Le mécanicien de Condorerl rivalise avec la nature organique en inventant des organismes machinaux ini se déploieront tout formés dans son imagination, sans qu'il soit hesoin 小. requérir la sanction de la pratique : "On peut inventer des chefs-d'rourer "n mécanique sans avoir fail exécuter ou agir une seule machine " (3). Condorer fonde ici la valeur probante du projet imaginaire effectivement communicable. mais qui ne sera positivement interprétable que du jour ou la théorie de l'application et la langue des arts seront fixées. Gependant, il insiste en louan'

(1) Condoncet, Elnge des académiciens, Brunswick el Paris, 1799, tome I1, p. 912.

(2) Ibid., p. 213 . A un lel programme, des études du mécn nicien s'oppose li: conceplionn développée par un représentant de la génération suivante, Burdin : a il ne s'ogit pas lant dau. cette science [la mécanique] d'établir des calculs profonds, des formules savantes sur des force. hypothétiques, ni d'inventer des machines ingénieuses, seulement par la combinaison de leurparties, que de bien éludier les lois des forces que la nnlure nous presente, en combinant le c:I cul avec l'expérience, de les mesurer exactement et de parvenir i les approprier ì nos usages l. plus convenablement, le plus utilement et le plus économiquement possible n, Considération

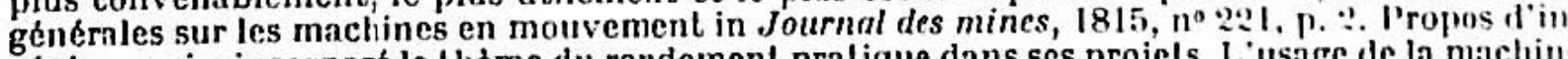
génieur qui a incorporé le thème du rendement pratique dans ses projets. L'usage de la machin. à vapeur fail émerger le problème de la conversion des énergies. Dans le premier liers "l" xixe siècle, la mesure des forces el la constitution de la thermodynamigue vont actualiser, it. concert avec le développemenl de l'électromagnétisme, l'extraction et de la transformation" des forces naturelles.

(3) Condorcet, op. cil., p. 213. 
Vaucanson, sur l'imagination inspirée, créalrice de configurations efficaces. Les modèles ne sont à ses yeux que d'un médiocre secours, plutòt seraient-ils même des obstacles : "Les ateliers des arts, les recueils de machines montrent ce qui a èté fail ; mais pour en tirer des résultats, il faut soi-même les former "(1). Celte capacité. d'invention est dirigée par une espèce de finalité organique qui vise moins à inventer de nouveaux arts qu'à épargner l'effort humain : "Le mécanicien est celui qui tantôt applique aux machines un moteur nouveau, tantòt leur fait exécuter des opérations qu'on était obligé, avant lui, de confier à l'intelligence des hommes " (2). Le mécanicien, c'est donc le projeleur d'aulomales qui transporte dans l'ordre machinal la lécondité du disposítif

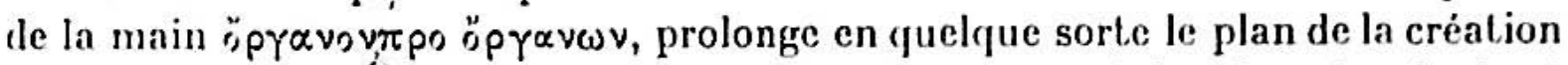
divine pour mieux presser la nature et en tirer " des produits plus abondants et plus parfaits "(3). Ces automales qui se substituent à la main de l'ouvrier, ce sont les machines-oulils que Vaucanson contribua justement, à perfectionner; comme le rappelle M. Daumas, “ il fut incontestablement le premier à construire en 1760, un tour parallèle muni d'un porte-outil à déplacement mécanique " (4) ; le premier à créer un tour industricl avant Maudslay (5), et ì animer mécaniquement des opérateurs, pour reprendre la terminologie de Halon de la Goupillere (6). $\Lambda$ la suite des technologues, Marx a bien marqué l'importance radicale de la machine-outil dans la genèse de la révolution industrielle : " La machine-outil est... un mécanisme qui, ayant reçu le monvement convenable, exécute avec ses instruments les mêmes opérations que le travailleur exécutait. auparavint avec des instruments pareils. Dès que l'instrument, sorli de la main de l'homme, est manié par un mécanisme, la machine-outil a pris place du simple outil. Une révolution s'est accomplie alors même que l'homme resle le moleur... La machine à vapeur elle-mème... n'amena aucune révolution dans l'industrie. Ce fut au contraire la création des machines-outils qui rendit nécessaire la machine ì vapeur révolutionnée " (7). Il faut certes apporter quelques correclifs i ce jugemenl catégorique ; on soupçonne mal le nombre des innovations tech-

(1) Ihid., p. 214.

(2) Ihid., p. 212 .

(3) Ibid., p. 213.

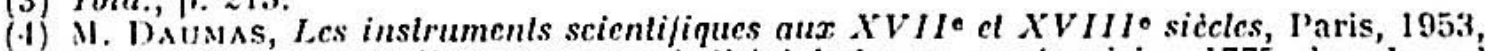
pp. I.|?--n. Le méme auteur cite un passage rle l'Arl du lnurneur mécanicien, 1775, dans lequel Ifulot atlribue an tour le très imporlant mérite de la précision : a N'est-ce pas i l'art du tourneur que la construction des instrumens de mathémaliques, d'astronomie, de physique. d'hydrauliquue, elc., doil. ses plus essentielles qualités? Et que seroient ces instrumens sans la précision yuie nul autre moyen que le tour ne sauroit leur procurer ? ? Une telle remarque a i la renconl re du jugement de Koyré : "c'est dans la construction des instruments que s'affirme la pensée technologique; c'est pour leur construction que s'inventent les premières maclinines precises s. Op. cil., p. $32 !$.

(:) T.e tour in fileler de Maudslay date de 1797. An contraire des dispositifs antérieurs de Vanranson et de Sénot, les machines-outils de Maudslay connurent rapidement une grande diflusion.

(j) n Une deuxième partie, placée h̀ l'autre extrémité de l'apparcil, est en contact direcl avec la matière it élaborer. On l'appelle operateur; elle remplace l'outil que ferait mouvoir en l'absence de la machine la main de l'ouvrier... J.N. Haton de la Goupilltíne, Traile des mécanismes el des résislances, Paris, 1864.

(7) K. I^ nx, Le Capilal, 1867, trad. franç. Joseph Roy, Paris, 1938-39, t. 11, p. 66-69. (C'est nous qui soulignons). Vide in/ra, p. 62. 
niques appelées par le développement mème de la machine á vapeur en lanl qu'organisme machinal perfectible (1), mais on ne peut manquer d'eltre frappe de la perspicacité de Marx sur ce sujet ; la véritable révolution induslrielle n'esL pas une révolution lechnique, mais bien technologique. dans la mesure oiı elle procède d'une invention el d'une définition des tâches et des opíraleurs.

L'appréciation de Condorcet, on sent bien qu'elle incline à la louangre dı génie qui invente sans être en possession de la théorie de l'invention yui inlégrerait le savoir théorique. Les rapports nécessaires entre théorie el pralique. si souvent invoqués, furent marqués des caractères d'une fausse Lransparence. Tous ceux qui ont médité l'amélioration des machines ont ressenti le brsoin d'une theorie de l'applicalion ; c'est dans ce sens qu'il faut interpréter le voru de: Wolff quand il appelle l'intervention d'u un troisième homme qui réunirail. lui la science el l'art n (2). Personnage un peu mythique prompt à risourlie:

(1) Cuvier dil de la " machine a vajeurs " quelle est. o de la géométrie el de l: ı mécani-


sociclé, 1826, p. 18.

II ne fail pas de doute que In solution de problèmes posés par l'amélioraliun du rould. ment des machines a vapeur, en vue de leur application i quantité d'opéraleurs a conlribue í periectionner certains d'entre eux; il en est allé ainsi des machines a aléser les cylindres.

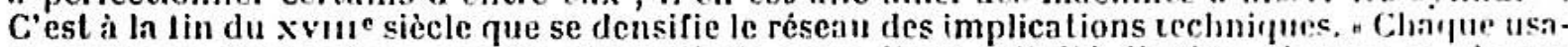
ge nouveau d'une chose appelle et multiplic ceux d'une inlinite jaulres choses ; re clanue chose appelle et multiplie coux d'une infinite d'autres choses; et chaque propriele nour.lle qui se decouve, airle it vaincre les obstacles qui arrêtaient l'emploi d'une unullilude al'aul res propriétés n. Cuvien, Ibit. Je mème thème est repris et amplifié trenle ans plus laral par Poncelet, à la veille de I'apogie de la revolution industriclle foncle sur l'énergie di la vapeur et la machinerie nutomatigue : c'est dans l'aceroissement général, lent mais incr-ssaul, el poul ninsi dire indéfini des décowvertes, des idées chimiques, physiques, mécaniqures, géomélriques ou mathématirues, appliquées ou non a la salisfaction de nos besoins, que riesirle lis perfectihilité de la race humaine, plus encore que dans le prélendu progrés des idées num:ilas. philosophiques et artistiques s. Travaux de la Commission française sur l'intuslrir des mulions,


20 section), Paris, 1857 , p. 3 .

(2) : Ceux yui veulent. Atre mutuellement secournbles se trouvent opposes; comme ch:ıcun des partis méprise l'autre, la science ei l'art ne peuvent que pâtir de Ieur incompriblusion muluelse. Dans ces circonstances, il serait néessaire que survint un troisirmr homme qui réunira't en lui la science et l'art; il remédierait à l'intirmilé des lhéoriciens, il délivrerail la. amants des arts du préjugé selon ruoi ceux-ci pourraient se parfaire sans la lléurir puil conviendrait d'al)andonner aux cerveaux oisifs que le monde ne saurait emplnyer il rion : (I ra. duit de l'allemnnd) in Préface de Worff i la traduction allemande de l'Archileclure hydran. lique de Bélicior, n.p., 1740.

Déjà, en i715, Swedenborg réclamail nvec insistance des agents organis:alrurs : - il conviendrait qu'à cliaque groupe de dix mathèmaticiens s'adjoigne un homme iminemment pralique qui pourrait mener les aulres au marché. Ce scul homme... se rèvèlerail plus ulile que les dix autres mis ensemble ". Cr. II. Divgise, L'ouwre scienlifique de E. Sucdenburg in Endeavour, no 67 (1958).

Ce thème est repris en 1825 par Augusle Comle qui réclame que les " rapporls putre la théorie et la pratique " soient a régulièrement organisés ". Il nssigne i la " classe tés ingénicurs comme corporation distincle n la fiche de servir d'a intermediaire regulier enl re les savants el les industricls pour les travaux particuliers n, Considéralions philosophiques sur lu science cl les savanls, novembre 1825, in Opuscules de philosophie sociale (181!1-2S), Ėl. I. l.erowx, I'aris. 1883, p. 231 .

Le molif est repris en 1826 par I'.11. SuzsNo dans son Guide du méranicien : "Si la prali. que n'est pas éclairée par les principes ou si les principes sout séparis de la praliefuי, 1. vaiu vous atlendrez des perlectionmemens remarquables dans l'industric ", p. i. - l:f. égialement, du màme auleur, les Principes généraux d'économic publique el induslriclle culurnie a'enlrrliens, Paris, 1826 , p. 11.

A la même époque, la ligure du Civil engineer prend de l'importance en Anglelerre; Smeaton, plus encore peut-etre que Walt, en donne le modèle. Tredgold situr. en is:s, Ies fonctions du Civil engineering dans une tradition explicilement baconienue : "Civil rugineering is the art of directing the great sources of power in Nalure for the use and convenience 
l'écart loujours tendu entre les fécondités possibles d'un savoir théorique en développement et l'évolution des exigences techniques. Il n'a pas échappé aux savants du $x{ }^{\prime \prime}{ }^{e}$ siècle que si la géométric est une condition théorique nécessaire de la construction pratique, "le géomètre a encore beaucoup à apprendre pour être un vrai mécanicien ; il laut que la connoissance des différentes parties des arts, et cela est presque immense, lui fournisse dans les occasions des idées et des expédiens; il faut qu'il soit instruit des qualités des métaux, des bois, des cordes, des ressorts, enfin de toute la maliere machinale (Beckmann parlera dans le même sens de la maleria technologica)... pour n'être pas trompé par des accidens physiques imprévus qui déconcerteroient les entreprises " (1). L'Encyclopédie tient le même langage et proclame la nécessité de correctifs empiriques ; les éléments de mathématiques " seroient nuisibles en plusicurs occasions, si une multitude de connoissances physiques n'en corrigeoienl les préceptes dans la pratique ", et ces connaissances embrassent aussi bien le domaine technologique (au sens actucl) que proprement physique. Aul.rement dit, la construction des machines ne serait pas entièrement réductible a une théoric mathématique ; entre les conditions de l'exécution pratique, " il y en a, et en grand nombre, et de très essentielles dans l'usage qu'on ne peut mème soumettre à cette partie du calcul qui s'étend jusqu'xux différences les plus insensibles des quantités n(2). Or, Leonhard Euler, dans un mémoire

of man ; being that practical application of the most important principles of natural philosoply which has, in a considerable degree, realised the anticipations of Bacon, and changed the aspect and state of affaries in the whole world. The most important object of Civil engineering is to improve the means of production and of lraffic in states, both for externa and internal trade "; cité par W.H.G. AnмYтAge, A social hislory of enginecring, London, 1961 , p. 12.4 .

L'apologic des fonclions du e lroisième homme "woltien sera reprise à satiétié dans 'e milieu doctrinal de la toute récenle Ecole centrale : a ne saurnil trop le dire, ce qui relarde ic plus les applications des nouvelles découvertes, des théories scientifiques aux arts industriels, c'est qu'un trop petit nombre d'hommes instruils se trouvent dans la position de s'occuper journellement à la fois des progrès des sciences nalurelles et des fécondes ressources qui en découlent pour l'industric manufacturière... n, Annales de l'industrie française et étrangère, t. I, Paris, 1828, p. 14 .

Un propos analogue est tenu ì la même époque par le polylechnicien H. de Villencuve ıui appelle, dans une formule plus saisissanle, Is concours de l'homme à théorème et de l'lonmme ì expérience ", Sur quelques préjugés des industriels in Annales des sciences el de l'induslrie du milli de la France, Marseille, 1832, p. 11.

Les mèmes idées circulent ensuite avec une nutre terminologie ; cf., par exemple : ‘ L'industrie manque d'ingénicurs de manufacture, de conducteurs de grands lravaux, de bons constructeurs et conducteurs de machines et d'appareils, de chimistes el de pliysiciens applicateurs ", Napoléon LANDais, De l'éducation el de l'inslruclion en France, Paris, 1837, p. 258. l.a earence ile techniciens français dans les années 1840 est attestèe par Morin: "('u'on se irporte aux luuit ou dix dernières annees oil le developpement des grands travaux publics ne lrouvait pas assez. d'agents capables el uffrait tant de débouchés pour lesłuels manquaient les sujets instruils ", A. Monın, lecoles d'arts et méliers in Le Monileur universcl, 21 juillet 1850 , 1. 10 .

(1) Fontenelle, Euvres..., l. VIII, p. 312. En celte matière, les opinions de Fontenelle ne sont pas neuves; elles ne font que cristalliser des réflexions déjà anciennes sur la pensće lochunique. Cif., par exemple, Bonaiulo Lonivi dans ses Forlificalioni..., Venise, 1609: . I1 gindicio del Alecnnico che deve ordinnre, e comandare a gli essecutori dell'opera, consiste in grandissima parte nel sapere provedere le difficulta che apportano le diversità delle materie, con clie si conviene operare; e tato piü deve in ció esser cauto quâto clie di lali impedimenti accidentali non se ne puó dar regola sicura », p. 195.

(2) S.v. Art. 
contemporain (1) proclamera la souveraineté du calcul infinitésimal dans tout essai de perfectionner la théorie des machines ; il voit justement dans son application la seule voie qui permette de balancer la part accordée nécessairement par les constructeurs aux connaissances étrangères à la géométrie (2). Son De machinis in genere enregistre le défaut de maturité de la théorie des machines, telle qu'elle se présentait au milieu du xvin ${ }^{\mathbf{e}}$ siècle et complète á cet égard les motions un peu moins explicites du passage de Diderot sur la Géomélrie des arts. Pour Euler, si le projet dessiné ne permet pas de prévoir l'effet de la machine, c'est que la théorie est infirme, qu'on n'en peut valablement déduire les éléments de la construction : "Bien que la structure d'une nouvelle machin. puisse paraitre conforme aux principes de la mécanique, on ne peut pourtanl se permettre aucune conjecture sur son effet avant qu'intervienne la probation expérimentale ; et, quoique souvent, ceux qui ont consumé beaucoup de peine et d'attention dans la construction des machines acquièrent une telle sagacili: en vertu d'une longue pratique, et qu'ils osent se prononcer en certitude sur l'effet des machines avant de consulter l'expérience, il s'en faut de beaucoup' que l'on puisse attribuer à leur savoir théorique une telle disposition ; il convient plutôt de la référer à la seule expérience. Par conséquent, celui qui se propos" de construire des machines, en seule possession des règles habituelles de la mécanique élémentaire, soit, il ne pourra rien prédire de leur effet, soit, comme il arrive le plus souvent, il sera frustré des espérances qu'il avait conçues. L'oir on conçoit clairement que la connaissance habituelle des machines, telle qu'ell. est exposée dans la mécanique élémentaire, est absolument défeclueuse, et II" mérite en aucune façon le nom de théorie "(3). Reproche bien plus grave qu" d'incriminer cette théorie de ne pas rendre compte de tous les détails rencontre: dans la pratique, comme le rappelle Euler dans le même mémoire.

Bien entendu, la question des froltements est nouèe à ce problème: si les travaux d'Amontons au début du siècle (4) avaient donné une assis. expérimentale a la connaissance de la friction, la théorie en était encore bien douteuse cinquante ans plus tard. Elle demeurail " malyré les calculs, un. affaire de mathématiques expérimentales et manouvrières" nux yeux des

(1) L. Eulen, De machinis in genere in Nova Comment. Acad. St. Pelcrsb., 1750-51, pp. 254-85.

(2) La préface de la Chamber's Clyclopaedia définit bien le poids du savoir non susceptible de definitions mathématiques : "An art... appears to be a portion of science, or general knowledge, considered not in itself, as science, but with relation to ils circumstances, or appendages: In a science, tlie mind looks direclly backwards \& forwards, to the premisses \& conclusions... in art we also look laterally, to the concomitant circumstances... To art, ... belong such things as mere reason would not have alleined to things which lic oul of the direct path of deduction, and which require a peculiar cast, or turn of mind... . 5th ed., 17.42, p. ix.

(3) Op. cil., p. 255-6.

(4) * M. Amontons... donna un moyen de calculer assés exactement la valeur des frotte mens \& le décliet qu'ils causent à une machine, ce que l'on avoit pas eu jusqu'à présent. meme par une estime grossièrc... \$. Hisloire de l'Académic royale des sciences pour 1649, I'aris. 1702, p. 106. - Cet effel du frotlement seul peut paroltre étonnant \& forl a1u desstis de ci qu'on auroit imaginé à veuë de pars. Par là il est aisê de voir combien l'on doit sc méprendre dans le calcul d'une Machine, quand on n'y considère que les rapports de la puissance \& dil poids \& de leur distance au point d'appuy \& que l'on néglige les frollemens comme on fait d'ordinaire, ou du moins qu'on conte qu'ils n'iront pas bien liaut ... •. Ibid., p. 109. 
théoriciens, le frottement joue le rôle de bouc émissaire responsable de tous les désaccords entre l'effet supputé et l'effet obtenu. Il n'empêche que le frottement, dira Euler, non sans ironie, quoique il " perlurbe notablement le foncliunnement des machines, c'est néanmoins à tort qu'on l'invoque à tout propos. Car la connaissance des machines dont on fait habituellement parade est si imprarfaite que, même en l'absence de tout frotlement, il serait impossille d'en tirer une évaluation tanl soil peu précise de l'effel des machines " (1).

$\mathrm{Si}$, donc, la construction des machines exige des connaissances qui, par nature, se dérobent à l'emprise de la mécanique, il n'en demeure pas moins pour linler que le fondement de la théorie des machines est défectueux. A ses yeux, ce dernier problème peut être résolu à l'intéricur de la science mêmé, et plus précisément par le recours à l'analyse supérieure; sans quoi, la connaissance des lois du mouvement ne peut ètre ni exposéc, ni appliquée à la pralique (2). Ainsi s'établira la communication entre la théorie et la pratique dans la lignèe mécanique. Quant à la première tâche de rectification, elle incombera aux lechnologues qui établiront la communicalion selon la lignée non mécanique. Théorie des machines el opérations industrielles suscilent des problemes qui se trouvent bien définis vers 1750 ; désormais, la pratique individuelle et naïve cessera d'avoir cours, en droit.

La technologie, en tant que discipline spécifique, objet d'enseignement régulier, de recherche et de diffusion, ne naîl pas seulement d'une réflexion inspirée par des problèmes proprement techniques. Elle procède encore de la volonté de lígiférer sur la technique, compte tenu des moyens de production et des besoins sociaux. Vers la fin du xvire siècle, il y a un désir évident de classer et de systématiser les informations répandues dans les récils de voyage, touchant à l'état des métiers et du commerce; il s'agira désormais, pour des administrateurs éclairés, de recenser les ressources en vue d'une utilisation plus raltionnelle. La multiplicilé des dénominations témoigne d'une convergence encorc tatonnante des intérêts : à la lopographie polilique d'un Leibniz, répondent l'arithmélique politique de Boisguillebert et la slatistique (au sens premier de slaluum scientia) d'Achenwall.

C'est dans une note de 1678 , relative à l'administration, que Leibniz, alors conseiller du duc Jean-Frédéric, trace le programme des investigations statislirgues du xvm ${ }^{\mathrm{e}}$ siècle (3). A cette époque, paraissent plusieurs ouvrages trai-

(1) Op. cil., p. 256.

(2) Jbitl., p. 255.

(3) II s'ingit d'une note rédigèe en allemand dont nous donnons ici la traduction litlérale : "Topoyraphia politica. Description de l'état actuel du pays. Lia aussi le nombre et la conditinn de tous les biens immobiliers, des constructions, de tous les habitants et de leur propriciti. Tous les produits ou matières brutes qui se trouvent dans le sol, l'endroit, la quanfité el la qualité; toutes les manufaclures ou objels qui sonl le produit d'un art ; ce qu'on consomme approximativement i cliaque endroit dans le pays ; quelles marchandises sont : chacun par son travail el combien il travaille. Liste de ceux qui dépassent les autres par leur 
tant de la richesse des nalions et de leur gestion. Dans son Chrislenslanl. Ludwig von Seckendorff intègre des vues économiques décidées. La mème année, 1685, P.W. Hornigk lait sentir dans son Oeslereich ueber alles wann es nur will, tout l'avantage qui résulterait d'un recensement systématique des moyens de production, et du traitement mathématique des questions manufacturières (1). William Pelly introduit systématiquement les données quantitatives dans sa Polilical Arilhmelic publiée en 1691. Boisguilebert brossera peu après dans le Délail de la France (1695) un tableau assez noir de l'économic* du pays et propose en 1707 des remèdes draconiens dans son Faclum de la France. Après la mort de Louis XIV, le Régent ordonne, entre aulres mesurede sauvegarde, une vaste enquête sur les ressources naturelles ill manufacturières (2). Le mercantilisme va tenter d'unifier ces aspirations dispersées. en prenant pour principe que la richesse d'une nation s'accroît aussi bien par les échanges que par la produclion. C'est dans ce contexte qu'il falut comprendre l'initiative du Diclionnaire de commerce de Savary (3).

appliention el invention el qu'on peut utiliser pour des tâches particulières " (Sämllirhe Srhri/len und Brie/e, I. Reihe, $2, n^{\circ} 70$, pp. 74-5). A ce texte est annexée une note de l.cibniz: " villes, aggloméralions, villages, hameaux, maisons isolées. Paysans. Nombre de gens ; di. morgen (arpents de terre); de maisons, des champs, des prés, des bois; bonnes cartes givographiques. Les rivières et'leur cours. Les parties non bâtirs de la terre. Combien de solde : troupes, combien de marchands, de compagnons, proportion d'es métiers. Recenser non set1lement ceux qui vont mourir, mnis aussi ceux qui viendront, comme en Angleterri. L.etaxes douanieres d'importation et d'exportation. Pretia rerum, quantite de monnate dans le pays ». On peut rapprocher de ces texles, un passage de la correspondlance de Friedrich Athif Ilansen, * agent general de l.eilnniz il Paris - (Ibid., n* 491, p. 4!s).

Dans un projet pour la fondation de l'Académie des arts el des sciences en Allemagur. Leibniz note explicitement que la décadence des manufactures allemantes est libe i l'inc:ip:acité de tirer profit des competences des artisans et des maitres du pay's qui sont forcés d'ofrit leurs services là où on sait les apprécier. Une des taches de l'académie serail précisímenl d." mettre un cerme it ce brain train, ear a il faut garder les talents (ingenia) de la contrelaimle. plus que la marchiandise, plus que l'or, le fer, les armes et autres choses n (Bedencken ron Aufrichtung einer Academic oder Societäl in Teulschland, zu Au/nehmen dir kiunsl. unil Wissenschallen, in Werke, ed. Klopp, I, p. 136).

(1) ITornigk prétend explicilement que * maintenant l'art mathématigue a une granule main dans les manufactures : (p. 84). Il demande ailleurs la publication d'une: encyclopédie. technique oủ seraient consignées les connaissances mécani(ques et plıysiłpurs propress à accroitre la production. La rédaction derrail en être confiée à des spécialist és intègres qqui n'auraient

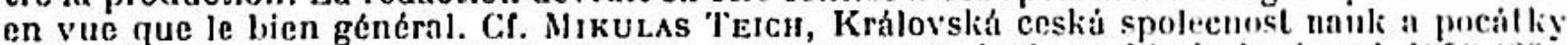
vedeckého pruzkumu prirody v Cechách, in Rozprav! Ceskoslovenské akudemie trd, 195:! (699), cahier 4, p. 7. - Près d'un siècle plus tard, ce sera le langage que tiendra Roland de la Platieres (vide in/ra, p. 56 ).

(2) Les réponses, parvenues au cours de 1716, se trouvent dans les arehives de l'Ac: démie des Sciences. Elles n'ont pas encore fait l'objel d'une recherclie approlondie. Cr. In nolice de Jean PIt.ISI : L'enquete ordonnée par le Régent sur les richesses naturelles de ln France (1716-1717), in Documents pour l'hisloire des lechniques, $n^{\circ} 3$, juin 1964, p. 373-1, reproduit in Revue d'hist. des sciences, t. XVI (1963), no 4.

(3) Dictionnaire universel de commerce. Les deux premiers tomes parurent it Paris '"I 1723, Ie troisième en 1730. II fut commencé par Jacques Savary-Desbruslons, inspecteur néni:ral des manulaclures, et continué par son frère le chanoine Savary. Celle entreprise visait i la normalisation des produits de l'industrie et du langage des metiers, en v'ue d'uniformiser la réglementation économique. Le pouvoir connaissait les plus grandes difficultès ì régler les dispositions relacives à la nature et à la qualité des marchandises. * Comme dauns ci's rìglementa il esl parlé de quantilé de choses, et qu'on y emploie divers termes qui ne sont guère connus que des ouvriers qui y travaillent, on perdoit bien du temps à se Inire expliquer par ceux qu'on consultoit, la vérilable signitication de ces termes, qui ne pouvoient pas manquer de paroltre nouvenux à des personnes accoutumées à décider des plus importantes aff:tires de l'Elat, mais qui n'étoient pas faites au détail et au jargon des ouvriers el des gens de métier ", l. I, p. xvi. 
Il faudra altendre le premier liers du xvin ${ }^{\mathrm{e}}$ siècle pour que, sur le continent, les disciplines économiques deviennent matière d'enseignement. Nous trouvons ici encore Leibniz qui appelle el justifie les réformes, lorsqu'il écrit sur la division civile des sciences, selon les Facultés et les emplois : "Quelques uns ont cru avec quelque raison, qu'on pourroit ajouter aux autres la Faculté économique, qui contiendroil les arts mathématiques et mécaniques, et tout ce qui regarde le détail de la subsistance des hommes et les commodités de la vie, où l'agriculture et l'architecture seroient comprises n (1). Il faut surtout éviter en ces matières la rupture entre théorie el pratique. Présente, et opérante dans les arts manuels, mais encore dans la médecine, l'art de la guerre et chez les virtuoses, leur alliance est la condition nécessaire du "grand dessein $n^{*}$ de Leibniz (2). " et si les principes de loutes ces professions et arts et mème des métiers, étaient enseignés pratiquement chez les philosophes, ou dans quelque autre faculté de savants que ce pourrait être, ces savants seraient véritablement les précepteurs du genre humain... Mais, ajoute Leibniz, il faudrait changer en bien des choses l'état présent de la littéralure el de l'éducation de la jeunesse et par conséquent de la police ".

La première étape du projet technologique est fixée par Christian Wolff. Dans un texte plus abstrait, qui traite également de la classification des sciences, puisqu'il s'agit du chapitre De parlibus philosophiae du Discours préliminaire à sa Philosophia rationalis sive Logica de 1728, Wolff résume dans un nom et codifie dans une définition toute l'aspiration technicienne du xvII ${ }^{\mathrm{e}}$ siècle. Mais il ne propose pas l'exploilation systématique des forces et des richesses naturelles sous la direction des savants, dont parle Bacon. Plus modestement, il s'agit de réunir en un corps de doctrine cohérente le savoir implicite dans les opérations de l'art et de l'inscrire sur la carte intellectuelle du système universitaire. "Possibilis quoque est philosophia artium, etsi hactenus neglecta " (3), car toul art, comme le droit ou la médecine, renvoie aux raisons de ses opérations qui en expliquent la possibilité. Même un art manuel aussi servile que la fragmentation du bois met en jeu une structure conceptuelle implicile qui régit l'exćcution des opérations instrumentales : " il y a une raison pour laquelle on peut couper le bois, et pourquoi on peut le faire à l'aide d'un coin, ou cependant aussi bien par la hache " (4). Or - et c'est là le point essentiel de la conception wolffienne de la philosophie des arts - la conceptualisation des règles auxquelles est soumis l'usage des instruments et des outils, même les plus simples, fait intervenir des rapports et des concepts susceptibles d'un traitement mathémalique. "Les forces du coin et l'altaque qui le pousse peuvent être démontrées

(1) Nouveaux essais..., IV, 21. - Parmi les * quelques-uns ", mentionnons Christian Thomasius qui écrivait qu'a on devrait aussi enseigner, dans les universités, l'économie comme une des disciplines du droit, el il faudrait nommer pour cela un protesseur spécial... ". Caurele der Rechts-Gelehrlheil, XVII, \$1.

(2) * Le grand dessein que j'ai, et qui enferme tous les autres, c'est l'avancement des arts cl des sciences utiles aux hommes, et avantageux à l'Etal , écrivait-il dans une lettre au duc Jean-Fícédéric (Sämll. Schr. u. Brie/e, I. Teilie, 2, n॰110, p. 121).

(3) Logica, Disc. prel., ch. III, \$ 71 .

(4) Op. cil., clı. II, §39. 
mathématiquement. Il y a donc une connaissance philosophique et mathématique de cet art servile, d'où la philosophique puise toute sorte de certitude n.

La discipline dont le concepl est ici pour la première fois défini est, conformément aux vœux d'un Leibniz ou d'un Hornigk, une discipline mathématique.

L'innovation conceptuelle de Wolff est soulignée par la dénomination. A cette philosophie des arts, Wolf donne le nom de technologie : "Lam Technicam aut Technologiam appellare posses n, opérant ainsi la mulation sémantique décisive du sens d'un terme de rhétorique en terme désignant un discours rationnel sur l'activité technique. "La Technologie est donc la science des arts et des œuvres de l'art, ou, si l'on préfère, science des choses que les hommes produisent par le travail des organes du corps, principalement par les mains n(1). On le voit, Wolfe ne se contente pas d'une indication sommaire (comme celle du Diclionnaire de Phillips) : il est le premier à définir le mol dans son acception moderne, à formuler le projet d'une discipline et à lui assigner une place exacte dans l'ensemble des sciences. Cette technologie emprunte ses principes à la physique, en particulier à la physique expérimentale, sans se confondre avec elle. "Ars versatur circa corpora naturalia " (2) ; la connaissance de ces corps, de même que celle de la structure et du fonctionnement des dispositifs instrumentaux est du ressort de la physique et de la mécanique. La lechnologie est l'étude des règles opératoires et des ouvres : « reddenda hic potissimum ratio est regularum artis et operum, quae arte perficiuntur " (3). Ces règles sont la conséquence des théories philosophiques; dans la classification et l'exposé des sciences, la technologie doit suivre la physique. Le problème de sa division interne est abordé - il faut, soit établir autant de disciplines qu'il y a d'arts divers, soit, pour limiter leur nombre, former " artium quaedam genera " - sans qu'il puisse être résolu à partir d'un simple projet, car il suppose un savoir déjà achevé, constitué. Comme " nous n'avons [même] pas, jusqu'ici, une histoire minutieuse des arts " (4), il est impossible d'établir une classification efficace qui supposerait une connaissance d'ensemble des activités techniques.

Historiquement, le projet de Wolff n'a pas eu de suite; jusqu'à l'avènement de Beckmann, on ne parlera plus de technologie et l'enseignement des arts sera incorporé dans les sciences camérales. Wolff a cependant pris activement part à la diffusion de savoir technique de son temps (il préfaça la traduction allemande de l'Archileclure hydraulique de Bélidor cependant qu'il encourageait Réaumur à publier les planches des Descriptions) et sa philosophie des arts conceptualise les collections et les descriptions des opérations el outils, prolonge et unifie des remarques et des projets des théoriciens, découvre et thématise un domaine nouveau de la réflexion philosophique. "L'arl apportera

(1) Op. cit., ch. III, \& 71 .

(2) Op. cil., cli. III, \$113.

(3) Op. cit., ch. III., §71. - WolfF a donné deux éclıantillons de cetle technolngie traitée selon les normes scientifiques : le premier concerne l'architecture civile (a est enim architectura civilis hac ratione pertraclata species Technologine ", ibid.), le second, Tenlamen de vera causa mulliplicandi /rumenlum, l'agriculture.

(4) Op. cil., ch. III, § 114. 
le secours aux philosophes "(1) ... Les opérations de l'art, de même que les expériences, meltent très souvent au jour les faits naturels (facla nalurae) qui autrement resteraient latents... Par le ministère de l'art, la connaissance arcane (arcana cognilio) se réduit ainsi à la connaissance commune n (2). C'est pourquoi Wolff recommande aux philosophes de " recueillir et décrire exactement les phénomènes qui se présentent dans les ateliers des artisans et ailleurs dans les arts (par exemple dans l'économie rurale); car ils constituent la partie de la connaissance historique arcane qu'il est impossible d'obtenir autrement avec, pour seul guide, les sens" (3).

Ce texte important de Wolff est contemporain de la fondation a Halle de la première chaire de sciences camérales : Frédéric Guillaume ler appelle, en 1727, Simon Peter Gasser aux fonctions de professeur. Le programme de cet enseignement (4) est d'abord dicté par les besoins des Chambres : assurer l'instruction des fonclionnaires de l'administration, en particulier dans le domaine financier : les taxes régaliennes, les douanes, le fisc, la comptabilité d'Eltat, mais léjì le premier programme contient des malières du futur enseignement technologique : les guildes et les métiers, les fabriques et leur accroissement. Le manuel classique de Just. Christoph Dithmar, Einleilung in die ökonomischen. Polizey- und cameral-Wissenschaften ( ${ }^{\mathrm{re}}$ èd. 1731, $6^{\mathrm{e}}$ éd. 1769) souligne davantage encore la contribution des arts et métiers à la nutrition et à la richesse, à la "félicité temporelle " (5) ; désormais, la place prise par les métiers el les manufactures dans l'évolution de l'économie s'accroîtra par rapport aux ressources domaniales et régales du prince. Aux sciences camérales pourra se substituer une nouvelle discipline qui ne sera plus exclusivement. subordonnée aux décisions politiques et économiques de l'arbitraire princier. Le terme de "caméralistique " subsistera - Schmalz publiera encore en 1823 à Leipzig une Encyclopédie des sciences camérales qui comprennent l'économie politique et, une Getverbskunde, doctrine des mètiers où la technologie prend place entre l'agriculture, la sylviculture, les mines et le commerce - mais il subira une concurrence de plus en plus forte de la "technologie".

Depuis le milieu du xvir ${ }^{\mathbf{e}}$ siècle, le foyer des sciences politiques et camérales se transporle de Halle à l'université récemment fondée à Göttingen. En 1743. Achenwall fonde la slatislique et la fait entrer dans les programmes de l'enseignement; pendant deux ans, de 1755-57, un des principaux représentants de la caméralistique allemande, J.H.G. Jisti fait des lectures sur les

(1) Op. cil., ch. II, \$ 39 .

(2) Op. cil., ch. I, $\$ 24$.

(3) Op. cil., ch. I, \$ 25 . Maj. in Preussen anf der Universiläl Halle allergnädigsl fundierlen Pro/ession uber die Oeconomischen- Kameral- und Police! - Wissenschaflen, Halle, 1728.

(5) C'est. l'objet de la science économique. La police aura pour tache d'enseigner * commo:nt, maintenir l'être intérieur el extérieur d'un Etat dans un hon ordre et constitution pour liı félicité de lous a; les sciences camérales, * comment utiliser, améliorer el appliquer à la conservation des affaires publiques les domaines et régales du prince el comment élever les revenus du prince de ces domaines, aussi bien que des prestations dues par les sujets et d'autres fonds publics " (I. Abtheilung, \& 7 et 10). 
sciences domaniales et l'économic, mais s'intéresse également aux manufictures (Beckmann lui-même publiera les deuxième et troisième éditions de son Vollständige Abhandlung von den Manufakluren und Fabriken). Dans la seconde moitié du siècle, deux amis de Beckmann, l'historien et statisticien juriste A.L. Schlözer et le géographe et statisticien Büsching s'y illıstreront dans les nouvelles disciplines.

Cet enseignement avait un caractère éminemment pratique ; il incluait la Gewerbelkunde, la science des méliers et l'agronomie, les deux disciplines qui incubent la technologie ; en outre, on donnail à Ciöltingen des cours d'architecture civile, d'architecture hydraulique et Gmelin y professa la chimie appliquée aux arts el métiers. Mais il n'existait aucun enseignement réunissant dans une mème discipline arts et métiers, enseignement rendu urgent par le progris des manufactures en Angleterre qui devail transformer la face de l'liurope. II se trouve que la consécration universitaire de la technologie est contemporaine: du moteur de Watt. Elle n'en fait pas moins corps avec l'ancien monde des arts et méliers; elle s'enracine dans l'univers des guildes, de l'économie artisanale ct. paysanne du régime absolutiste; l'information qu'elle transmet, les schemats qu'elle décrit, la communication rationnelle qu'elle instaure supposent encor: un savoir-faire empirique quasi-ésotérique incomplètement explicité (1).

Le sentiment que les technologues allemands prenaient du retard économique de leurs pays, relativement ì d'autres nations, les a portés à recluercher à l'étranger des modèles d'organisation et des méthodes techniques. L'industric anglaise était au $\mathrm{xvn}^{\mathrm{e}}$ siècle plus active, plus développée que celle d'aucun autre pays; mais elle était le lieu de transformations lechniques fui échappaient pour une bonne part à la conscience des observateurs continenlaux ; des entrepreneurs étaient jaloux de leurs procédés, les Transaclions de la Royal Society accordaient assez peu de place aux questions industrielles, les patentes et les inventions, annoncées plus fréquemment dans la seconde moitié du siècle, n'étaient pas loujours dignes d'intérêt (2). Les processus décisifs n'apparaissaient donc pas clairement sur le fond bigarré des transformations

(5) Dans Science and Technology in the eighteenth cenlur! (apud Hislor!! of Science, vol. I, 1962, pp. 30-43), D.S.L. CARDwel. fait remarquer que, même en l'absence d'une théorie scientifique cohérente et achevée, le traitement scientifique des problèmes techiniques peut partiellement s'imposer. La machine á vapeur conçue et réaliséc bien avant sa théorie totale est une application segmentaire de notions scientitiques définitives concernant la pression atmosphérique. La mécanique classique n'a que peu de rapports avec une théorie générale des machines qui doit intégrer la connaissance des sources d'énergie, el ne peut se constituer que du jour oii l'on sait mesurer les puissances mécaniques et les échanges énergétį̣ues. Les motifs technologiques seront alors englobés dans la science des machines. On comprend des lors l'échec des tentatives d'llassentratz. On comprend également pourquoi le termie de technologie qui commence par désigner un discours systématique sur les arts utiles en viendra à se charger d'un contenu scienti.ique "and come ultimately to be regarded as almost synonymous with applied science . C.f. C. Singen, E.J. Holmyand, A.A. HAL.., A hislory of technolog!!, $3^{\circ}$ ed., Oxford, 1956, t. I, p. vii.

(2) Comme le nole J.G. Fonsten en 1790 , c'est ì un " petil nombre de ciloyens " que l'industrie anglaise dut son essor (Voyage philosophique... /ail en 1790, trad. Pougens, l'aris, an IV. pp. 182-3). Citoyens souvent réunis dans des sociétés provinciales, par exemple la célèbre Lunar Sociely de Birmingham. Si l'éducation professionnelle des classes inférieures se développe, au début dı Xrxo siècle, dans les cités industrielles, la science de l'ingènieur apparaft timidement dans quelques chaires universitaires. A partir de 1795, W. Farisir traite a Cambridge des productions industrielles et de la construction des machines. 1. Universily Calendar de 1802 désignait ce cours comme excitant à une "real practice "les personnes " already acquainted wilh the principles of mathematics, philosophy and cliemistry" (p. 81). 
lechniques dont les déterminismes se perdaient dans une totalité socio-économique complexe. L'Angleterre incubait alors le stade embryonnaire d'une sociélé machiniste avancée, la France exhibait le stade achevé d'un type d'organisation sociale plus proche des structures allemandes archäques. C'est assez naturellement que les technologues germaniques cherchèrent des enseignements en France, dont ils entendaient la langue. Le prestige de l'Académie balançait bien celui de la Royal Society et diminuait l'éclat des sociétés scientifiques allemandes. Le projet de traité sur les arts avait suscité beaucoup d'intérî́t et quand les premières Descriptions parurent avec bien du retard, elles furent accueillies avec faveur.

Le programme d'une enquête sur les arts avait été donné à l'Académie, comme on l'a vu plus haul, en 1675 . En fait, les choses trainèrent, el les premiers documents attestés sur cette activité datent de 1693 (1). Et trois ans plus tard, l'Hisloire de l'Académie renfermait un commentaire Sur la Descriplion des Arls qui est comme une excuse à la lenteur de sa publication : "Le travail de l'invention est le plus agréable \& en mène temps le plus glorieux, l'on seroil assez porté naturellement à n'en entreprendre point d'autre. Mais comme l'Académie a plus en vûë d'être utile au public, que de s'occuper avec plaisir, ou de s'attirer de l'éclat, elle a embrassé volontiers un travail sec, épineux \& nullement brillant, tel que celuy de la Description des Arts dans l'état oủ ils se font aujourd'huy en France "(2). Ayant ainsi protesté de ses bonnes intentions, le secrétaire promet que " cette Description entrera dans les derniers détails, quoiqu'il soit souvent très difficile, ou de les apprendre des artisans, ou de les expliquer, \& elle représentera soit par discours, soit par figures toutes les matières qu'on employe, tous les instrumens \& toutes les opérations des ouvriers". Il s'agit d'abord d'un enregistrement des procédés existant, et la première justification que donne l'article est bien d'ordre archéologique : "On assure à la postérité les Arts, tels du moins qu'ils sont présentement parmi nous, elle les retrouvera toûjours dans ce Recueil, malgré les révolutions $\&$ si nous en avons perdu quelques uns d'importans qui fussent chez les Anciens, c'est que l'on ne s'est pas servy d'un semblable moyen pour nous les trans-

(1) - Le recueil des dessins et des gravures ayant apparlenu à Réaumur et conservê à I'Institul monlre que certains dessins ont été approuvés dés 1693 . Le manuscrit de Jaugeon sur l'art de consl ruire les caracteres donne aussi la dale de 1693 pour le début des travaux de l'Académic, J. Proust, Diderol el l'Encyclopédie. Paris, 1962, p. 183.

(2) Sur in Descriplion des Arts, in Hisloire de l'Académie royale des sciences pour 1699 , p. 177. - La même altitude est relevée plus d'un siecle plus tard par Burdin qui, en 1815, dans le Journal des mines avoue * convenir que la science des machines... n'a pas marché d'un pas égal avec la mécnnique rationnelle. La nécessité de recourir sans cesse à l'expérience, les litficultes et les incertitudes qui se présentent dans la mesure rigoureuse des forces, tant actives que passives, qui agissent dans les machines, n'ont pas peu contribué à rebuter les esprils qui se sont jetés de préférence dans l'élude de l'astronomie et de la haule physique lesquelles donnent plus de prise aux calculs el présentent à l'imagination des résultats plus vasles el plus attrayants ", Considéralions générales sur les machines en mouvement, loc. cil., pp. $2-3$. 
mettre (1). Ces descriptions faciliteront cependant la comparaison des u pratiques de France avec celles des autres Païs n, elles seront enfin l'occasion pour d'« habiles gens qui ne peuvent se donner la peine, ou qui n'ont pas le loisir d'étudier les Arts ches les Artisans... de travailler à leur perfection n, étant bien entendu que l'u Académic ne manqquera pas non plus à marquer dans les occasions ce qu'elle jugera qu'on y pourroit ajouter, ou du moins ce qui seroit à désirer n (2). Tout cela dit sereinement, comme il convient à une académie, mais un peu trop tout de mème. On trouvera plus de feu dans un Averlissement bien postérieur, celui de 1761 : "Ne doit-on pàs attendre de nouveaux degrés de perfection dans les Arts, lorsque les Savans exercés sur les différentes parties de la Physique se donnent la peine d'étudier \& et développer les opérations souvent ingénicuses que l'Arliste exécute dans son átelier n (3). Quant aux approbations les plus chaleureuses, c'est de l'étranger qu'elles viendront. "Depuis l'invention de l'Imprimerie je ne crois pas qu'on ait formé de projet plus grand ni plus utile que celui de Messicurs de l'Académie royale des sciences $n$ proclame J.E. Bertrand dans sa préface de la réédition neuchâteloise des Descriplions qui connaîtront à la mème époque une traduction allemande par Jusli et Schreber (4). Le professeur de Neuchâtel louait les académiciens d'avoir su " donner une idée exacte \& détailléc des métiers, décrire avec netteté les opérations les plus difficiles, faire connaitre avec exactitude les outils \& les machines emplö̈ées par les divers artisans qui travaillent pour nos besoins, nos commodités ou nos plaisirs, parler un langage intelligible aux plus ignorans, pousser la précision au point qu'un homme doué de quelque talent puisse, aprés une lecture attentive, exécuter lui même les procédés de tous les arts... ". Cependant, il note les défauts que présente la langue des arls; il appelle de ses væux l'introduction d'une nomenclature uniforme des instruments et des opérations :

(1) Dans la Préface du mème volume, Fontenelle dénonce la cécité trop commune devant l'univers des métiers : "Il est étonnant combien de choses sont devant nos yeux sans que nous les voyions. Les boutiques des artisans brillent de tous côtés d'un esprit \& d'une invention, qui cependant n'attirent point nos regards, il manque des spectateurs it des Instrumens \& à des Pratiques très utiles, \& très ingénieusement imaginées, \& rien ne seroit plus merveilleux, pour qul en scauroit être étonnè n. Le même argument sera repris plus fermement par Diderot: a ... se familiariser avec les objels : ils en valent bien la peine, soit qu'on les considére par les avantages qu'on en tire, ou par l'honneur qu'ils font à l'esprit humain. Dans quel système de physique ou de métaphysique remarque-t-on plus d'intelligence, de sagacilé, de conséquence, que dans les machines à riler l'or, à faire des bas, et dans les métiers de passemantiers, de gaziers, de drapiers ou d'ouvriers en soie ? Quelle démonstration de matliématiques est plus compliquée que le mécanisme de cerlaines horloges, ou que les différentes opérations par lesquelles on fait passer ou l'écorce du chanvre, ou la coque du ver, avant que d'en obtenir un fil qu'on puisse employer ì l'ouvrage ? Quelle projection plus belle, plus délicale et plus singuliere que celle d'un dessin sur les cordes d'un sample, et des cordes du sample sur les fils d'une chaIne? Qu'a-t-on imaginé en quelque genre que ce soit qui montre plus de subtilité que de chiner des velours? Je n'aurais jamais fait si je m'imposais la tache de parcourir toutes les merveilles qui frapperont dans les manufactures ceux qui n'y porleront pas des yeux prévenus, ou des yeux stupides ", s.v. Arl, éd. Assézal, p. 369-370.

(2) Op. cil., p. 117.

(3) On y trouvè également l'allusion à une science de l'application dans le sens de la technologie beckmanienne, quand l'auteur de cet avertissement évoque * les secours qu'on peut faire passer d'un Art dans un autre, \& que l'Ouvrier est rarement à porlée de connaitre . Cité par J.E. Bertrand dans son édition des Descriplions, en 1771, p. xvi.

(4) Schauplatz der Kansle und Handwerke, 21 vol., 1762-1805. 
"J'ose donc inviter les Savans de Paris à entreprendre à perfectionner á cet égard, leur langue; qui deviendra la langue commune de l'Europe »(1).

Quand a la fin du siècle, l'Institut tracera le Programme pour la continualion de la descriplion des arls, il insistera sur ce que "la description d'un art est bonne lorsque un discours clair et précis, accompagné des dessins et des lables nécessaires, la rend intelligible à quiconque veut pratiquer l'art ». Ces exigences de précision trouveront, en quelque sorte, leur récompense dans ce que lous les termes de la description, "par une altention soutenue à dire chaque chose dans le lieu qui lui est propre ", iront s'insérer dans un "système qui embrasse l'universalité des arts "; el ce ne peut être qu' " un système philosophiqque, une méthode qui passe du simple au composé, une déduction suivic... "(2). On reconnaît bien là, à une époque qui bavarde sur les signes, l'écho longlemps répercuté de l'aphorisme de Condillac, " les langues sont des méthodes analytiques ".

Nous touchons ici à un noud important du réseau constitulif de la lechnologrie. Il y a une langue technique, à loute époque, nécessaire, mais jamais très bien fixée. Or, lout discours tant soit peu approfondi sur les techniques suppose qu'on l'ait définie au préalable, pour un temps assez long. Sur ce thème, Diderot a dit des choses décisives.

La possibilité de rendre publics, de communiquer les procédés des arts dépend de la création d'une langue unifiée des métiers. Or, avant l'Encyclopédie, c'est à peine si l'on peut parler de la langue des métiers (3) : la terminologie varic parfois d'une manufacture à l'autre; l'insularilé et l'imperfection de la langue technique résultent tantòt d'une surabondance de synonymes, tantòt du déraut de dénominations propres, pour telle matière, tel outil, telle opération. Tout comme les structures corporatistes et le secret des fabrications, l'irrégularilé terminologique fait obstacle au développement des manufactures. Instru-

(1) Op. cil., p. xiii.

5.et, 1798 .

(2) Institui' national, Séance publique, 15 vendémiaire, an VII, p. 3. Le souci de réformer la terminologie teclinique a préoccupé les comilés révolutionnaires qui ont bien compris tue toute réforme radicale doil prendre racine dans la première éducation. Ct. le Rapport sur la composition des liures élémenlaires destinés à l'Instruction publique, par L.F.A. Arbogast. On y lit, après la rétérence obligée à Condillac, que * les termes el sur-tout les termes techniques, representent toujours une nouvelle combinaison d'idées ou un fait constaté suffisammenl; ils consacrent une analyse déjà faile pour en faciliter d'autres plus difficiles. L'état de la science se trouve tout entier dans la langue qu'elle fait, dans la nomenclature dont elle se sert ; mais dans beaucoup de sciences et d'arts, cette nomenclature est encore vicieuse ; elle (*; $L$ ail-tlessous des connoissances acquises, et souvent en contradiction avec les faits les mieux constalès $n$, p. 11 .

Ce programme fait suite à l'enquete demeurée sans lendemain qu'avait instituée le Journal des Arts el Manufaclures, en vue d'éclaircir le sens de mainl vocable des métiers : * les correspondans voudront bien nous taire parvenir les définitions accompagnées de tous les dévcloppemens nécessaires pour en fixer le sens. Ces précautions sont indispensables pour parvenir à une synonymie exacte des arts et métiers, et en donner un vocabulaire exempt I'ambiguitté, ouvrage important qui produiroit le bon effet d'exclure du langage de l'industrie cetle confusion facheuse qui fait que les ouvriers d'un atelier n'entendent pas ceux d'un alelier voisin $n, t$. J, p. 52 . I 7,5

(3) Dans un texte antérieur à 1643 , Comenius faisail allusion à la " confusion babylonienne " de la langue des artisans : "Confusionem Babylonicnm patiuntur lingux omnes, non solum inter se invicem, sed et in semet ipsa unaquaequae. Nam et Artifices ipsi in tradendis artibus, vocum et terminorum significationes confondunt, ut se mutuo vix intelligant, aliquando etiam idem ille vix se ipsum *. Two Pansophical works, op. cit., p. 137. 
ment de divulgation, l'Encyclopédie aspire à réaliser la communicabilité universelle des arts, en constituant un vocabulaire homogène, réglé comme celui de la géométrie, toute attribution étant normalisée. Cette constitution de la terminologie lechnique unilaire achève et unifie le monde des arls et métiers, en permettant de le considérer comme un réseau complexe mais unique (1) d'opérations transformatrices, rationnellement décrites. C'est par celte volonté d'unification sémantique 'que l'Encyclopédie se distingue des Descriplions de l'Académic, plus spécialisées, plus critiques, plus avancées, mais plus dispersées.

Cette unification ne concerne pas seulement la normalisation du vorabulairc. Elle va jusqu'à la syntaxe du langage des arts, à la détermination des rapports logiques dans une fabrication ou dans une machine donnée. Celte nouvelle syntaxe, proposée davantage que réellement appliquée, apporte d'abord une simplification dans la description des opérations et des machines : "... j. suis convaincu que les manouvres les plus singulières, et les machines les plus composées, s'expliqueraient avec un assez petit nombre de termes familiers et connus, si on prenait le parti de n'employer des termes d'art que quand ils offriraient des idées particulières $n(2)$. Mais de plus, une machine qui a atteint la perfection - par exemple, le métier à bas - peut être conçue comme un modèle exhibant el réalisant une structure formelle : on peut la regarder comme un seul et unique raisonnement dont la fabrication de l'ouvrage est. la conclusion" (3). Etant donné que "les machines composées ne sont que des combinaisons des machines simples" et que "tous les mouvements sont réductibles, sans aucune erreur considérable, au mouvement rectiligne et au mouvement circulaire n (4), il est possible de décrire la structure des machines el leurs opérations à l'intérieur d'un système, à partir d'un pelit, nombre de notions primitives. La constitution de la langue des arts implique done, en meme temps, la normalisation du vocabulaire et la réforme de la syntaxe. Cies tâches n'incombent pas à l'artisan ni à l'ingénieur, mais bien au logicien : " il serait done i souhaiter qu'un bon logicien, à qui les arts seraient familiers, entrepril les éléments de la grammaire des arts ". Le premier problème que Diderol entend lui soumeltre serait de "fixer la valeur des corrélatifs, grand, gros, moyen, mince, épais, faible, petit, léger, pesant, etc. n, c'est-à-dirc un problème de normalisation du système des mesures. Le second, tout aussi essentiel, concerne la détermination des formes et des opérations : il faudrait établir des classes

(1) L'unificalion du réseau des opérations transformatrices était la condition du progriss

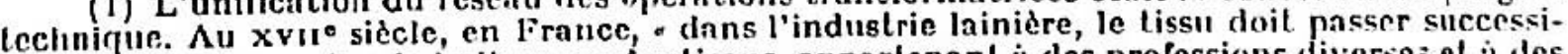
vement dans les mains de lutit ou neul artisans, appartenanl i des professions diverses et il des communautés rivales. Cette fragmentalion du processus de fabrication empèche l'artisan d'imnginer el d'imposer une innovation lechnique ou une économie. Les slatuts des communautés, les réglements royaux, le protectionnisme douanier, toul contribuail is rendre plus difticiles, moins tenlants le progrès technique et l'invention s, P. DEYos, La produclion manufacturière en France au xvm' siècle et ses problèmes, in Dix-sepliemc siécle, 1966, 70-71, p. 62.

(2) Encyclopédie, art. Art.

(3) Ibid., art. Bas.

(4) Ibid., art. Art. 
d'outils et d'instruments, de même que des classes d'opérations dont chacun ou chacune serait désigné par le même terme (1).

Le logicien que Diderot appelle de ses voux, a effectivement existé ; il avait proposé, quelque soixante-dix ans plus tôt, non seulement une grammaire des arts, mais encore un système de notation des composants et des opérations des machines. G'est Lcibniz; son projet de caraclérislique universelle devrait permettre de représenter au moyen d'une langue symbolique appliquée aux figures géométriques, les éléments de structures machinales. Si cette caracléristique était achevée, "de la manière que je la conçois, dit-il, on pourroit faire en caractères, qui ne seront que des lettres de l'Alphabet, la descriplion d'une machine, quelque composée qu'elle pourroit estre, ce qui donneroit moyen à l'esprit de la connoistre distinctement et facilement avec toutes les pièces et mème avec leur usage et mouvement sans se servir de figures ny de modelles et sans gener l'imagination, et qu'on ne laisseroit pas d'en avoir la figure présente dans l'esprit autant que l'on se voudroit faire l'interpretation des caracteres " (2). L'utilité pratique du projel - l'économic des modèles et même des figures qui simplifie le raisonnement - est étayéc par l'idée d'une science unitaire réduisant successivement la matière machinale à la mécanique, la mécanique à la géométrie, la géomètrie au langage symbolique commun : "Je croy qu'on pourroit manier par ce moyen la mécanique presque comme la geométrie, et qu'on pourroit mesme venir jusqu'à examiner les qualites des materiaux, parce que cela depend ordinairement de certaines figures de leurs parties scnsibles " (3). En vertu du mécanisme universel, des éléments de ce qu'on désignera plus tard technologie pourront être soumis au mème traitement caractéristique que la mécanique. Cela ne fut qu'un projet.

Cependant, l'idée était séduisante de fixer dans une notation symbolique configurations successives et mouvement organique des machines. Les représentations graphiques ordinaires peuvent bien procurer l'image d'un état donné d'une machine, voire les trajectoires de certaines parties mobiles ; mais, elles ne peuvent rendre compte des vitesses et de leurs variations. Il fallait inventer un code capable d'exprimer le plus d'informations possibles sur la

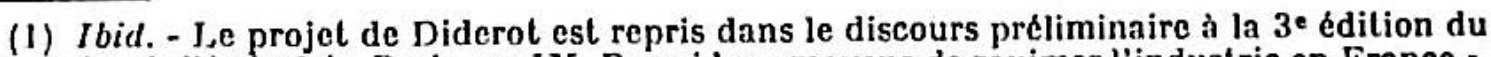
Dictionnaire de l'industrie, Paris, an IX. Parmi les a moyens de ranimer l'industrie en France ", figure cette injonction: " rajeunissez les arts et métiers par une nouvelle nomenclature. un nouvel idiỏme,; il importerait de formuler une "grammaire générale des arts contenant une classification et une courte définition des ustensiles, outils et instrumens utiles et communs à un grand nombre d'arts et métiers, et sous des chapitres sépnrés, une courle définition des oulils et instrumens de chaque art en particulier, indication de la manière d'en faire usage, de leurs effecs et des résultats de la main-d'cuvre ", p. xxxvı.

(2) Jettre de Leibniz à Huyghens du 8 septembre 1679 , Der Bricfwechscl von $G$.W. Leibniz mil Malhemalikern, ed. Gerhardt (Hildesleim, 1962); Beilage, p. 570-71. - Devani le scepticisme de Huyghens, Leibniz entre dans les détails du projet : "Je puis demonstrer que ce que j'ay avancé suit de ma caracteristique lineaire ou geometrique dont je vous ay cnvoyë un essay. Car premierement je puis exprimer partaitement par ce calcul toute la nature on definition de la figure... Et je le puis en toutes les figures, puisqu'elles se peuvent expliquer loutes par des spheriques, plans, circulaires et droites, dans lesquelles je l'ny fait.... Or toutes les machines ne sont que certaines figures, done je les puis décrire par ces caractères, et jo puis expliquer le changement de situation qui s'y peut faire, c'est-à-dire leur mouvement. (Leltre non dalée, ibid., p. 580).

(3) Ibid., p. 571 . 
structure géométrique et cinématique d'une machine. Celte tàche fut Lentée par Babbage. Il publie, en 1826, dans les Philosophical Transaclions, une mélhode qui permet de "déterminer une partie quelconque de machine, de connaîlre à tout moment donné son état de mouvement, sa relation aux mouvements de toute autre partie, et s'il le faut, de remonter l'enchaînement du mouvement. par tous les relais successifs jusqu'à la source motrice originelle (1). Sa notation est constituée d'éléments géométriques, lignes et points, et de nombres représentatifs des caractéristiques du dispositif, le tout assujetti à des règles synlaxiques. Pour lui, ce "langage des signes " se justifie par le "grand pouvoir que l'analyse tire d'une signification condensée " (2). En outre, comme il l'écrira plus tard, le champ d'application de cette notation s'étend à la " description d'un combat sur mer ou sur terre ", aussi bien qu'à la "représentation des fonctions de la vie animale " (3), c'est-à-dire, à toute structure réductible à un modèle machinal. Il insistera encore sur l'avantage que l'on peul. tirer de ce: que son système permet des descriptions parfaites sans recourir i la moindre terminologie (4). Ce faisant, il dépossède l'homme des métaphores anthropomorphiques du monde factice des machines, il expulse de cet univers le verbe et il anticipe sur les traitements programmés de l'information (5). Son souci de la notation condensée s'applique encore dans une direction plus " technologique ", au sens contemporain, quand il réclame l'élaboration d'un code des apparences matérielles, plus particulièrement une notation universelle des couleurs ; problème difficile entre tous, dont il ne pouvait seulement que souligner l'avantage qui résulterait de sa bonne solution : " l'utilité de tels assortiments d'ćtalons colorés permeltrait à toutes les nations de parler une langue relative aux couleurs, à la fois précise et universelle ». Il touche là à l'un des molifs majeurs de la technologie, la spécification exacte et normalisée des malières el des productions.

Si Leibniz, Diderol et Babbage appellent donc la creation d'une symbolique universelle des structures machinales et de leurs productions, avant mème. cependant, toute tentative sérieuse de constituer une telle langue, des discours et des bavardages technologiques se font entendre partout oủ des hommes songent à organiser la machinerie sociale, en y privilégiant l'activité transformatrice de l'homme sur la matière. Parmi beaucoup de voix discordantes, Beckmann vint qui invenle la technologie et fonde son enseignement.

(1) C. Baввage, On a method of expressing by signs the action of machinery, in Philosphical Transactions, 1826, part II, p. 260. Il insiste sur la o di ficully of retaining in the mind all the contemporaneous and successive movements of a complicaled machine, and the still greater difficulty of properly timing movements ".

(2) Ibid., p. 260.

(3) Passages from the li/e of a philosopher, London, 1864, p. 1.13.

(4) Ibid., $\mathrm{p}$. 192. Voir aussi, The Exposition of 1851 ... vicus on the industr!, the science and the government of England, London, 1851, p. 138.

(5) * The Science of Calculalion which becomes continually more necessary at each slep of our progress, and which must ultimntely govern the whole of the application of Science to the Arts of Life,$A$ Trealise on the Manu/aclures and Machinery of Greal Brilain, by Peter ВАRLOW, to which is prefixed an Introduclory view of the principles of Manufacturcs, by Ch. BAвBAGE, London, 1836, p. 81. 
Le: mot apparail furtivement pour la première fois dans un lexte en 1772 (1); c'est l'époque où Beckmann commence à enseigner la discipline qui fera sa réputation. Son Anleilung zur Technologie de 1777 fixe le lerme, définit le concept et expose la matière.

Celle technologic apparait d'abord comme une extension naturelle de la carrière de Beckmann. Agronome, naturaliste, caméraliste, économiste, il n'ignore pas la physique ni les mathématiques, il possède une solide instruction philologique, tant, théorique que pratique. Il fail un voyage en Hollande, passe deux années à Saint-Pétersbourg et retourne par la Suède où il reste plusieurs mois. Ses journaux de voyages révèlent un observateur extrèmement minulieux, attentif au ménagement de son temps, a l'exactitude de ses comptes rendus; il se lie vite avec le monde savant - Linné le reçoit très cordialement - , ne laisse échapper aucun objet de curiosite, aucune rencontre fructueuse. II visite les ateliers, les manufaclures et les fabriques, il descend dans les mines. Mais surtout, il n'omet de noter aucun dètail de ce qu'il voit et entend, el s'applique à corriger les relations de voyages antérieures. On peut reconstituer ses déplacements heure par heure, pas à pas. Sur recommandation de Büsching, il devient, à son retour, en 1766, professeur extraordinaire d'économie à Göttingen où il se fixera jusqu'à sa mort.

Son enseignement, s'oriente d'abord vers l'agronomie, mais bientôt, il donnera des lectures sur des sujets très variés : comptabilité commerciale, banques, sciences camérales, minéralogie, botanique, arts et métiers, marchandises. Mais ce qui importe surtout dans cet enseignement, c'est son esprit et sa méthode. Les sciences camérales de mème les parties technologiques incorporées avaient èté dispensées principalement, sinon uniquement, sous forme de discours. Beckmann bouleverse des habiludes hien établies. Il ne recourt pas sculement - comme les naturalistes - aux collections minéralogiques et aux ressources du jardin botanique; traitant de métallurgic ou d'agronomie, il exhibe en même temps les modèles de diverses machines et outils de sa collection privéc (2). Mais l'emploi des schémas et des modèles trouvera sa place la plus importante dans un nouvel enseignement qui se constitue entre 1770 et 1777 : celui de la technologic. J.S. Pütter, historiographe de l'enseignement

(1) Physikalisch-ðkonomische Bibliothek, tome III (1772), p. 309.

(2) Les deux jugements suivants sur l'enseignement de Beckmann sont moins intèressants par leur contradiclion - apparenle seulement - que par l'indication qu'ils donnent sur le changement d'orientation de l'enseignement supérieur allemand.

a) - Ses leģons, qui parurent, dans le temps une nouveauté piquante, furent fréquentées par léliln de la jeunesse studieuse, que les nntions les plus civilisées de l'Europe envoyaient i) I'Universile de Ciocltingue; el i'on peut affirmer que les hommes d'Etal el les adminislrateurs de l'Allemagne les plus distingués ont été ses audileurs n. (Biographic universelle ancienne el moderne, Paris, 1843, l. III, nrt. Beckmann Jean, par Stapfen).

b) * On enscigne encore à faire le devis d'une distillerie, d'une goudronnerie, d'un moulin de gruau, on enseigne combien de fibres doil avoir ln toile et le taffetas dans la chatne e.l dans la lrame, on enscigne comment fabriquer le tromage et comment fondre le fer, comment expulser les chenilles et les hannetons, mais on $n$ 'a encore aucune idée ae principes supérieurs d: la science politigue n (Leopold Knug, Beobachtungen aber Nationalreichthum des pretussischen Stants, I, préf., p. 5, Berlin. 1805, cilé d'après Jul. Löwenberg, in K. BruHss u.a.: A. von Humboldl, l'(1872), p. 51$)$. 
supérieur en Allemagne, note l'orientation pratique des cours de Beckmann 'jui " possède de nombreux modeles, des échantillons de malérianx bruls, de marchandises principales el de leurs modifications n(1). Mais Beckmann va plus loin : si les outils, les machines et, leurs produils ont leur place i l'école, e'est. réciproquement l'école toute entière qui se déplace dans les ateliers pour suivr: l'enchainement des opérations d'une fabrication donnée. "Les travaux "uxmêmes sont montrés chaque fois aussi dans les ateliers et les manufactures... pour qu'on puisse les voir dans leur succession propre. Dans celte intention, il (Beckmann) parcourt aussi chaque été, avec les auditeurs qui veulent bien le faire, quelques salines, verreries, fä̈enceries, elc. voisines...; aussi fail-il parfois avec quelques auditeurs qui le souhaitent particulièrement un voyage. technologique dans le Harz et dans d'autres endroits voisins, ètant donné qute la région autour de Götlingen est vraiment très riche en objets trchnologigures divers " (2).

C'est donc à la manière d'un naluraliste décrivant minutieusemrnt ses objets - allant les chercher au besoin dans leur milicu propre - el élablissant. leur classification que Beckmann pratique l'enseignement de la technologie, mais - trait essentiel - cet enseignement intègre les arts ot méliers dans l'univers économique : la technologie n'est pas d'abord un prolongement de la mécanique ou de la chimie, elle est une discipline camérale, économį̣ur. Aussi, son intention n'est pas d'iństruire des artisans, mais, en premier lieu, d'informer les officiers des chambres princières, les administrateurs et les fonctionnaires sur le travail artisanal. En ce sens, la technologie beckmanienne esL bien plus près de l'Encyclopédie que des Descriplions de l'Acardemir. Les cours de Beckmann sont destinés d'abord aux futurs caméralistes el c'rst i eux que pense Beckmann en première ligne lorsqu'il rédige son Anleitun! (3); mais il s'adresse également aux agriculteurs cl aux négociants et son public: se recrute effectivement parmi des "fils de riches commerçants et artisans qui ont déjà complètement appris le métier paternel n (4) et qui désirent ininsi

(1) Versuch einer akademischen Gelehrlengeschichle, II (1788), p. 337.

(2) Ibid. - A propos des richesses du Ilarz et de leur valeur dexpérience. on ne peut manquer de rappeler les réflexion que Leibniz adressail au duc Jean Frédéric : e V.A.S. a dans son pays un trésor presque inćpuisable... De plus, c'est une source d'une infinilé d'expériences et belles curiosités, et c'est le fondement sur lequel V.A.S. peut batir un jour ce beau dessein qu'elle a formé d'une Asscmblée pour l'avancement des sciences, qui par ce moyen pourra être rendue perpétuelle, el passer jusqu'à la postérité... [le Harz] enferme dans son sein de grandes ricliesses el il s'agit seulement de les en tirer, mieux qu'on n'a fait... je ne parleray ici presentement que des machines, mais surtout de celles qui servent i élever les eaux... on n'entassera pas lant de pompes sur pompes, qui content beaucoup i faire el ì entretenir. * (Sämll. Schriflen v. Brie/e, I. Reihe, 2, no 73, p. 83.

(3) - La comnassance des métiers, des labriques et des manufactures est indispeusalile i quiconque veut se consacrer it la police $\mathrm{cl}$ awx sciences camérales. Car ou dev ra au moins connaltre ce qu'on doit arranger, établir, ordomner, apprécier, diriger, entretenir, améliorer w uti]iser. Les questions : quels méliers font defaut à notre patrie, lesłuels de ceux qui un!. manfuent pourraient etre introduits avec prosil, d'où taut.jl apporler les materiaux, d'oi amène-t-on les arlisans, à quel endroit consiendrait-il de les installer, quest-ce qui del:unrise les métiers que nous avons, comment peut-on les aider, dans quelle mesure chacun participe nu bien commun, comment peut-on calculer leur revenu? - ce n'est qu'après avoir acipis celte connaissance que les caméralistes pourront répondre a de telles queslions, ainsi quì beaucoup d'autres également importantes. "Anleilung zur Technologie, préface.

(4) Pütren, Versuch..., II, p. 340. 
complèler leur instruction. Compléter, non remplacer : le technologue, au sens de Beckmann, n'est pas un artisan et la connaissance des métiers ne signifie pas leur pratique. "Elle [la technologic] ne doil pas former des tisserands, des brasseurs, ni aucun artisan en général ; pour l'exercice de leur art, ceux-ci ont besoin de beaucoup de savoir faire et de nombreux tours de main qui tous doivent être acquis séparément par un excrcice pénible, mais qui sont inutiles á ceux auxquels je m'adresse "(1). La fonction de technologue est une fonction de stralégie globale : "Le général doil connail.re le métier des artilleurs, mais ce n'est pas une honte pour lui si les artilleurs savent pointer le canon avec plus de précision et plus rapidement $》(2)$.

L'Anleilung zur Technologie de 1777, qui résume cet enseignement, est le premier manuel de la nouvelle discipline. Il est important, d'abord et surtout, par son titre, par le concept qu'il introduit et définit. L'activilé artisanale y devient objet d'une science : la La technologic est la science qui enseigne le traitement des produits naturels ou la connaissance des métiers. Au licu qu'on montre sculement dans les ateliers comment on doit suivre les instructions et les habiludes du maître pour fabriquer la marchandise, la technologie donne une instruction approfondie et selon un ordre systémalique, permettant de trouver, à partir de principes véritables et d'expériences sùres, les moyens d'alteindre ce but final, et d'expliquer et tirer parti des phénomènes qui apparaissent pendant le traitement " (3). Le discours beckmanien se propose donc de traduire la consécution des actes transmissibles uniquement par observation directe et imitation des gestes/en un enchainement de propositions ne relevant que de "principes " et d'expériences sur lesquels repose le procédé en question. L'activilé technique de l'homme est traitée d'après le modèle déductif d'une science exacte.

Beckmann a une conscience très nette de la nouveauté de son procédé et la dénomination "technologie "souligne la coupure séparant une discipline scientifique des présentations encyclopédiques antéricures qui tendaient à embrasser la totalité des cas particuliers, mais ignoraient les similitudes dans les opérations et leurs principes. "Je me suis risqué, dit-il au même $\$ 12$ de l'Anlélun!l, à utiliser le terme de lechnologie au licu de celui d'histoire des arls (Kunstgeschichte) en usage depuis un certain temps et qui est au moins aussi incorrect que le terme d'histoire naturelle pour désigner les sciences naturelles. G'est le récit des inventions, de leur progrès et de la fortune d'un art ou d'un métier qui peut être appelé hisloire de l'art ; la technologic qui explique complètement, méthodiquement et distinctement tous les travaux avec leurs conséquences et leurs raisons est bien davantage. Assurément, les mots suivants : $\tau \varepsilon \chi$ vo $\lambda \circ \gamma i \alpha$,

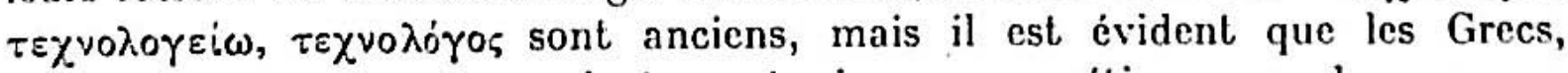
en les prononçant, ne pensaient pas toujours aux métiers, pas plus que par

(1) Beckmann, Anleilung..., préface.

(2) Ibid.

(3) Ibid., Introduction, § 12 . 


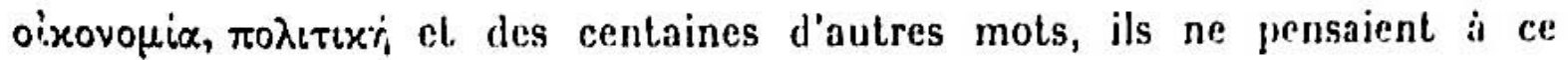
que nous enlendons par ces lermes. "

Que doil contenir une telle technologie ? Une description et une classification naturelle des métiers suivant "l'égalité ou la similitude dans le procédé lui-même et dans les raisons (Gründe), sur lesquelles il repose n (1). Mais ce: manuel des arts el méticrs est pris dans un contexte caméral, économiquue : l'Introduction délinil les concepts d'art, de métier, de malériaux (maleria lechnologica), mais développe en mème temps des considérations sur les guildes et li's corporations, sur le choix de l'emplacement d'une labrique ou manufacture, sur les éléments qui entrent dans le prix de la marchandise. L'ordre des métiers présentés ne suil pas l'ordre " naturel " exposé préalablement; crrlains meltiers (serrurier, par exemple) sont absents et malgré le trailement détaillé, complit, reposant sur une connaissance intime el directe, de certains d'entre rux, la partir: yraiment neuve et importante du livre consiste dans la préface et dans l'introduction.

Le projel beckmanien est suffisamment ferme et étendu pour que, cent ans après, un Karmarsch puisse écrire l'histoire de la technologie dans ce suns ; mais quand il met à exécution son propre projet, le professeur de Gültingen m. fail que reprendre et condenser des exposés antéricurs, au point que maintes présentations prébeckmaniennes de disposilifs d'industrie attestent souvent plus de maturité dans le traitement scientifique de la création technirjur. Beckmann exhibe bien la nécessitè d'une régulation des principes d'application, sans offrir, en contrepartic, de réalisation qui réponde aux exigenees de se's principes. Dans ce premier manuel gît déjà l'ambiguïté qui affecte insidieusement le concept de technologie. Elle naît de l'écart entre la décision claire d'un traitement discursif et déductif des opérations techniques, el le mode lout empirique de description isoléc des métiers sans référence aux principes unificatiurs annoncés. Ce que l'ouvrage de Beckmann ne contient pas est, en définitive, aussi déterminant que ce qu'il renferme pour la destinée de la technologie. Les réfirences de Beckmann, relatives bux métiers dans les ateliers of les fabriques. donnaient place à des descriptions délaillées de mécanismes et de machines ; il n'y a aucune trace de cela dans l'Anleilung où Beckmann privilégie les arts chimiques, il consacre loute son attention au traitement et it la transformalion (Verarbeilung) des matériaux. La technologie beckmanienne ignore le détail des mécanismes et ne regarde guère le machinisme industriel. A l'époque où se' prépare - au loin, il est vrai - la révolution industrielle du xıxe siècle, la nouvelle discipline qui se donne explicitement pour domaine la fabrication manufacturière et qui crée un concept susceptible d'embrasser les opérations treluniques et les postulats économiques impliqués dans l'industrie, se réalise dans la description d'un monde corporatif des métiers et des modes de production condamné à brève échéance. Dans un concept prospectif la technologie beckma nienne enveloppe une archéologie.

(I) Ibid., Introduction, \$ 13 . 
L'orientation de la technologie et sa délermination conceptuelle se ressenliront de ce champ d'exemples, de cette limitation. Le concept évoluera dans deux directions : au sens qui la raltache aux descriptions beckmaniennes, la l.elinologie deviendra une discipline particulière des techniques, discipline de porlée: assez limilée : connaissance des marchandises el de leur fabrication. D'aullere part, dans tes pays anglo-saxons, le mol se fixera dans le sens de la définition théorique ‘u'en donne Beckmann et linira par désigneril'ensemble de Pactivilé technique fondée sur l'application des sciences aux procédés de l'inInsilitie.

L'essor de la technologie heckmanienne, sa diffusion rapide, attestent "'pentant la recomnaissance de l'aclivité technique comme composante essenlielle de l'ordre social. Col essor vient satisfaire au besoin d'introrluire, a lous les niveaux d'instruction un enseignement sur les modes de production dont la transformation pèsera bientôt, sur la société 'ntière. Dans la décennie qui suil. la publication do l'Anleilung, le nouveau terme et concepl est universellement répandu en pays germaniques; dans les universités, les écoles supérieures et. les icoles militaires, on fonde des chaires de technologic.

Celle-ci fait. d'abord partie de l'enseignement caméral. II. Jung-Stilling la professe à l'Ecole supéricure camérale de Kaiserslautern à partir de 1778 ; 13.F.J. Hermann, un disciple de Beckmann, en donne des cours en 1781 à Vienne, oii il public la même année ses réflexions Sur l'introduction à l'élude de la terhnoleggie. L'annéc suivante, il part pour la Russie, oi il contribuera à la naturalisation de extle discipline par ses descriptions technologiques des provinces russes il. par sa participation aux travaux de l'Académic de St-Pétersbourg. J.(i. Cunrarli l'enseigne au couvent de Berg près de Magdebourg. $\Lambda$ l'Université de Halle, centre important des sciences camérales, son enseirnement est confić i) (i.F. von Lamprecht et a Fr. Meinert. On l'enseigne, entre autres a Leipzig, à Innshruck, à l'Académic Caroline de Stultgart oi l'apprendra le jeune Cuvier (1) i) Tühingren, et, bien entendu, à Berlin oì s'illustrera plus tard Hermbstädt. lin France, Haffner, professeur de Lhéologie à l'université de Strasbourg, inlègre dans son programme d'études superieures une traduclion libre de la préface de l'Anleilung de Beckmann (2).

L'aclivilé universitaire est doublée d'une importante activité d'édition. Pour lous les degrés de l'enseignement, les manuels et les traités de lechnologie, imilint. (’. complétant l'ouvrage classique de Beckmann, se multiplient. un peu partoul, ; cependant que la technologie commence à se diversilier en branches spéciales, apparaissent, dans tous les pays d'Europe, les grandes encyclopédies .l. les dictionnaires dressant un tableau du savoir technique, destinés non plus i) l'honnête homme, mais au spécialiste. La lechnologie, d'abord science pour

(1) Dans une lettre de Caen (22 juiu 1789), il prie son correspondant l'faff de " faire [s+: compliments les plıs empresses it lous ceux qui se souviemuent de [lui], el en particulier à Cins, Selımid, Wrisser el. Drâch ". Weisser fut son prolesscur de technologie à l'Académio Caroline de Slut.lgarl on 1788 . I,elles a P/a//, p. 94. Vide in/ra, p. 19.

(2) IlAFjesen, De l'educalion liltéraire on essai sur l'organisalion a'un établissemenl pour le's hailes sludes, Strasbourg, Jaris, 1792, p. 230-232. 
administrateurs, se met au service de l'industriel, de l'ingénieur, du chimisl ‘, dı constructeur de machines (1).

Le concept lui-même cependant ne subit aucune morlification. I a discipline s'approprie progressivement les domaines les plus divers de la fabrioalion et dans la litléralure technologique la production industrielle remplace la descriplion des aris el métiers.

Vers la lín de: sa carrière, en 1806/ Beckmann revient encore une fuis sur la scène avec un opuscule qui, s'il ne bouleverse pas le concepl, du moins, ébranle les normes élablies par l'usage de la liltérature Lechnologique drejuis trente ans. On a vu que l'Anleilung, malgré la promesse d'un traitrment sicintifique, s'est contenté d'une simple descriplion empirique de plusieurs mitiers qui n'élaient reliés, ni enlre eux, ni aux principes des sciences. C'rest. l'Entururf der allgemeinen Technologie gui vient, au moins en principe, d'accomplir l..vceux de l'Anleilung en exhibant un fil conducteur qui prermet de regrouper lis opérations impliquées dans des métiers différenls : Beckmann abandonne l.. découpage descriptif qui doil suivre les étapes successives d'une fabricatiun donnée - et qui doil donc se borner à reproduire un elal de fail - en faseur w. la méthode comparalive. L'exposé du travail artisanal n'est plus lie a un mili.r particulier, mais à un procede général dont les variantes sont implipuces dins des métiers différents. "Celui qui s'est donné pour étude d'apprenire ì commaitre de nombreux arls et métiers el qui s'est exercé à en cmbrasser lieaucoup d'un seul regard, celui-lì ne peut pas ne pas observer qu'un tris grand nomlir. de méliers - quels que soient ses matériaux et les marchandises fahriquics soit, ont à exécuter des travaux divers dans la même intention, soit, satrent réaliser une même intention par des voies très différentes. "(2) Que faut-il rulın.dre par une intention? C'est le but propre commun a des procedés particuliers; ainsi, "le travail au rabot d'un menuisier, le polissage dis verres. lo massicotage accompli par le relienr, le calendrage des toiles a sont des activili:

(1) En 1781 parnit Technoloqisches Worterbuch de Jaconsox ; l'immense compendium

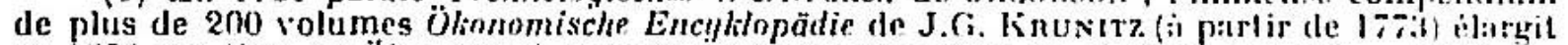
on 1784 son tilre en Ölonomisch-lechnologische Encyklopädie. Sa réplique latuçaise est l'Encyclopédie mélhortique de PANckoucke, mais le terme n'ipparaitra dans le litro d'une encycle. pédie françaiso gu'en 1835 avec le Dictionnaire lerhnologique ou Nonucau diclionnaire universtl des arls el méliers. En 18.45, Clı. LABoulaYe public une Encýrlopédie lrchnologique.

Contemporaines de ces owrages encyclopediques sont jes promières revies technologiques: Annales des nrts el manu/aclures, ou mimoires lechnologiques sur irs deronierles menternes

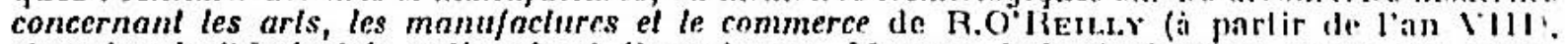
Annales de l'Industrie nolionale el elrangtre ou Mercure lechnologique (i) partir de $1 \leqslant: 0(1)$, Bullelin des Sciences lechnologiques, Tehhnolognilcheskii, Jnurnal de llenuAss jullie : Saint-Pétersbourg. Il faut y ajouter des collections comme la Physikalisch-öhonomische Bibliolhek de Becksann contenant des mémoires originnux el des comples rendus de live's et une multitude de publications analogues traitant les malières lechmologiques, mème si le mot ne tigure pas dans le tilre. En meme temps parnissent des bibliograplies de la teclinulogie comme celle de G.E. Rosentilat, Lileralur der Technologic, d.i. Verzeichniss der Bücher, Schriflen und Abhandlungen..., Berlin, Stetlin, 1795 ou celle de S.F. Ilrasnstr̈Dt, Bibliuthek der neuesten physischen, ehemischen, melallurgischen, lechnologischen l.ilerolur, 17ss. el les premiers exposés de son histoire : les Contribulions ì l'hisloire des deconverles de Brecksa.N. (1780-1805) et l'Histoire de la technologie de Poppr. - Toules ces publications achivenl et confirment la constitution de la discipline, sn prise de conscience alelle-même et son insertion dans l'univers de la culture.

(2) Enlwur/, p. I. 
procédant de la même intention, à savoir " surfacer les corps » (1). Une intention désigne done une classe d'opéralions; la technologie générale, au lieu de classer les méticrs va classifier les opérations, en comparant les différents procédés, les différentes réalisations d'une intention. Eille a pour but d'établir " une liste de toules les intentions différentes qu'ont les artisans dans leurs différents Iravaux, et en plus ane liste de tous les moyens par lesquels ils savent réaliser chacune de ces intentions " (2). Ce n'est qu'eusuite, une fois exposées les opéralions dans leur enchainement rationnel, yque viendra la technologie spéciale pour donner une description des métiers particuliers. L'Entwur/ doil logiquement précéder l'Anleilung.

C'est aussi l'oplique générale de la technologie qui change avec l'Entwar/. L'usage de la technologie ne consiste plus uniquement dans la transmission des schémas simplifiés des opérations d'un métier aux administrateurs et aux fonclionnaires de l'Etat, c'est-à-dire aux non arlisans. Cetle fois-ci, la technologie est susceptible d'intervenir en proposant un perfectionnement technique aux métiers eux-mèmes : le recensement et la comparaison des procédés qui réalisent, la même intention permetlent de transporler telle ou telle opération d'un métier ì un autre (3). On ne saurait assez insister sur ce concept de transport, qui rend possible de sortir des limiles d'un métier donné dans lesquelles élail enfermée la technologie classique, et d'établir des liens entre les métiers très différents.

Beckmann montre sur deux exemples comment il faul concevoir l'exéculion de son projet. Lin choisissant comme "intentions " exemplaires : 10 lia fragmentation, $2^{\circ}$ le polissage, planissage et le lissage, il énumère des procédés qui sont lous des espèces de ces intentions. Ainsi, en ce qui concerne le premier cas, Beckmann recense el commente loules les opérations de fragmentation, divisées en six groupes suivant les propriétés des corps : corps durs (exemple : casser, disséquer, briser, concasser etc.), corps mous (exemple : couper etc.), corps fibreux (exemple : romprc), mélaux (exemple: granuler), sels (exemple: dissoudre), eaux (exemple : faire la graduation).

Par l'Anleitung, Beckmann a fondé la technologie. Mais ce premier ouvrage de technologie ne visait que la reconstitution idéale de l'hisloire d'un produit par la description des étapes de sa fabrication, de la succession des opérations qui ne sont reliées qu'extrinsèquement, par le but, l'objet que se propose de construire l'artisan. L'Enlwur/ ne procède pas à partir de métiers existants,

(1) "Elle [la technologie] enseignerail de comlsien de manières et avec quelles variétés l'ouljls on polit, dépolit, diminue, humecte, séche, rectifie, cintre, durcil, raidit, condense, disperse, dilue, crible, chaulfe ou reiroidit, eclaircit ou onacifie, nssouplit et rend plus élastianes etc. les corps des espèces les plus diverses; ensuile, par quels moyens on clnrific, décoJore, vaporise, adoucit les liquides... I Ibid.

(2) Ibid.

(3) * De cetle manière, lorsque sera élaborée la lechnologie générale, et lorsque l'inclination technologique des savants continuera à crollre, nombre d'entre eux qui auront le temps el. l'uectision feront de surle que les maftres habiles essaieront de transporter des moyens el des outils divers [d'un métier à l'aulre] ". loid., p. 2. 
ni à partir de l'objet à fabriquer : le concepl primitif de la technologie est le concept d'opéralion permettant de découvrir le lien interne des métiers dans l'u intention n commune des opérations. L'opération n'est plus un simple maillon d'un métier particulier ; c'est plutòl le métier qui devrait être conçu comme lieu géomélrique particulier découpé dans le réseau des opérations. Le Projel de Beckmann rejoinl ainsi le projet de Bachelier qui se proposail de mellee en lumière "l'enchaînement qu'il convient de donner à la description de ces arts, remontanl à ceux qui sont, pour ainsi dire, les arts primitifs, dont les pratiques fondamentales se rencontrent dans plusieurs arts; pratiques qui sont seulement ou modifiées ou perfectionnées relativement à leur objet "(1).

L'Enlwur/ demeure, certes, ce qu'annonce son titre : essentiellement un projet. A de très rares exceptions près, la technologie en est, restéc au niveau de lat description. Comme le dil W.F. Exner, le biographe de Beckmann, "le dessein proposé dans ce Projet d'une lechnologie générale est resté un projel jusquj'aujourd'lui el, Landis que la technologie mécanique descriptive continuait à se développer pendant un siècle, tandis qu'elle ful divisée en technologic mécanique et en technologie chimique, tandis que la première bénéficiait, en particulier sous la direction de Karmarsch, de soins séricux el que la seconde a trouvé des représentants éminents dans Prechtl, Graham-Otto et dans d'autres, le projet beckmanien d'un traitement comparé, scientifique de la technologie est reslé en sommeil jusqu'à nos jours" (2).

Deux personnages les plus représenlatifs de la technologie allemande, Hermbstädt et Poppe, poursuivent dans la voie tracée par l'exemple beckmanien. Dans l'ouvre de Hermbstädt, apothicaire royal, professeur de chimie cl de technologie à l'Université de Berlin, cette dernière discipline atteint une forme classique. Cet auteur consacra de nombreuses monographies a la techuologie chimigue (blanchissage, teinturerie, fabrications du vinaigre, de la bière, etc.) et son grand traité Grundriss der Technologie est une sorle de remise a jour de l'Anleilung de Beckmann. Du point de vue du concept, il est ì noter que le lien de la technologie avec les disciplines économiques issues des sciences camérales est affirmé avec encore plus de vigueur que chez ses prédécesseurs et qu'elle est même identifiée à l'économie technique : "La technologie ou la

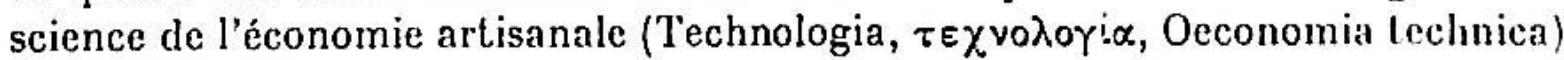
est celle branche de la science politique générale (Oeconomia politica) qui comprend la connaissance, empirique aussi bien que ralionnelle, des arts, des fabriques, des manufactures et des métiers" (3).

Ajoutons, enfin, qu'un lien entre les mathématiques, l'économie et la technologie s'établit dans l'œuvre, peu connuc, du comte Georges Bouquoy

(1) Rapport /ail à l'Académie des Sciences le 22 juillel 1772 par Messicurs Le Roi el Bailly sur un cours public des Arts el Mctiers, qui lui a elte présenté par Monsieur Bachelier, p. 22.

(2) W.F. ExNER, Johann Beckmann-Begrander der lechnologischen Wissenscha/t (Wien, 1878). Cr. aussi K. Kansansch, Geschichle der Technologie, p. 867-7.

(3) S.F. HenмвsтӓDt, Grundriss der Technologie (1814), § 1, p. 1. 
qui ajoute ì sa Theorie der Nalionalwirlschafl (Leipzig, 1815) trois compléments, dont le troisième porte le tilre Syslème de lechnologie du point de vue iconomique (1818).

Quand Reuleaux légiférant sur l'ordre machinal au cơur du xıxe siècle, tranche netlement entre une science des machines - réduite à un jeu de concepts operaloires - et une lechnique de leur usage fondée sur la physico-chimie des transformalions matériclles, il ne fail que consacrer un partage dont les signes apparaissent dans les projels pédagogiques de la Révolution française. Ceux-ci fonl, place aux arts, et la question se posera aux réformateurs de définir le champ de l'instruction proprement technique à tous les niveaux d'enseignement. C'est vraisemblablement à la prédication de l'Encyclopédie que l'on doit toul i la fois l'acecueil fail aux arts et les hésitalions, pour ne pas dire les polémiques, qui marquèrent celle greffe dans le nouvel ordre pédagogique. Après le relais des Descriplions académiques, l'Encyclopédie a transportè, en plein siècle des lumières, le projet baconien. Il suffil de se référer à l'article $A r l$ de Diderol, ou même il certains passfyes du Discours préliminaire de d'Alembert pour perecvoir le rebond, pris au vol, des molions de Bacon et leur naturalisation dans le discours encyclopédique. M. Simondon a certes raison quand il nous montre l'Encyclopédie déployant le spectacle des forces et des puissances; elle réalise un envoûtement : " G'est la société humaine avec ses forces et ses pouvoirs obscurs qui esl mise dans le cercle, devenu immense et capable de toul renfermer... Tout ce qui est figuré dans le livre encyclopédique est au pouvoir de l'individu qui possède un symbole figuré de toutes les activités humaines dans leurs dèlails les plus secrets. L'Encyclopédie réalise une universalité de l'iniliation..., tous les ressorts actifs, toutes les forces vivantes des opérations humaines sont rassemblèes dans cet objet symbole. Chaque individu capable de lire el de comprendre possede le voult du monde el de la société. Magiquement chacun est matitre de lout, parce qu'il possède le voull de toul "(1). Mais ne peut-on douler de l'existence de la coupure souvent notifiée au sujet du caractère "foncièrement majeur des planches de schémas et de modèles de machines qui sonl un hommage aux méliers el à la connaissance rationnelle des opérations techniques "?. Hommage assurément, dans ce défilé un peu désordonné qui participe encore de l'esprit des théatres de machine et annonce le climat des expositions du $x i x^{e}$ siècle. On y trouverait difficilement les signes d'invention radicale dans la présentation de l'univers des arts et métiers ; les planches de l'Encyclopédie démarquent, pour une bonne part, comme l'a montré $M$. Huard, celles qui furent préparées pour les Descriplions de l'Académie (2); el l'on pourrail trouver

(I) Iu mode d'exislence des objcls techniques, p. 94-95.

(2) G. Iluard, Les planches de l'Encyclopédie et celles de la Descriplion des Arts et Méliers de l'Académie des Sciences in L'Encyjclopédie et le progrès des sciences el des lechniques, Paris, 1952, pp. 35-46. 
par ailleurs des modèles de présentation dans Bélidor, et plus anciennement encore chez Lorini qui juxtapose les vues perspectives d'engins à de elairs schiemas de structure, y ajoutant même parfois des ligures de montage trés praticables. Enfin, ces planches, on le sait bien, n'étaient point destinées aux artisans dont elles reproduisent avec d'inégales minuties les outils et les altitudes (1). Ce qui, en revanche, demeure à l'actil de l'Encyclopédie, c'est d'avoir élevé la dignilé des métiers en assimilant la description des arts i l'histoire naturelle. Le regard des curieux plonge dans les ateliers an momrnt wi les peintres prennent leur theme de la vie des bons paysans.

Celle naturalisation des arts devail marquer en France les projets d'enseignement lechnique, lant élémentaire que supérieur, qui fleurirent dans les années de diffusion de l'Encyclopédie el des Descriptions de l'Academie. Ces deux publications suscilent dans leur sillage tonle une littérature lecimologique comme Ie dira Leclers en 1789 (2).

A un niveau élémentaire d'enseignement, on ne peut manquer d'èvoquar ici l'iniliative du peintre Bachelier, lié aux Lincyclopédistes, qui ouvrit en 1766; l'Ecole gratuile de dessin, dont un premier projet avait élé déjà proposé plus de vingl ans auparavant par Ferrand de Montholon. Le discours inaugural de Bachelier trace le programme d'unc éducation qui " au lieu de verser chacpue année dans la société un essaim d'hommes inutiles et dangereux, fourniront. aux ateliers des arts, des milliers d'ouvriers instruits lant en théorie qu'en pratique " (3). Un tel enseignement assurera, sclon Bachelier, "l'extension de l'industrie nationale "; on y professera gratis "les principes du dessin, de la géomćtrie pratique, de la mécanique, de la chimie, de l'hisloire naturelle... " (4). Curiensement, Bachelier proposera quelques années plus tard d'étendre cet enseignement dans un " cours public des arts et métiers " destiné aux " gens du monde, it qui il donnera les idées de la fabrique de toutes les choses dont ils font un usage habituel ", tout en étant également utile aux "savans et aux philosophes ". Le Lycée réalisera cette intention. Le programme de mécanique de cel élablisst:menl pour l'année 1786 nous est conservé ; c'est Condorcet luj-mème qui le

(1) S'il fallail rapporter d'aulres critiques bien fondées à l'encontre de l'Encyclupédie il sutfirait de mentionnel l'opinion de Roland quand il la met en paralliele av('e les / Descriptions, a suile de trailés complets dont chacun doit non seulement conduire lour rirer par la main, mais faire un ouvrier de chaque homme n, tandis que la collection de ljiderot est yualiliéc de a culosse sans proportion, compilation indigeste où les arls mécnuịues sont traités avec une inexpérience dont aucun ouvrnge ne donne l'idee $:$. (Manufaclures, arls cl méliers, 1'aris, 1785, t. I, pp. iii el xxiv). Opinion a compléter par le jugement de IBiol : a immense iravail, rédigé ì la liale par une foule d'écrivains différens... On peut même lui reproclice beaucoup d'imperfections dans les détajls; mais il n'en a pas moins rempli son véritable bul, yui èlail de metlre sous les yeux des gens du monde, une table des matieres où ils missent apprendre l'existence d'une foule de connaissnnces positives qui leur étaient entièrement inconnes ",

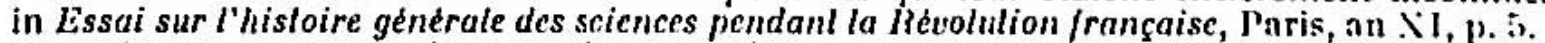

(2) a Ce n'esl que dans ces derniera siècles que les arts se sont vus liors des laboruloires de l'ouvrier, faire l'occupation de la plume et des discours polis... ils ont produil une si grande quantilé de livres que la lechnologie esl devenue un genre de lilléralure lrès considérable. Abrégé des éludes de l'homme fail, en faveur de l'homme a former... par M. L.FCi.enc, Paris, 1789 , p. 296.

(3) Discours sur l'ulililé des Ecoles élémenlaires en /aveur des aris mécaniques, prononcé le 10 septembre 1766, Paris, 1792, p. 16.

(1) Ibid., p. I5. 
présente : "nous expliquerons la théorie des machines simples, la manière dont on peut par la disposition des différentes pièces, produire un effet donné, si l'on connoîl la quantité et la direction de la force à employer; et la méthode de calculer l'effet des différentes machines, d'abord d'une manière abstraite, ensuite en ayant égard aux frottemens et aux forces perdues. Nous donnerons... la méthode d'évaluer les différentes forces motrices employées dans les machines, telles que la force de l'homme et des animaux, le poids ou le choc d'un corps solide, la pression de l'eau, l'action du vent, celle de la vapeur. Nous enseignerons le moyen de composer ces forces motrices, et de connoitre celle qui doit être prélérée, suivant le but que l'on se propose, ou les circonstances locales...n (1).

Ce texte n'est pas sans intérêl, car il préfigure un enseignement qui sera délivé a partir de 1793, par J.H. Hassenfralz, au Lycée des Arts sous le nom de lechnologie, et donl on trouve un programme succinct dans les annuaires de l'an III el de l'an VII. Ce qui caractérise le programme de 1799, c'est l'intention d'adjoindre a une description, sans doute classique, des a arts de produclions des malières premières", un cours sur "la sćrie des arts à l'aide desquels, on consLruit. les oulils et les instruments employés dans les arts et métiers. Dans cette série, l'art, de construire les machines occupe le premier rang ". Et ce qui relève l'inlérêt de cette initiative, c'est l'importalion de la notion de rendemenl dans la conception des machines : " Il y a un grand nombre de lraités de mécanique, et les lommes les plus célèbres se sont occupé des mélhodes, pour calculer le résultal des machines construiles; mais aucun n'a donné les élémens communs à ces machines, et n'a fait connoitre les moyens de produire un effel demandé avec une force donnée. C'est cette partic nouvelle de la science que le ciloyen Hassenfratz se propose de développer, ainsi qu'il le fait en ce moment, avec le plus grand succès à l'Ecole Polytechnique " (2).

(1) Discours sur les sciences malhématiques, prononces au Lycée le 15 février 1780, par II. de Condoncet, Paris, 1812, p. 29.

(2) La première annonce que nous avons repérée du cours de technologie d'llassenfratz. figure dans la première livraison du Journal du Lyede des arts datée du 15 avril 1793. On trouve un programme très succinet dè son enseignement dans l'Annuaire du Lupée des arts pour l'an HII: " T'echnologie (18) - Description générale des Arts et Métiers - Examen des élémens des machines et de leur application aux machines construites - Connoissance des détails et des procédés des manufactures. Par le citoyen Hassenfratz de la Société d'histoire naturelle, de celle du Point central el du Burenu de consultation des $\Lambda r l s$ •(p. 56). Un imprimé raturê de lit Bibliothèque nntionale suggère une introduction antérieure du terme par Hassenfralz. II s'agit de la Nouvelle Constilution des sciences, arls el méliers, avec te projet de décrel présenté d I'Assemblée nationale, el rédligé par la Société du Point Central des arts el métiers. Ce texte daté de mars 1792, alteste l'aclivile fébrile des a techniciens "et des inventeurs insurgés contre la sonveraineté de l'Académie des sciences. Il invoque ǹ maintes reprises le primal des arts utiles et répond en fait à l'espérance, candicle ou intéressée, qu'une masse de médiocres caresse de se faire entendre. La section $V$ du texle traite * De la classificalion générale des sivvans et des artistes :; le systéme aclopté est simplement celui de l'ordre alphabétique, car le iégislnteur ne doit * reconnoflre aucune espèce de prééminence entre des hommes qu'il ne peut considérer que sous le point de vue de leurs rapports avec l'utilité publique . la première classe esl celle de I' $\Lambda$ griculture, la seconde celle des Arls méchaniques el méliers. Celle dénominittion a été bilfée à I'encre et remplacée par Technologie, cours théorique el pralique des arls et méliers. En marge, mention du Con Irassenfratz. L'énumération suivante n'a pas été barrée : "Celte etude comprendra la description de tous les outils ou machines qui concernent les fabrications de toute espèce ; les moyens de perfection; les inventions; les préparations de 
Ce fut, à notre connaissance, le premier cours prolessé en France sous crlle dénomination qui ne devait pas jouir d'une bien longue forlune (1). Le lerme n'apparaît aucunement dans le tableau de l'enseignement polytechnique ; Hassenfratz y figure pour l'exploitation des mines el la physique grénérale. Pourtant, il ne fail pas de doute qu'il dut tenter de développer ses conceptions technologiques. Il les affirme d'abord dans le discours qu'il prononce le: 7 pluviòse de l'an VII : "L'examen, la détermination et l'étude des lois génírales de la nature doivent avoir pour objet spécial le perfectionnement de l'instruction, des travaux et de l'industric humaine. En conséquence, on aura soin en présentant chaque loi de présenter l'application qu'elle doil avoir dans les services auxquels les élèves de l'école sont destinés, ainsi que dans les arls el métiers " (2). Et co choix décidé pour l'application, il le propose alors, non plus trallement


Puis, ndjonction de la meme main : " La description des travaux des manufactures ou (ill dans ses ntellers".

Le Programme du Lijcée républicain pourl'an VI ne mentionne yu'un - Cours drs arle $" 1$ métiers, par le Citoyen lassenfralz $\times(p$. I2). Le programme pour l'an VII rintroduil le lerme de lechnologie avec un commentaire plus étorfe (p. 7).

L'arlicle Technologic du qualrieme lome de lis Physique de l'Enryrlopélir mélhorlique. Paris, 1823 , précise qu' un cours de lechnologie a élé fail par M. Ilassenfralz it l'Athénio de Poris. Ce cours a duré dix ans pour etre complété .

$1800-1801$

Le mol technologie apparafl sous la main de Cuvier, en l'an IX, daus le registre d'enlroe des Proces verbaux de I'Institul. Technologic est prononce par Fourcroy en lkn: il la tribune ifu Corps législatif, qui se réfere aux inilintives de 13 cekmann : a les arts mécaniques e.t rhiuipurs qu'on enseigne depuis si long-temps dans plusieurs universilés d'Allemagne, sous lo thrm de Technolngie aurout deux écoles speciales placées dins les villes les plus riches iu iulustriv. et en manufactures. Généralement désirées, ces écoles contribueront a la prospérilé naliousalu" par les métlodes nowvelles qu'elles feront connoitre, les instrumens et les procides firu conmus oll inconnus encore qu'elles répandroul, les bons modèles de machines yu'vlles munt rejusıl : en un mol par lous les moyens que la mécanique el ln climic fournissent aux arts. M Jisrours prononcé par A.P. Fourcroy, oraleur du gouvernement, sur le projel de lui relalif à l'instruclion publique, 30 germinal, an $X, p .16$. Le préfncier du Diclionnaire de l'induslrie, juhlic l'annfe précédente a Paris, réclamail que l'on atlachât a chacune des icoles centriles un démmis-


l'an XII el se maintiendra jusquen 1827 dans les rubrigues de la Nolice de l'almanach smise verre des associés.

La référence aux iniliatives pédagogiques allemandes se lrouve clıez l'rieur qui invaque l'exemple de l'enseignement de la chimie à l'école des mines de IBanská Š́tiasnica (Sclıcmnitz), Memoire sur l'ceole cenlrale des lravanx publics, messidor an III, p. 13.

Un autre emploi contemporain de technologie est à noler à propos de la nominalinn do vauruelin en l'an XII aux fouctions de professeur de chimie technolngic|ue an Jardiu des

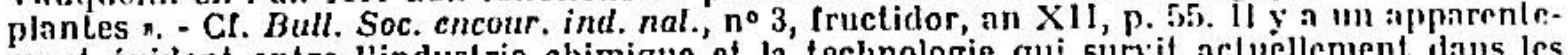
ment évident entre l'industrie chimique et la technologie qui survit netuellement daus les expressions comme "lechnologie des matières plastiques ", technalogie des hydrocarbures ?, ete. Cet emploi du lerme technologie qu'il imporle de distinguer des ealques ambigus de * lechnology ", renvoie ì des opérations et des spécifications définies.

(1) La clésuétude dans laquelle le lerme meme de technologie devait lomber daus lrs programmes scolaires est atlestee en 1845 dans la Revue génirale de l'archileclure cl des Irataus publics : - L'étude de la technologic officiellement reconnue aussi importante qjue colle du mantchoux : Notre collaboraleur M. Barral vient d'étre nommé professcur de leclunologie : - l'école municipale (François I er) ... Jusqu'à.ce jour, il n'y a qu'un seul professeur de techmulogie en France, tout juste autant que pour lo chinois ou le mantchoux... , 1. VI, col. $\because 67$.

Il serail téméraire de vouloir fonder l'histoire d'une nolion en démarquant pas à pas les vicissitudes d'un terme. La deslinée lexicographique de lechnologie est inseparable du nomadisme de la mode. En Angleterre également, on assiste a des avalars difficilement explica. bles du terme; ainsi, l'Universal technological dictionary de Cinsв , 1 re id. 1823,20 id. 1833 , sera réédilé en 1851 sous le titre de Technical Diclionary. Il faul, bien entendu, tenir compte, en cette occurrence, du vicillissement des néologismes.

(2) Journal de l'Ecole polylechnique, an VII, p. 239. 
comme la conséquence de l'exigence idéologique el constilutionnelle qui prétend que "Lous les Français sachenl un métier", mais dans le champ d'une concurrence économique internationale : "la force d'une nation environnée de nations commergantes dépendant... de l'industrie de ses habilans n (I). On est éclairé sur les inilialives pédagogiques d'Hassenfratz à l'Ecole polytechnique en 1799 par un discours oplimiste de Gayvernon prononcé également le 7 pluviôse : "La géométrie descriplive de la première année est terminéc par un cours d'élémens des machines... Personne n'était, encore parvenu à décomposer les machines failes el à faire, de manière à en déterminer les élémens ; c'est un cours absolument neuf que l'on doit à la réunion des lumières des hommes instruits qui composent. l'enseignement de l'école; ce travail a été fait par le Cen Hassenfrat\% qui est chargé de celle partic de l'enseignement. Ce cours ramenant la construclion des machines à la simplicité qui leur appartient procurera aux arts, aux manufactures ot à l'industric française les perfectionnemens qu'ils auraient inutilement attendus ailleurs "(2). Fourcy précise qu'effectivement 27 lecons d'élémens des machines furent délivrées en 1799 aux élèves de première annèe (3). Mais Hassenfratz n'a pu unir, dans un mème enseignement, physique a. composition des machines. Les notes de cours manuscrites conservées à la hibliothèque de l'Ecole, prises à ses leçons de physique ne répondent pas aux partis précédents. On sait seulement qu'il encouragea et conduisit des visites l'aleliers. Qunt au calcul de l'effet des machines, les mécaniciens de l'Ecole le revendiquaient, sans qu'ils eussent au demeurant acquis une grande sutreté mílhodologique. En 1811, Ic Conscil de perfectionnement soultaitail encore qure lo cours de mécanique " renfermâl un plus grand nombre d'applicalions du ralcul i l'e//el des machines, lout en ne dissimulant pas combien le choix des txemples demandail de travail el de recherches, pour être réduil à ce qu'il peut ofrrir de plus ulile, et ne contenir que des résultats dont la vérilé soil incontes-

(1) Ibirl., p. 241.

(2) Noid., pp. 253-54.

(3) Hisloire de l'Ecole polylechnique, Paris, 1828, p. 376. L'explication des machines sera encore :nnexéc au cours de géométrie descriptive dans le programme de 1807 . I1 y est prévu cntre autres, l'étude a des machines simples, du mouvement circulaire, du mouvement rectiligne, du mouvement de va et vient ; de la lorme des machines par lesquelles ces mouvements se combinent deux à deux; division de ces machines en dix séries... " (Conseil de perfeclionnemenl, 6 novembre 1807, fol. 21). L'explication des machines bénéficiera des classifiéltions systénntiques de I.anz el Bétancourt. a Les instituleurs de géométrie descriptive présentierent au Conseil d'instruction, pour tenir lieu du précis cles leçons sur les élrmens des machines, dont ils étaient aussi clanrgés, l'ouvrage encore mauuscrit de Lanz et Bétancourt intitulé Essai sur la Composilinn des Machinrs. Les auleurs on offraient la propriété à l'Ecole, :ulx condilions qu'elle pourvoirait aux frais d'impression el de gravure, el quil leur on serait remis deux cent cinquante exemplaires. L'oftre fut accepléc. (lFourcy, op, cit, p. 278). Charles Labonlaye dira de cel ouvrage, en 1848: " ce travail est un important pas de fait, mais il est inoui que depuis quaranle ans on se soil le plus souvent contenté de le copier, sans jamais tenier de l'amóliorer. II est pourtant bien insuffisanl et offre de très grands dérauts... horner li composition des machines à la transformation des mouvements... con rondre le moteur physique qui imprime le mouvement avec la machine... enfin, le travail de MM. Lantz et Bétancourl, conçin sans vues scientifiques, n'offre rien de salisfaisnnt à l'esprit, ne peut servir de base a aucun enseignement rationnel " (Association polylechnique, Cours de cinematique, Síance d'ouverture, 7 janvier $1848, \mathrm{pp}$. 18-19). Labouln ye cherche manifestement à justifier sa propre entreprise qu'il inspire des conceptions exprimées en 1830 par AMPÉte dans son Essai sur la philosophie des sciences : la cinematique *doit renfermer tout ce qu'il y a à dire des différentes sortes de mouvement, indépendamment des forces qui peuvent les produire. 
table n (1). Il est vrai qu'il faudra l'invention du Irein de Prony pour disposir d'une technique sûre de détermination de l'u effet dynamique des machines de rolation ", ou de la "quantilé d'action fournie par un moleur ", selon que l'on adopte la lerminologie de Prony (2) ou celle de Fourneyron (3). 11 semble bien, en définilive, que Hassen[ralz, d'ailleurs sollicité par d'innombrables lâchess. n'a pu réaliser et imposer l'autonomic d'un enseignement de la technologie i l'Ecole polytechnique. Le projet d'une science unitaire de l'aclivité machinofacturière ètail peut-être cohérent dans ses visées, il ne pouvail. l'êttre dans s’s moyens ; aussi Hassenfratz dut-il se résigner à la dispersion de son programme entre plusieurs enseignements dont ehacun mettait en aruvre un oulillage: conceptuel distinct el provisoirement insulfisant. II faudra allendre Poncelet pour que soil fondée une théorie scientifiquement achevée du " mrilleur étah)lissement des machines $n$ (4), il laudra que se constitue la cinémalique des opérateurs, selon les vues d'Ampère, pour que la construction des machines it de l'ordre machinal s'affranchisse du poids de l'empirie.

La convulsion révolutionnaire n'en excite pas moins une nouvelle réticulation des activités industrielles et réclame des talents scientifigues leur application aux problèmes économiques. "Les Arls méchaniques ot chimiques lies aux sciences par la pratique et la théorie... sont peut-ètre de loules liss orcujations humaines, celles dont la Révolution française a le plus favorisí le sueces. ()n sail assez l'activité qu'ont prise depuis trois ans les manufactures de lous les genres y, s'écrie Fourcroy devant le Lycée des Arts en alvril 1793 (5). Cippendant, cel accroissement de l'activité industrielle serait, sans lendemain, si cllt: n'élail sontenue par une nouvelle organisation pédagogique ; "l'èlucát ion nal ionale a besoin de s'appuyet sur des bases entièrement nouvelles ", allirme Lindel (6) ; et ces bases, les réformateurs cherchent à les définir avec passion. car il ne s'agit de rien moins que de régénérer l'humanité dans le rayonnement. de Paris, source de la révolution, mais aussi " asyle de toutes les connoissances

(1) Founcy, op. cil., p. 304.

(2) Nole sur un moyen de mesurer l'cf/el dynamique des machines de rolation par .I. de Prony, s.d., - ... donner la mesure de l'effet dynamique... d'un systeme toumant, par le poids et la position d'une masse qu'on maintient dans un état d'immobilite ?.

(3) Founneynos, dans son Mémoirc sur l'emploi da /rein de $M$. de l'ron!l, note l'intérèt que la méthode introduira dans les contestations entre fabricants de machines a vapeur nu

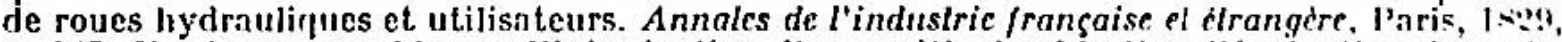
p. 145. Il est remarquable que l'introduction d'une méthode objective d'évaluation des puissances motriecs a coincidé avec la fondation de l'Ecole centrale des arts et mauufactures, lo développement des chemins de fer, el la tloraison de toule une littérature l'informaliuil technologique (vide in/ra, pp. 65-6li).

(4) Le problème est posé dans le Cours de mécanique appliquéc ant machincs (èd. lillm. 1830), éd. 1874, p. 50: :Condilions du meilleur elablissemenl des machines, rendre all maximum leffel utile ou la yuantilé d'ouvrages confectionnée, et au minimum la dépense en lravial moteur el en argent ; de sorle que l'unité d'ouvrage de chaque espèce soit fournie au moindre prix possible :

5) Discours sur l'élal actucl des Sciences el des Arts dans la République Française prononcr à l'ouverture du Lycée des Arts le dimanche 7 avril 1793, l'an second de la République, par A.F. Founcroy, in Journal des inventions el decouverles, vendémiaire, an 11 , $\mathrm{n}$. 6is.

(6) Instruction sizr la manière d'inventorier el de conserver dans loule liciendue de in Republique, lous les objets qui petuvent servir aux arls, aux sciences el d l'enseignement, proposéc par la Commission temporaire des arts et adoptée par le Comilé d'Instruction publique de la Convention nationale, Paris, an II, p. 2. 
humaines el le dépòt de tous les trésors de l'esprit... c'est à Paris qu'il faut rassembler tous les monumens des sciences et des arts... dont l'étude seule peut former le dernier degré de l'instruction publiqque : c'est là qu'il faut organiser pour les siècles et pour l'univers l'école suprème de l'homme $n$ (1). Tout aussi urgente, l'organisalion des premiers degrés demande les soins du législateur. Contre ceux qui rêvent d'une éducation sentimentale nourrie du symbolisme des fêtes (2), Hassenfratz réclame une sévère éducation professionnelle : "On néglige dans l'instruction publique la partie la plus essentielle, celle du développement de l'industrie nationale, l'éducation des arts el métiers, et l'on remplace celte éducation par des rêtes " (3). Les projets d'institution d'un enseignement public des arts et méliers furent effectivement étudiés. Lavoisier et Monge ne dédaignèrenl pas de s'en occuper. Les Réflexions adressées à la Convention par le Burcau de consullalion des arls el méliers préconisent l'organisalion de trois enscignements fondamenlaux pour ceux qui se destinent à la pralique des arts, savoir "dessin, géomélrie graplique ou descriptive, chimie applicable aux arts" (4). Ainsi, se décide une répartition qui s'imposera durablemenl dans la plupart des écoles lechniques. Le rapport prévoil certes la diffieullé de traiter des " arls que l'on peut considérer comme mixtes et emploient, is la fois des instrumens mécaniques el des agens chimiques n, mais co qui importe avant tout, c'est que l'enscignement, soit réduit à un système analytique. Les rapporteurs insistent sur ce que toute machine est " susceptible d'èlre diccomposće, d'être réduite en élémens simples n et dislinguent dans leur "xamen le calcul de la force, objet de la mécanique théorique, de "la direction de l'agence et le moyen dont la force est appliquée ". Ce qui est proprement l'ohjel, de la "mécanique pratique, science qui n'existe point. encore ou du moins

(1) Qurlques idtes sur les arls, sur la néressilé de les encourager, el sur divers Elablissemens nicessuires à l'enseignement public, Paris, l'an II, PP. I6.4-(j5.

(:) On connatl tes thèmes exposés au débul de juin 1793 par lakanal, rapporleur du Comile d'iustruction publique (Arehiurs parlemenlaires, Mavidal el Laurent, LXVIII, 507). 1.es jroposilions ne furent pas adoptèes phr le pouvoir législalif; mais on en trouve des échos diuns de nombreux libelles, par exemple dans be l'éducalion dans les grandes républiques, par J.G. LABENé, an III : "Voulez-vous que votre constitution soit. impérissable ?... Donnez vous des institutions civiles; créez une morale publique; étnblissez. des rites nationaux; organisez des fêtes républicaines; paitrissez sous vos mains l'opinion publique tandis qu'elle se prête encore ì toutes vos impressions », p. 239. Ce gout de la rête donl les témoignages sont innombrables atteste le dynamisme organisateur de la Révolution qui, par la suite, sera déviè dans la planification industrielle de la sociélé libérale également travaillée par de grands mythes.

(3) Réllexions sommaires sur l'éducalion publique par le républicain J.H. IIAssenfnatz, s.l.11.1I., p. 6. - Le même texte est reproduit dans le numéro dix du Journal du Lycde des arls, en date du 29 juin 1793. L'auteur so plaint amèrement que les Arts aien Plan d'Educalion soumis à la Convention par le comite renouvelé d'instruction publique ; pour lui les fâtes " belle idée métaphysique n ne peuvent etre prises en considération que chez un * petuple isolé , ; leur organisation détourne le pays de la compétition économique européenne : a prenons garde que pendanl que nous nous occupons ì organiser des fêtes, nos voisins n'organisenl leur industrie et ne détruisent nos manulactures et nolre commerce. Ce "I'est pas avec des rêtes que les Anglais sont parvenus à acquuérir une grande prépondérance dans la balance polilique de l'Europe . In planification économique et industrielle lui semble un hul en soi ; par lî, il se sêpare du jacobinisme rlı́torique el annonce le rationalisme lechnocratique : a La plus belle fête que l'on puisse donner à la République Française est d'organiser l'Edication des Arls el Métiers, de donner un grand essor à l'industric nationale, de l'activité ì nos fabriques, ì notre commerce... ", p. 16.

(4) Réflexions..., par le Bureau de consultalion des arts el méliers, Paris, s.d. [1793], p. 19. 
sur laquelle il n'a point été rédigé de trailé méthorlique el élémentaire ". Nuus retrouvons ici le point de vue de Condorcel sur la science des configuralions. Cependant, les rapporteurs prélendent faire régner la même clarté dans l'‘nnseignement de la chimie industrielle : "Le professeur fera voir que los operations chimiques relatives aux arts peuvent se classer, se décomposer comme las. machines... $n(1)$. Ce souci de réunir en une théorie analytique les nombrense's opérations des arts, on le voil encore apparaitre dans la Pélilion du Direcloire du Llycée des Arls signee de Lavoisier et Désaudray : "Tous les arts et millier-. malgré leur grande variété, se rapportent à un très petit nombre de principuss qui n'exigent peut-être pas beaucoup plus sl'intelligence et de travail que less objets destinés à être enseignès à l'école primaire. On pourroit donc facilemenl instituer des écoles primaires de ces différens principes applicables à lous los arts qui en dépendent "(2). Mais c'est sans doule dans les rares, mais fermes. lexles de Monge sur l'enseignement que nous pouvons le mieux ferceviir l'espérance mûrie d'une révolution pédagogique. Il avail certes un inctrumenl tout neuf de représentalion et d'investigation à offrir aux spécialistes de la mécanique pratique dont nous venons de voir que des trailés leur faisiaim défaut. Sa géomélric descriptive qu'il enseigne à l'Ecole normale ct. ì l'kérole. polytechniquue, il la présente comme "un moyen de chercher la véritć... propre à exercer les facultés intellectuelles d'un grand peuple et a contribuer par li au perfeclionnement de l'espèce humaine " (3). S'il professe une telle confianre dans les vertus de sa géométrie, e'est. qu'il entrevoit, qu'ells pourrail modifier radicalement les caractères de la production manufacturiere. Non seulemunt. elle doit faciliter considérablement la construction des machines " all moyen desquelles l'homme mettant, à coptribution les forces de la nature, ne se riserve. pour ainsi dire, dans ses opérations d'autre travail que celui de son intrlligence $"(4)$; mais encore, en introduisant dans les esprils des exigences d'exictilude, elle répandra le besoin de la normalisation des procédés el parlant l'uniformité des productions. "Il faut diriger l'éducation nationale vers la connaissanes des objets qui exigent de l'exactitude... accoutumer les mains de nos art istes au maniement des instrumens de tous les genres qui servent à porter la précision dans les travaux, et mesurer ses divers degrés " (5). Que l'élude de la géométrie fût inséparable d'un bénéfice moral, c'était là un thème rebatlu de lia pédagogie depuis un siècle, mais c'est un thème neuf que dévoloppe Monge. quand il prédit que désormais "les consommateurs devenus sensibles ì l'exactilude pourront l'exiger dans les divers ouvrages n (6). Proposition significative qui préfigure, en pleine crise de production, le langage de l'économic industrielle la plus prospère, el annonce de nouveaux rapports entre l'homme et. l'objet fabriqué ; celui-ci s'offre désormais comme la solulion répétéc avec la

(1) Ibid., p. 18.

(2) Pétition présentéc a la Convention nationale sur l'Instruction mublique par le Directoire du Lycée des Arls in Journal du Lejcde des Arls, no 11,15 juillet $17 ! 13$.

(3) G. Monge, Gémétrie descriplive, Paris, 1811, ip. vint-ix.

(4) Ibid., p. Ix.

(5) (6) Ibid., p. vit. 
meilleure approximation possible d'un problème qui comporte théoriquement une solulion idéale. Tel objel qui contient en lui les puissances du calcul, il ne restera plus qu'à le soumettre aux conditions formelles du fonclionalisme esthélique développées par Dupin en 1824 (1) pour entrer de plain-pied dans l'ère de la machinofacture moderne; la possibilité de notation de loules les opérations produclrices permet. dis lors de jeter sur un marché une population d'objets identiques, qui sera sans lendemain, du jour oì un des délerminants de la notalion aura changé, tandis que l'objel d'extraction arlisanale peut nailre identique en des lemps et des lieux éloignés qui ne se comnaissent pas.

Avec Monge, se constitue une théorie complète el universelle do la représentation des objets " susceptible d'une définition géomél.ique n. De cette impeccable description graphique des corps, il peut "déduire tout ce qui suit nécessairement de leurs formes et de leurs posilions respeclives $n$ (2), c'est-à-dire qu'il peul nolamment décrire les projections et les sections de tel corps donné, dans différents sites, mais encore déterminer la forme d'un modèle qui salisfasse is telles conditions préalablement formulèes. La théoric de Monge crée un langage universel de description ou de conceplion de modèles communicables, inlefligibles. Le prestige dont jouira ce système entrainera par un effel d'induclion le développement du dessin linéaire qui tendail d'ailleurs à s'imposer pour des molifs extratechnologiques. Le dessin que Degérando, définit la " philosophie des sens " (3) est considéré alors comme un langage, un système de signes. Il apparaitra avec évidence comme le médiateur nécessaire entre le projel lechnique et. l'objet, et devra donc être enseigné non seulement aux ingénieurs (4) mais "surtout aux gens du peuple dont les travaux consistent presque toujours à imiler des formes " (5). Celte imitation n'est industriellement salisfaisante que si elle se conforme à des normes d'exactitude rigoureuse et de précision qui ne peuvenl ètre exprimées que par le dessin linéaire, en attendant que

(1) C. Dupis, Aux manu/acturiers cl aux che/s d'alclicr, dedicace préceddanl le Discours d'outerlure d'un cours de mécanique appliquée aux arts, le 11 novembre $18 \% 4:$. ... faire acquérir aux produits de l'industrie les qualités qui les rendent désirables : $1^{\circ}$ La convenance rigoureuse fles formes, d'nprìs l'usnge que les produits sont destinés à remplir; 201 'ćlégance et la benuté de ces formes, résultat d'in choix heureux des justes proporlions que doit recevoir chaque parlie, pour concourir a la perfection de l'enseml,le; $3^{\circ}$ la précision du dessin, la continuité bien senlie des contours el des superlicies, l'exaclitude des joints, la solidité des assemblages, le beau poli des surfaces. 'Toutes ces qualilés des produits de l'industrie ne peuvent étre nhlenues que par des procédés empruntés anx règles, aux méthodes de la géomélrie . Anna. Iss de lindustric nalionale el élrangère, l. XVI, n 5!!, p. 196.

(2) Op. cil., p. viti.

(3) Des signes el de larl de penser considérés dans leurs rapporls mulucls... par J.M. de Gizando, t. II, l'nris, an VIII, p. 391.

(3) Nevel, instituteur de dessin à l'Ecole poly lechnique déclarail, le 7 pluviòse an VII, que, - c'est par le secours du dessin qu'onl été conservées cl transmises une multitude d'inventions utiles aux arts, aux manufactures, au commerce, i la guerre. L'ingénieur qui ne s'est point rendu familier ce moyen de fixer sa pensée, expiera par de longs regrets les suites de sa négligence ", op. cil, p. 250 .

(1) L'enseignemenl du dessin linéaire d'après une méthode applicable à lontcs les écoles primaires, par L.B. Francazun, 2" éd., Paris, 1827, Développemens préliminaires, p. 1 
les procéclés partiellement automaliques déchargent les ouvriors d'un lanm. part de leur pouvoir de jugemenl sur les objets fabriquees (1).

A la même époque, l's vertus d'une organisation (2) administ ralia. de. activités industrielles s'imposent clairement en France. Le's inlassaliles iniliallives du Comilé de Salut public qui réquisitionne les savants, riossissenl. ¿ metlere sur pied une efficace industrie de guerre. L'intervenl ion de l'lilat lian-

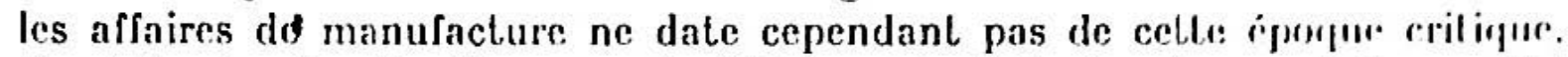
Il est à peine besoin d'invoquer le dirigisme de Colbert qui preserivil puanliti: de rìglements et de spécificalions, souvent ressentis comme des ent ras is icom-

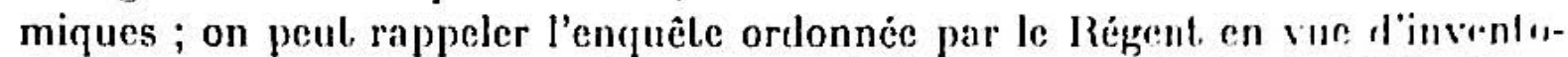
rier les ressources du pays qu'avaient affaibli les guerres de louis XIV; il y it encore lieu de noter les intentions politiques qui inspirèrent la rédlarlion du Diclionnaire de Commerce de Savary, ou les préoccupations de l'urgol. Le pouvoir de l'ancien régime avait établi en province des inspecteurs des manulin:tures et délégué des missions chargées d'enquèter à l'étranger sur les procédli-: de l'industrie (3). Certains de ces inspecteurs accomplirent de remarqualilies tàches de documentation; ainsi, Roland de la Platières, lo fulur minisl re 小. l'Intérieur, qui publiera l.rois volumes de l'Encyclopédie mèlhoulique, ronsacri's

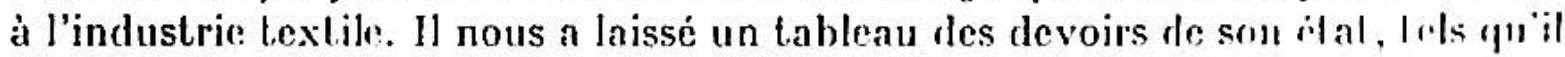
sc les représentail on 1777, alors qu'il n'étail, qu'élève-inspelent des manufarlures : "L'Inspecteur est l'homme du Conseil, envoyé dans les P'rovineses, punr

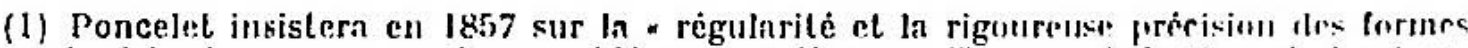
"ii'apporlent toujours asec eux les procédés aulomatiques ", Trumaux de let commission/ramgaise sur l'industrie des nalions, op. eil., t. 111, p. 50.


ment entreprise d'un grand peuple en un Etal, on s'est frèuuemment se'rvi du lrrm. urganisation... Dans un pareil ensemble, chaque membre doil être non seulement un mu.y.ri, maiaussi une fin ; el toul en contribuant ì la possibilité de l'ensemble, determinc is stui lour pir l'idée même de cet ensemble, dans sa siluntion et dans sa fonclion propre - (1 rad. (ilutis

Le thème biologique de l'organisation scra complété daus l'idéolugie jacohiule par l'argument anlagoniste de la désorganisation. Auguste Comte définira rn ls:?: le systim. social contemporain par une competition entre * deux mouvements... l'un de desorg:unisatiun.


1883 , p. 60 .

(3) Le métallurgiste fi. Jars consacre un long temps à visiter les plays miniers: :m intérèt s'est porté, entre autres, sur ln région de Banská Stiavnica, qui eot alors. a a ec Froiturest. le plus notable centre d'enseignement minier. Comme le dit. Jozer Vlachović, - il saisit bien l. fajt qu'une simple empirie ne suffit. plus au perfectionnement de la leclunolugie métallurgiøü. Ainsi, il indigyn indirectement, combien il est indispensnble fiorgnniser un ilalilisiemenl

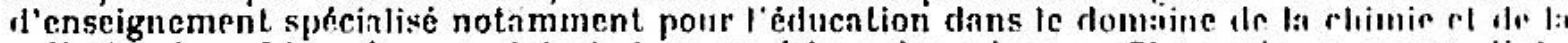
métallurgic ". L'enseignement lechnique supérieur des mines en Slot auluie an Xvile sierle.


- G'est Jacquin qui crén en $1663-64$ un premier laboraloire d'ensrignement de climie a l'irnle des mines de Banská Šliavnica, initintive qui anticipe dans le domaine de la prod:tgugie sur celle d'un Liebig à Giessen. En se référant il cet exemple, Fourcroy recummande l'iusii. lution, ì l'Ecole cenlrale des travaux publics, de * celte méthorle gui a le doubble aviulay"* de foire concourir tous les sens à la fois aux progrès de l'instruction et de fiver l'allowtion des élèves sur une foule de circonstances qui delınppent presque loujours dauns les leçons, oun nux professeurs, ou aux auditeurs * (Gazetle nalionalc ou le Monileur mninersel, $n^{\circ}$ \&, ocliili $s$, vendémiaire l'an 3). - Autre voyage d'étude ì signaler ici, celui de $1 l_{\text {Assen }}$ - Anstz qui rap. pelle dans sa Siderolechnic, Paris. 1812, que Ir gouvernement frautgis Ir charge: en I? conjointement avec Stoutz et Lefebure d'Ilellencourt, d'aller étudier l'art de: fabrifluer lo. fer el l'acier dans les usines de la Slyrie el de la Carintlie. 
examiner l'ćlat des arts et du commerce, jour observer les causes de la lenteur des progries de ces différentes parties; rechercher les moyens propres à leur donner de l'extension \& à les conduire à la perfection dont elles sont susceplibles. Il est question du bien public \& celte espérance doit leur élever l'àme... Il faul qu'un tel homme ait reçu une éducalion mâle \& vigoureuse, donl la vie frugale, laborieuse \& sans faste soil le fruil, que l'urbanité de ses meeurs l'annonce \& qu'un désintéressement absolu le caractérise. Son extérieur sera modeste ; son âme sensible et humaine. Echauffé de l'amour du bien, il n'aura que cet objel en vue, il s'y adonnera tout entier... " (1).

Qu'une description méthodique des ressourees d'un pays el des aptitudes te l'organisme social doive précéder tonte décision économique importante, e'est, lì une idéc conlagrieuse a la clarniere des deux siècles. Le travail se définit e progressivement comme une fonction sociale et Saint-Simon ecrira, en 1818, dans l'Induslric que la politique est la "science de la production ".

$A$ la faveur de l'unification des mesures qu'arait décrétée la Convention, et, de la centralisation corrélative des pouvoirs, des services de statistique seronl, mis en place. S'agissail-il de dénombrer des produclions définirs, la lichele n'offrait pas de difficulté insurmontable (2) ; clle élait moins facile quand il importail d'évaluer des forces de production mal délerminées, incomplètemenl développées ; leur recensement n'offe alors que des lableaux de configuralions opaques. On ne peut, du jour an lendemain, fonder une statistique des virturalités sans Ic secours, toujours contestable, de présupposés économétri‘ur's. Aussi, n'y a-t-il pas lieu de s'élonner qu'aient èté formés ì l'époque révolulionnaire des projels de décrire, dans leur entière varièté, l'ensemble des propriélés du pays considéré comme un immense organismr. Telle étail bien, scmble-t-il, l'intention de Siauve, quand il demandail en l'an V qu'on instituât une Socièle ambulante de lechnographes. Les membres auraient eu pour mission, de " parcourir les campagnes, peindre les siles, décrire les monumens, visiter les ateliers, pénétrer dans les entrailles de la terre, inlerroger la nature, analyser ses différentes productions, lui arracher en quelque sorte ses secrets les plus cachẻs " (3). Leurs investigations auraient eu pour lin de délerminer l'ampleur efficace des "secours du gouvernement aux manufacluriers el aux artistes n; ils eussent été les auxiliaires du progrès technique en aidant à " perfectionner

(1) J.eltre de $\mathrm{M} \cdots$ écrile de Naples, le 10 janvier 1777 , i $M \cdots$ Elive Inspecleur des Manufaclures en France, in Lellres écriles de Suisse, d'Halie, de Sicile et de Mallhe a Mul $\cdots$ à Paris, en 1776, 1777, 1778. Amsterdam, t. IV, 1780, pp. 322 et 3315.

(2) En théoric, du moins; car, l'élnblissement des slatistiques industrielles rencontre communément la dérinnce des manufacluriers; cf. C.A. Costaz, lessai sur ladministralion de l'agricullure, du commeree, des mamufaclures of des subsistances, J'aris, 1818, p. 103.

(3) L..M. Sinuve, Projel d'élablissement d'une socielé ambulante de icchnographrs, Paris, an V, p. 17. L'joće de Siauve apparaft déjà dans le programme du Journal des arts el manuJacturrs (publié sous la direction de la Commission Exécutive d'Agriculture et des Arts), P'aris, an III, * rassembler lous les matériaux qui pourront furmer ì la lungue une bunne géograplic industrielle de la France n, p. l5. Ilassenfratz avait déclaré devant le Comité d'Instruction publique, lors de sn $48^{\circ}$ sénnce le 12 mars 1792 , ì propos de l'enseignement de la géographle élémentaire, qu'il importait de a lamiliariser de boune lieure les jeunes gens avec les idées des relations industrielles que les Français peuvent avoir avec les diverses nations, Guillaume, proces verbaux, p. 140. 
les différentes méthodes " industrielles, et ils auraient amélioré enfin l'élat social, en se préoccupant au cours de leurs enquètes d'u amplifier l'inst ruclim. lui associer cette morale pratique qui est à la portée de lous les esprits ; affranchir tous les hommes du joug des préjugés... n (1), le tout grâce à la collaboration de "ciloyens doux et paisibles propres à développer (ces) principes et ì propager (les) découverles " (2).

La pensée de celle évangélisation technographique, on la relrouve plus mûrie dans un texte à peine postéricur de Chaptal, son Essai sur le perfectionnement des arls chimiques en France. Il s'y préoccupe de définir te "systime de conduite bien approfondi "que le gouvernemenl doil suive pour developper lia richesse industrielle de la France. Pour lui, la police des manufactures st réduil "A trois moyens également faciles. Le premier de lous consiste is former de-: fabricans éclairés. Le second se borne à rendre la fabricalion plus économiqur. Le troisième a pour but d'indiquer aux fabricans sur le sol de la Républiqure, lis.: emplacemens les plus convenables aux divers genres de fabrication "(3). Wills le détail, il pròne toules sorles de mesures qui répondent assez bien a un projert. de libéralisme économique contròlé. L'action du gouvernement ne sera jamais contraignante, elle vise à orienter l'utilisation des capitaux dont il faut enconrager l'investissement - en écartant le " mauvais système d'administration qui ne voyoil dans les fabriques qu'une source d'impôts el jamais la hase principale de la prospérité publique " (4). L'intérèt du pouvoir est encore de slimuler la fécondilé d'invention el développer les talents professionnels. "Le siul moyen qu'it le Gouvernement de s'acquilter envers les arlistes de lit dwll. sacrée de lour éducation; c'est de former pour enx des écoles d'instrution

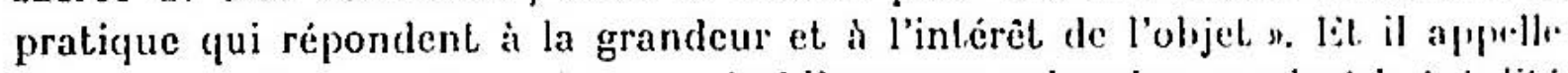
de ses voux la formation " de grans établissemens qui embrasseraicent la lotalit: des operations qui appartiennent aux fabriques a (5). Enfin, la diminution des frais de main-d'ceuvre fera la prospérité du fabricant qui developpera dans se:ateliers la mécanisation des Lâches el la division du travail : "l'ouvrier qui rest." toujours attaché à l'exéculion de la même partie contractera tellement l'liabitude du mème travail qu'il fait, micux et plus vile "(6). Les mèmes thèmes s" trouvent repris dans le volumineux essai De l'industrie frangeise oi il examin.

(1) Ibid., p. 17.

(2) Ibid., p. li3. SIAUve a également publié un Projel sur les Elablissemens publics constilués pour les sciences el les arts, s.d.. dans lequel il souhaile la création d'un Ninistire d... sciences et des arts (p. 3). Idée qui étail dans l'nir ; on lit dans le second numéra du Journal des Sciences, arls el mélicrs, en date du 29 janvier 1792 , que n Les sociétés rémies des lnsentinns, du Point central, de la Commune des arts et d'autres travaillant en commun a la rédaction d'un plan général d'organisation des $A$ rts et des Sciences pour lout le Royaume... *, pr. 13.

SiLvestre prônera en l'an VII que l'on adjoigne au College de Prance, une e unisersite. de degré supéricur soù l'on enscignerail "quelques parties négligées telles que le commerec, les arts et métiers, l'économic rurale... - in Mapporls généraux des travaux de la sucití philomalhique de Paris, IV, p. 8t. an Vill, p. 3.

(3) Essai sur le per/eclionnement des arls chimiques en Jrance, par J.A. Chaptal, Paris,

(6) Ibid., p. 50 . 
les moyens de relever l'économic nationale au lendemain de la Restauration. S'il rompt des lances en faveur de la mécanisation des opéralions industrielles (I), c'est. lout en rappelant les initiatives qu'il avait prises, du temps qu'il itail ministre, lelles que l'instilution d'une stalistique générale de la France (2), la protection accordée à la toule récente "Sociélé d'encouragement ", et l'organisalion d'exposilions périodiques des produits de l'industrie agricole et manufacturiere. Ainsi, se.l.rouve préfiguré, dans se's grandes lignes, ce que sera le $\mathrm{x}^{\mathrm{e}} \mathrm{x}^{\mathrm{s}}$ sicclı: mamufaclurier el son "élan industriel "dont. Saint-Simon est a la mime àvoque le prophète exalté (3).

La mème année que l'essai de Chaptal sur l'industrie française paraît un ouvrage qui, dans une élape déjà avancée de la révolıtion industrielle, donne une formulation des prohlèmes liés à l'aclivité lechnique de l'homme; le Plan de Irrhnomomic (4) du premier directeur du Conservatoire national des arts et militers, (ierard-Joseph Christian. Quoique parfaitement. inconnu, (il n'est citie par aucune bibliographie, mentionné par aucune histoire de la teclonologie) le

(1) . I.'industrie manufachuriere... a operi: un changement tolal de nos monurs, nos lois,



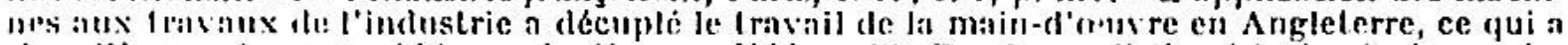
singuliitreuneul augmenté ln prorluction... * Ibidl, p. 89. Peu it peu, l'u écart technolngique * des pajs contineulaux avec l'Angleterre ee réduira dans le premier tiers du siècle. La puissance imbustriefle de l'Angleterre dépendra alurs au premicr ché fe ses ressources en capital. Vers 1.:5, ce sont des facteurs purement économiques qui limiteront le dévelopjement de cerlai-



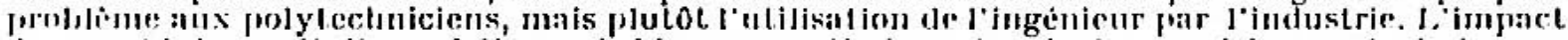
du machinisme bt:it parfaitement bien ressenti daus Jes ecoles supérieures lechniques :

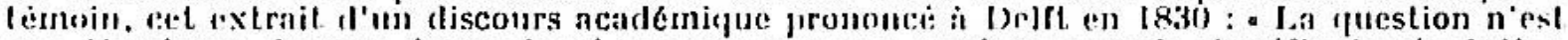
pas, Messieurs, de nous demanter si nous approuvons ou réprouvons la stupéfiante révolution yui a teforle sur te monde par l'applicalion des machines, s'il faut l'accepter ou la rejeter. La revolution s'est accomplie; ses sujtes agissent encore et sont mente loin d'avoir atteint leur pleine maturité. Des evénements d'une lelle ampleur ont besoin de plusieurs siècles pour clépluyer la gamme entière de leurs conséfuences, qu'elles soient parallèes ou contraires au systime entier des affaires lumaines. Il est diss lors de la plus gramde importance de ne pas se liisser entrainer, inertes et les yeux fermés, par le courant d'un tel événement, mais au eoulratre de l'écinirer dis le début de la lumiere de notre entendement et de notre perspicncité el de uons tenir sur nos gardes. Une telle atlitude nous conférera la compétence d'agir lorselur la: lnsoin se fern pressint, i le pouvoir de gouverner lii, oil autrement nous n'aurious ite


l: communaulé des peuples el cela de telle manière yu'au lieu de nous entratner ì leur suite, "lles righlent leur rytlume sur les progrès communs d'une existence sociale bien organisée el temiant. vers une harmonic interne a. Discours sur a l'influence des maclines sur l'ensemble

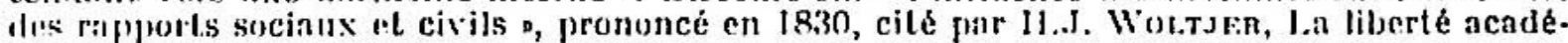
uni,fue: t:L l'orure universilaire, in Enseignemenl supérieur el rerherchrs scientifiques aux Payslins, lotis, sol. IX, no 1, p. 4.

(:) " $\mathrm{A}$ peisue parvem an ministère de l'intérieur, j’éprouvai le besoin de comnofl re toutes

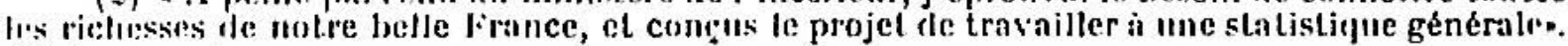
lhid., p. xiviv.

(3) Itans son Intustrie littéraire el scirnlifique lignée auec Intustrie conmerciale el manularluritre, Paris, 1817, A. Tureany ini s'intitule "Fils adoplif de M. Saint-Simon .




probluits de l'industric sont d'essence morale, incurnent de l'énergie morale sera un des thèmes favoris des scirntistes. "'esl en vnin yu'un cherche ì séparer l'homme de ses ceuvres... on est émerveilló des résultals dus nux machines... Ce sont. jusque dans les plus simples ot les plus grossiers détails des prodiges de force uive, de force morale... *. 1. l'AssY, Les Machines et leur influenete sur le développenent de la sociêlé, Paris, IsGfi, p. !1.

(4) Vues sur le s!̣slème genéral des opéralions induslriclles on Plan de Irchnonomie, Paris, 1819. 
Plan de lechnonomic est un des ouvrages les plus riches, les plus muirs in las plus philosophiques de cette histoire.

Il est vrai que le terme n'est. plus le mème. Pourquoi frechnonumir substituée à technologie ? Si Christian forge ce vocable, c'est dans unre vue critique : la technonomie est une crilique de l'évolution historique de In lechnologie. Le courl historique de cette dernière - retrouvé et réinventi, presque textuellement quelque cinquante ans plus tard par Karmarsch qui, nalurellement, ignorail Christian - analyse la réalisation des projels diss lechnologues. Si, les premières connaissances, telles qu'elles sont exposires, piar exemple, dans divers Théâtres de machinęes, restèrent longtemps " un recur.il w. faits isolés, de documents pratiques... qui occupaient la mémoire salns cxercir la raison " (1), la Lentative de leur organisation rationnelle devail ittre pricedis. par un découpage de la pratique d'un métier en une suile d'opérations : on s. proposail d'alsord d'u examiner les délails dont se composent les differents arl: el de les décrire chacun en particulier, en cherchant pourtant it expliquer les motifs de chaque procédé, el à montrer comment il se lie à celui qui préciolle. comme à celui qui le suil dans le même art. C'est. ainsi qu'on rangea, dans utı. sorle d'Encyclopédie, les divers travaux industriels, avant de penser is los classer d'une manière régulière " (2). Cette période qui englobe en particulin. les Descriplions et l'Encyclopédie, procédait donc par dissection des arts en éléments opératoires, en suivant fidèlement la pratique d'un art donné, sans s'interroger sur les similitudes des opérations clles-mêmes. Ce niveau de l'analyss: descriplive n'est pas dépassé - on l'a vu à propos de Beckmann - dans l. travail effectif des lechnologues : "lorsque l'industric s'étendit de toules s's parties, que les fails et les observations se mulliplièrent, que l'administration publique cut à se prononcer journellement sur ses intérêts, on sentil la nécessite de présenter, sous des formes' didacliques, les connaissances praliques yu'on avait recurillies sur les arts; on écrivit des traités de technologie, "1 an les vit. surtout en Allemagne, exposés dans des cours publies, ì còté dres hranchers les plus importanles des connaissances humaines (3). Mais en ce qui conerrne li manière dont les métiers sont décrits dans ces trailés, on ne peut pas les regrarder " comme autre chose qu'un arrangement, une simple classification systématique des procédés des arts " (4). La lechnologie beckmanienne, dans sit réalisation, se borne à reproduire un enchainement empirique dans les opérations d'un métier : "on y chercherait en vain des fails généraux, des déductions théoriques ot fécondes, en un mot, une doctrine qui les domine el les emlirasse tous " (5). En absence d'une telle doctrine, elle ne fait que juxlaposer les méliners différents ; "chaque art a eu son traité particulier et une place arbitraire; 小" sorte qu'on peut apprendre à connaîlre tous les détails de l'un, et, n'isoir aucune:
(1) lbid., p. 35.
(2) Ibid., p. 34-35.
(3) Ibid., p. 35.
(1) Ibid., p. 35 .
(5) Ibid., p. 35 . 
nolion, ni du précédent, ni du suivant : car il faudrail pour cela qu'ils fussent éclairés par une lumière commune "(1). Enfin, les divisions des arts et métiers adoptées par les technologues procédent soit ì partir du but, soit á partir des matières premières, donc de criteres extrinsèques, de sorte que " les cours de technologie, lels que nous les connaissons aujourd'hui, ne présentent... qu'une suite de trailés particuliers sur les divers arls dont se compose l'industrie générale " (2).

Ces descriptions el classificalions ne " creuseront jamais les fondements mêmes de la puissance el des ressources de la production n (3). C'est pourquoi le terme de Lechnologie qui désigne en fait, non un traitement systématique, mais unc reproduction des enchaincments empiriques des opérations d'un art, doit ètre remplacé par lechnonomic qui accomplirail ainsi ce que la première avait promis sans être en mesure de le réaliser.

Le concepl primitif de la technonomie n'est pas celui de l'art, de métier, ni crelui de produil ou de manière premiere. C'est le concept d'opéralion. Sans le savoir sans doule, Christian renoue avec le Projel de Beckmann de 1806. Mais tandis que Beckmann étail tourné vers le monde clos des arts el métiers, Clıristian écrit à une époque de transition où le travail artisanal subsiste encore, mais oủ le mode de travail industriel a acquis une prépondérance qui va en croissant. C'est pourquoi la technonomic est la science des opéralions induslrielles el, en particulier, une science des conditions économico-techniques du processus de l'industrialisation.

Les métiers peuvent être divisés en trois classes suivant le mode sous lequel ils s'exercent : soit, ils exigent une allention soutenue, soil ils s'exécutenl par une habileté mécanique devenue habilude ; une troisième classe comprend les métiers qui réunissent les opérations appartenant aux deux espèces précédentes. Possible pour les deux dernières calégories seulement, la mécanisation des opérations manuelles peut s'effecluer de deux manières : "soil direcLemenl, en faisant faire par un mécanisme les mèmes mouvements que la main, soit indirectement, en substituant une autre combinaison de mouvements propre à faire arriver au même bul „ (4). Dans le premier cas, la mécanisation suppose que les mouvements de la main ont été décomposés en une succession de gestes dont chacun est appliqué de manière univoque au mouvement que doit exécuter la machine. Mais alors, une opération relativement simple peut souvent exiger un mécanisme trop complexe. Dans le second cas, la technonomie doit proposer un schème opéraloire, non à partir de l'arliculation des grestes de la main, à laquelle devrail se conformer la machine, mais à partir de la tâche à exécuter elle-même. Il s'agit là d'une véritable invention technologique, consistant dans la détermination de la séquence oplimale des opérations lechniques en vue d'une tâche donnée : " on aborde franchement toutes les conditions

(1) Ibid, , p. 35.

(2) Ibid., p. 36.

(3) Ibid., p. 37.

(4) Ibid., p. 49. 
du travail ; ... sans s'embarrasser du mode de travail manuel, on cherche is remplir toutes ces conditions par les voies les plus simples et les plus en harmonie avec les règles de l'économie manufacturière $n$ (1).

Dans la troisieme classe des métiers, il convient de séparer les procédlés quui relèvent de l'attention, des autres qui sont mécanisables. L'avantage du découpage des opérations d'un art apparail aussi lorsqu'il s'agit d'établir les principes de l'apprentissage : on sépare ainsi " ce qui doit être indispensablement le sujet d'un apprentissage plus ou moins long, de ce gui appartient tout simplement i la main-d'reuvre, ou de ce qui convient au service des agents de la nature "(2). Laisser i un homme seul le soin de toules les operations d'un métier implique un apprentissage long; " mais ru'on divise méthodiquement ces opérations ; qu'on emploie pour chacune des outils micux conçus, at le temp. d'apprentissage sera très court, el le travail se fera même avec plus de priccision et de régularilé " $\langle 3\rangle$.

La technonomie est donc l'étude du travail industriel. Elle a comme point de départ, non les principes théoriques, mais le travail à cxéculer : c'est i part ir de la tâche proposée que le technonome doit chercher les moyens ot les instruments les plus appropriés pour l'accomplir : " on ne doil jamais oublier que ce sont les résultals du travail qui intéressent spécialement le technonome : ot. parmi la multitude de moyens qu'il peut avoir pour les obtenir, la qualité ou la perfection des résultats, ainsi que l'économie de l'opération, fixent son choix. $"(4)$

Ce sont les choix économiques qui déterminent des décisions technonomiques et qui définissent la spécificité de la technonomic relativement aux sciences fondamentales. Elle n'en est pas une simple application. Les exigences économiques de l'industrie limitent les choix techniques et bornent le chimp d'application des déterminátions physico-chimiques des opérations.

Avec Christian, nous sommes au cœur du problème fondamental de li Lechnologie : il s'agil de délinir une nouvelle composition du traviil humain, centrée non plus sur l'habileté et l'iniliative de l'individu manicur d'outils, mais sur l'enchainement des opérations exéculées par les machines dont. l'homme devient l'auxiliaire, l'annexe et même l'instrument. C'est chez Marx, informé des travaux anglais (Babbage et Ure en particulier), que s'articulent. selon une nouvelle configuration les idées esquissées par la génération de leclinologues conlemporaine de la mécanisation industrielle. Intégrée dans une autre problématique, l'appréciation critique de la technologie par Marx renvoie aujourd'hui aux théoriciens du machinisme des grandes fabriques; i Christian notamment, qui a clairement thématisé le savoir technique el scientifique impliqué dans le travail industriel. Mais les technologues s'ingenient, it analyser

(1) Ibid., p. 75 .

(2) Ibid., p. 50.

(3) Ibid., p. 51.

(4) Ibid., p. 66-67. 
ct prédire le développement des processus industricls, à en discerner le profit iconomique. En se siluant hors du cercle de la seule programmation technique et en prenant pour instrumenl d'appréciation les rapports du travail ouvrier avec les conditions socio-économiques de la production, Marx discerne les tensions qui dans ses vues ne peuvent manquer de se prorluire el d'aboutir à une désinlégration de l'ordre économique capitaliste.

En reprenant à son compte les analyses des technologues et en les complèLanl, Marx distingiue le travail manu/aclurier de la grande industrie moderne. Ce travail est une élape intermédiaire entre l'arlisanal et l'industrie : par la fragmentation des opérations, elle prépare la grande industric, mais cette parcellarisation demeure encore assujettie aux exigences particulieres du travail manuel : la technologie reste dans la dépendance de l'organologie. Effecluée d'abord dans la pralique, c'est-à-dire dans les usines elles-mèmes, l'analyse des opérations manufacturières procède dans deux directions : "d'un côté, clle [la manufacture] a pour point de départ la combinaison de métiers divers et indépendants que l'on désagrège et simplifie jusqu'au point où ils ne sont plus que des opérations partielles et complémentaires les unes des autres dans la production d'une seule et mème marchandise ; d'un aulre còlé, elle s'empare dr: la coopération d'artisans de même genre, décompose le même métier en ses opirations diverses, les isole et les rend indépendantes jusqu'au point où chacune d'elles devient la fonction exclusive d'un travailleur parcellaire n (1). Mais, même cette décomposition accomplie, loute opération s'exécute par la main et, doil être conçue en fonction des possibilités anatomiques el physioloriques de l'organe. "L'analyse du procès de produclion dans ses phases particulières se confond ici tout à fail avec la décomposition du mélier de l'artisan dans ses diverses opérations manuelles... Cette base technique n'admet. l'analyse de la besogne à faire que dans des limites très étroites. Il faut que chaque procédé partiel, par lequel l'objet de travail passe, soil exécutable comme maind'ceuvre, qu'il forme, pour ainsi dire, à lui seul un métier à part " (2).

Le passage décisif s'opère, selon Marx, en faisant abslraction des organes de l'homme dans l'exécution de la tâche. La technologie commence au moment oì l'homme et la machine échangent leurs fonctions : l'ouvrage n'est plus façonné par la main de l'homme s'aidant de la machine; il est l'auvre de la machine qui se sert de l'homme. La main humaine comme organe modelant la malière esl remplacée par la machine-oulil, la machine à faire des machines. C'est l'exéculion de l'ouvrage, et non seulement l'augmentation du pouvoir mécanique, qui sont désormais assurées par la machine. La technologie affranchit le travail de la dépendance des parlicularités de l'organisme vivant qui, celle fois-ci, doil s'adapter à la composition et au rythme du travail collectif fragmenté selon les exigences des mécanismes machinaux (3). C'est donc la

(1) Le Capital, trad. fr. de Joseph roy, Paris, 1938-39, II, p. 33.

(2) Ibill.

(3) Manx applique cetle visée technologique au monte viyant en assimilant les organes aux outils et instruments destinés à assurer la production de la vie : "Darwin a attiré Pallention sur l'hisloire de la teclinologie naturelle, c'est-ì-dire sur la formation des organes vếcétaux et animaux considérés comme instruments de produclion pour la vie des plantes el des animaux... La technologie révèle le comportement actif de l'homme vis-à-vis de la nature, le processus immédint de production de sa vie, el par suite, ses relations sociales et les représentations spirituelles qui découlent d'elles :. Le Capilal, II, p. 65. 
machine qui gouverne la décomposition des prociedes, "n particulir lia machine-outil. C'est, aussi pourquoi, selon Marx, la révolution imbu-frirlll. s'opère, non simplement a partir d'une machine-moteur ingmentant lit puissance, mais comme on l'a déjà vu, a partir de la machiar-osutil qui oblige a repenser, a reconstruire les opérations élimentaires at leur agencement. Leur fragmentation el recomposition imprimera all travail humain l'empreinte du modèle machinal, la lransparence al l'uljectivili du savoir rationnel. "Ge voile, qui dérobait aux regards des hommes le frudlement matéricl de lqur vie, la production sociale, commença í etre soulesie durant l'époque manufacturière et fut entièrement déchiré à l'avenem.nt, de la frtatul. industrie. Son principe qui est de considérer chaque procérle en lui-mime ol d. l'analyser dans ses éléments constiluants, indépendamment de leur cxirul iun par la force musculaire ou l'aptilude manuelle de l'homme, cría lis scirom. toute moderne de la technologic. Elle réduisil les configurations de la vire industrielle, bigarrées, stéréolypées et sans lien apparent à des applicalionvariées, conscientes et réfléchies de la science naturelle, classifiees d'aprís leurs différents buts d'ulilité" (1). Tous les thèmes de la technologie - anily... objective des procédés de la fabrication, technique de l'applicalion des scin-nces, planification consciente de cette application, motif d'utilite économique sont résumés dans ce texte.

Le recensement des buts utilitaires est effectué près de trente ans flus liit par Léon Lalanne dans l'Essai philosophique sur Ia technologie (2), dir.ctrmenl inspiré de Babbage, qui analyse par ailleurs la nature des procédes lechnoloniques d'après les sources et les emplois de la force, de leurs applical ions at d. l'économic industrielle. La classification des métiers en fonction de's luuls sociaux s'impose dans la mesure où des procédés analogues engremlrent du. produits bien différents.

L'idée que "l'industrie est la base du nouvel ètat social " (3) rst affirmi. par Lamé et Clapeyron à l'époque oì le concept de travail change de sịnification. Désormais, le travail est juridiquement libre, mais applirpue à res liaches de plus en plus spéciales el parcellaires; objectivé dans la mesure des lemple et des rendements, projeté aussi dans l'espacc abstrait des valorisal ions éconu-

(1) Op. cil., II. p. 18I. - Près d'un el demi siècle après Wolfr, Marx est anene a furmulurer le vou d'une histoire de la technologie : E En somme, une histoire critigue de la tichnnlo!fie aurait montré combien peu les inventions du xywe siécle appartiennent it 1 so seul indivielu. Jusqu'ici, il n'existe pas une telle couvre *. Hitl.

(2) Extrait de l'Encỵclopédie Nouvelle, Paris, 1840.

(3) Plan décoles générales et spéciales pour lagriculture, lindustric mamu/acluri re, 1

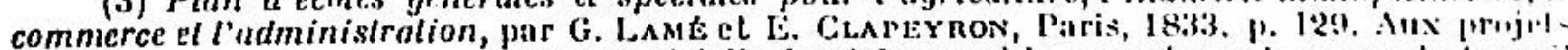

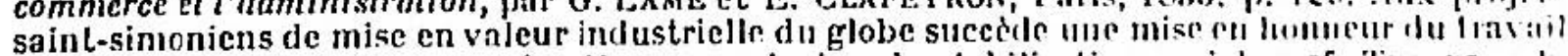
de laquelle le capitalisme espère tirne un principe de stabilisntion sociale ; cr. Tunass, - lit richesse el la pauvreté avancent appuyées l'une sur l'autre en se procurant de's jouls:iane.. réciproques "; le travail n'institue pas seulement des liens de suborlination, il est quallitio , l. - puissant moralisateur ", grace a quoi * s'accomplit le progress sucial ", Discours de CuNis GRIDaine, ministre de l'agriculture et du commerce, 28 novembre IS47. 
miques et morales. A ce nouvel ordre conviennent de nouvelles institutions : c'est toute l'u éducation générale " qu'il faut réformer, car " l'organisation du Lravail n'est pas un vain mol "(1) et doit être étendue á toutes les activités sociales, comme à tous les ordres d'enseignement. La solidarisation des processus techniques, la régulation de la production, tel est l'horizon que se donnent les réformaleurs. Dans l'immédiat, Lamé et Clapeyron raniment les projets de Fourcroy et de Chaplal, demandent des cours de pralique industrielle. C'était justement le but que venait de se donner à un niveau supérieur l'licole centrale des arts et manufactures fondéc peu auparavant, ì l'époque où Auguste Comte énonçait le ròle de la "classe des ingénieurs".

Dins ces mêmes années, le programme de l'enseignement délivré à l'Ecole polytechnique el son adaptation an nonvel ordre industriel ćtaient de plusieurs côtés mis en question. Cournot, dans son traité Des Instilulions d'instruclion publique en France, résume un peu hâtivement l'évolution des doctrines pédagogriques de l'Ecole polytechnique; elle a été " dès l'origine et est restée longtemps une école consacrée aux hautes mathémaliques, aux conceptions théoriques et abstraites. Plus tard, on s'est aperçu que les sciences physico-chimiques, dont le rôle et l'importance sociale grandissaient, pourraient bien ètre aussi utiles it un futur ingénieur... que des théories de mécanique rationnelle qui semblent. n'atre... que des amusements de l'esprit humain " (2). Balzac, bien auparavant, s'élail fait l'écho d'opinions un peu faciles des praticiens, mises dans la houche du Grégoire Gèrard du Curé de village, "belle âme, homme supérieur ", issu de Polylechnique pour médire des écoles $(3)$, il trouve finalement. une sorle.

(1) I'lan d'écoles..., np. cil., p. 1.

() Jes criliques nunncées de Cournol font écho à quelques censures beaucoup plus ardentes prononcées dans les tout premiers temps de l'licole; ainsi, . l'enseignement de l'école polytrehnigue porle sur une infinité d'objets de théories slıstrailes, telles que celles de la géométrie trunscendante, qui n'auronl jamais d'application dans la pratigue... Ces connoissances... ne peuvent convenir... à ceux qui doivent être occupés toute leur vie d'opérations pratipues, pour lesquelles les spéculations de la haute géométric sont tolalement inutiles p, upinion de J.F. Baration sur lécole polyterhnique, 24 nivỏse an VI, p. 9.

Lal critique de Cournol ne l'empéche pas de noler que "l'Ecole polytechnique el l'Ecole centrale rénlisent bien cette idée d'une Facullé économiqune, mise en avant par Leibnitz, comme Lint d’autres idées, bien avant que les temps ne fussent môrs pour la saisir, laquelle compren. drait (dans leur généralité, bien entendu) " les arts mathémaliques et mécaniques, et tout ce qui regarde la subsistance des lommes et la commodité de la vie ", Des Instilutions..., Paris, 186.1, p. 165 .

(3) "Maintenant est-ce que, par cetle organisation, l'Elat gagne des travaux d'ulilite publique mieux faits ou a meilleur marché ? D'abord les entreprises particulières se passent très hien d'ingénieurs... dans les pays où ces institulions n'existent pas, les travaux analogues sont at moins aussi bien faits et moins conteux qu'en France... Je sais qu'il est de mode en prirlant de nos Ecoles, de dire que l'Europe nous les envie; mais depuis quinze ans, l'Europe qui nous observe n'en a pas crée de semblables...... La Belgique, les Elats-Unis, l'Allemagne, l'Angleterre, qui n'ont pas d'écoles polytechniques, auront cliez elles des réseaux de chemins de fer, quand nos ingénieurs en scront encore á traçer les notres, quand de lideux intérêts cachés derrière des projets en arréteront l'exéculion... - Le Curé de villinge, Ire éd. 18.11, Ed. Nolson, pp. 250-70.

Autre protestation conlemporaine, aussi virulente, mais inspiréc par une toul autre idéologie, celle d'un ancien polyteclınicien, Victor Considérant : " nos Ingénieurs, ce sont en général des liommes de talent el de probilé, mais ils doivent s'apercevoir qu'ils jouent un rôle inférieur s̀ celui auquel il sernit bon qu'ils prélendissent. Ils fonctionnent comme des instruments scientifiques, comme des machines d'exécution. lls se laissent gouverner par les préjugés de la société, ceux qui devroient se rendre aptes à lui imprimer la direction industrielle la plus favorable. D'oú cela vient.-il ? de ce qu'ils se renferment trop étroitement dans leurs 
de salut spirituel à organiser, au fond d'une région déshérilée, la prospérilé d'un vaste domaine et des campagnes voisines. Le cas psychologique est plausible, mais la protestation virulente, et plutôt injustifiée qu'il supporte, témoigne d'une altitude assez commune dans les cercles industriels dès avanl le milieu du siècle. Il n'y avail, bien entendu, pas lieu de récuser l'extraordinaire fécondilé intellectuelle des premières années de l'Ecole polylechnique, mais bien plutil, de procéder à une sorte de retour au concrel ; l'imitation des bonnes lechniques, repérées par tâtonnement empirique, améliorées par approximations successives, apparait souveht alors plus profitable, plus économique aux nouveaux maitres à penser de l'industrie. "Les sciences théoriques, pouvait-on lire dans le: Prospeclus de l'Ecole centrale, ne sont composées que de généralités trop incompliles encore, pour que l'on puisse en déduire les lois exactes de celte foule de thieorèmes compliqués qui se rencontrent mème dans les arts les plus simples n (1). Gette réalité plus riche que tous ses théorèmes, il faut se l'assimiler par la fréquentation des modèles qui seront reproduits par les élèves : " Dans l'intention des fondateurs (l'objet de l'enseignement) consiste à faire exécuter par charque élève, une véritable encyclopédie des arls et manufaclures. Au moyen des dessins et des expériences exécutées par l'èlève, on espère qu'il s'appropriera tous les fails connus, qu'il les concevra et les combinera comme des idérs qui lui seraient propres... " (2). On entre ainsi dans un ordre de l'application tempéréc.

éludes technigues, de ce qu'ils s'occupent trop exclusivement des proceddes spreiaux de l'arl. Qu'ils étudient un peu plus l' Economic et les Sciences sociales, les condilions generales rt supérieures du progrès de l'industrie et de la prospérité des nations . Déraisun al danyers te l'rngouement pour les ehemins de ler... Paris, 1838, p. 19. - Balzac incarne en 18.11 les iuterits d'une bourgeoisie libérale qui trouverait en elle-même les ressources du génie entreprencur et Ies initiatives du modelage social par l'action sur les objets. Y'our lui le systeme des concours stérilise l'individu, et les Ecoles sont l'instrument de la bureaucratie improdnclive. Considéranl dévolue, au contraire, à l'ingénicur le rôle supérieur d'organisalion globlale de la sorcieț: : si l'ingénicur est sujet it critiques, c'est en raison de son confinement daus des inilialives trop segmentaires, faute de conscience socialiste. Dans un pamplilet antéricur de quelegues amnérs. Considérant proclame qu'a il s'ngil de produire l'invention el faire la tlécuuverte du míc:auismin naturel d'industrie dans lequel l'lomme travaillera par plaisir el par passion, anl lieu de tra-

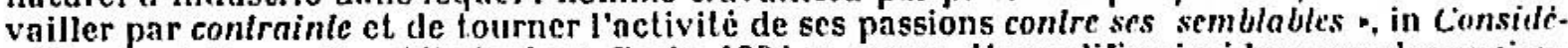
rations sociales sur l'archilcclonique, Paris, 1834, p. xxxy. Il amplifie ainsi les vues des anciennes technologies a caméralistiques " cl prérigure les aspirations marxistes.

(1) Annales de l'Industric /rancaise el étrangère, t. I1, Paris, 1828, p. 393. Déjì, près It

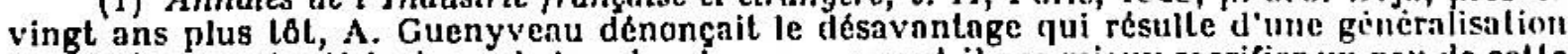
trop théorique des théorèmes de la mècanique : « ne vaut-il pas mieux sacrifier III pen de cetle généralité, si justement précieuse aux géométres, pour se procurer des expressions plus simples et d'une application facile...? ... Les formules générales de la mécanique renferment toutrs les conditions du mouvement diun point du corps, peuvent sans doute servir it résoudre tous les problèmes possibles sur les machinrs, mais ici leur généralité mème esl un inconvénient....", Essai sur la science des machines, Lyon, 1810, pp. 5-6. - Cournot exprimera plus tard ic besoin croissant de la société industrielle en praticiens : "les résultats moyens et non les exceptions brillantes sont ce qui inléresse effectivement les services publics n, Des Institutions.... op. cil., p. 444 ; le mérile des techniciens habiles à répéter et perfectionner les procédés est valorisé dans ce poncif des médiévisles du xix ${ }^{\circ}$ siécle : a les construcleurs de calhédrales du moyen-age connaissaienl les procédés, mais nullement la théorie de la géométrie descriplive ", Ibid., p. 447

(2) Annales de l'Industrie..., op. cil., p. 390 . Il est significatif dans le même ordre d'idéc qu'en 1810, Girard publie en France les mémoires de Smeaton, relatifs à des expériences de 1752 données comme modèles. Cette traduction sera rédilée en 1827.

La "complication inherrente à certains travaux industriels " que signale PoNcelet dans son Introduction d la mécanique industriclle, 1829, ne relève pas d'un enseignement théorique supérieur, mais désormais d'un enseignement proprement professionnel. 
du savoir théorique, où l'univers technique est à nouvcau présenté comme une nature factice que l'on peut former et diriger par des règles, sans qu'il soit besoin, pour les praticiens, de se représenter à tout moment les lois qui la fondent.

Il est bien remarquable, qu'à l'époque de la création de l'Ecole centrale, on assiste a une soudaine floraison de publications " lechnologiques "qui viennent s'ajouter à des organes plus anciens, tels que celui de la « Société d'encouragement ". Ces publicalions (1) se présentent comme des collections plus ou moins systémaliques de procédés et de productions ; clles réalisent une exhibition encyclopédique des opérations de l'industric, elles exposent les ingéniosités pratiques des manufacturiers et de leurs techniciens. Rendant compte d'une pluralití d'expériences particulières, elles renouent avec la tradition des Descriplions académiques, tout en la brouillant par la profusion des notations ; pour un lemps, elles perpétuent le genre de l'histoire des arts qui s'exténuera sous l'abondance de ses productions. Un nouvenu corporatisme, ouvert, se constituera peu à peu, celui de la spécialisation Lechnique qui formera ses propres instilutions, ses propres organes; ainsi, se manifesteront de nouvelles divisions de la science appliquée, où survil altérée une pensée teclınologique qui use de concepts opéraloires et de qualités, et réconcilic, en dernier ressort, l'ivresse des théitres de machines avec la rationalisation bourgeoise du $\mathrm{xix}^{\mathrm{e}}$ siècle. Celle-ci se déploie dans le goût d'organiser et s'exprime dans la production, l'échange el la manipulation des objets. La multiplication des produits est donnée comme un moyen d'accroître la richesse de groupes privilègiés, ellemême justifiée par le thème de l'enrichissement général; mais c'est encore une fin en soi, source de contentement intrinsèque. Poncelet déclare ouvertement que la "perfectibilité de la race humaine " réside dans l'accroissement des idécs scientifiques "appliquées ou non à la salisfaction de nos besoins" (2), et, dans le mème élan, fait l'apologie de la "multiplication, de la vulgarisation, de la reproduclion rapide, économique des objets de consommation el de jouissance malérielle, artislique et intellectuelle "(3).

(1) Diclionnaire lcchnologique it parlir de 1822, sous la direction de Francaur, Moland, Lenormand, Roniquet et Payen.

En 1824, la Description des Expositions des produits de l'industrie française, par LenorMANn et. de MlOR.ÉON.

Fin 1826, Ie Manuel dn Manufachurier ou Archives des Découverles cl procédés de labrication mubliés dians la Grande-Brelagnc, par P'ELouze; la même année, le Bullelin des Scicnces lechnologigues (50 section du Bulletin universel des sciences el de l'induslrie, sous la direction du baron de Fenussac); en 1826 encore - particulièrement réconde pour notre objet du'Industriel, Journal principalement destiné à répandre les connoissances utiles d l'indusirie genérale, par im. Cimistian... Dubrun-Faut... el Leblanc.

En 1827 , apparalt le Monileur de l'industrie française par une * société d'amateurs de la Technologic " (Ies collaborateurs seront en 1829 de Jouffroy, Odolant Desnos, Robert, Bailly de Merlieux, Calla, Francœur, Bambey, Héricart de Thury, Hoyau, Labarraque, Larresclee, Mériméc, etc.).

En 1828, paraissent les Annales de l'Industrie /ranģaise el clrangère, par BénARD, Duмas, PAYEN, Mol.And et PeCLET, ainsi que le Journal du génie civil.

Les Elémens de Technologie de Franceur seront publićs en 1833.

(2) Machines et outils spécialcment employés à la /abrication des malières lextiles..., Paris, 1857 , op. cil., p. 3.

(3) Ibid. 
Lin lait, le dynamisme organisateur de la production du $x i x^{e}$ siècle se: déploie sur plusicurs niveaux, cux-mêmes solidarisés : "l'organisalion nalurclle de l'industrie appelle une distribution des fonctions "(1). Au plus bas niveau, celui de l'atelier et de l'entreprise, c'est la fabrication qui polarise une pensée technologique issue des écoles professionnelles. Le produit doit salisfaire à des conditions techniques dont la réalisation est souvent expriméc par des métaphores biologiques. D'un tracteur construit par l'ingénieur Dietz, il est dit en 1839 qu'u après avoir éprouvé plusieurs transformations, (il) a atleint dans loutes ses parlics, l'unilé que l'on remarque dans toute son organisalion n (2). Mais cet instrument bien organișé ne prend loute sa valeur aux yeux de ceux qui le célébrent comme " fait social accompli n (3), que par sa fonction d'organe: dans une organisation d'un degré supérieur, celle des " voies de communicationl... agents puissanls de circulation el de richesse (qui) forment entre eux un vaste système que l'esprit progressil tend à compléter chaque jour " (1). Ce " locomoleur " est proposé comme un rouage d'un " vaste mécanisme n dont. less éléments, en vertu d'une harmonic calculée, ne "s'entre-choquent " pas mais " se prêlent un muluel appui ". Il s'agil done de recomposer l'organisme social selon une machination progressive de tous ses domaines. Au niveau le plus élevé. le dynamisme organisateur du siècle se donne pour idéal la coordinalion économique d'une nation entière. C'est là une notion qui s'impose à ceux qui ont. appris de la puissance souveraine du calcul que toul peut être projeté et tolalisé dans des représentations intellecluclles. L'Ecole polylechnịjue a inculié l'hubris des ingénieurs technocrates.

Tout discours sur la technique agrège des éléments hélérogènes. Non seulement, il implique la définition de l'objet, mais il doit poser les staluts de la production dans chaque moment de l'histoire sociale. Or, aussi hien la production que le produit sont chargés de connotations extrascientifiques, propremenl mythiques, comme les elhnologues nous le montrent surabondanment. Il faul se défaire d'une opinion commune selon quoi la technique serait neutre, pour cette scule raison qu'un mème objet technique peut être utilisé à des fins radicalement différentes, ou que des processus d'usinage très comparables peuvent donner naissance dans le mème lieu à des objets de forme et de fonctions tries diverses. Le produit technique peut bien être le fruit de l'application d'une science constituée dans le lit d'un formalisme aristocratique, il n'en incorpore pas moins une intentionalitè d'usage ou de signification. Bien qu'il puisse prendre une valeur esthétique prononcée, l'objet teclnnique se distingue de l'objel. d'art par sa fixation nécessaire dans un réseau social de fonclions aisément

(1) A. Vissciress, napport sur l'organisation de l'enseignement induslriel, Bruxelles, 1852 , p. 101 .

(2) Rapporl sur le remorqueur Dielz, 1839, p. 12.

(3) Ibid., p. 5.

(4) Ibid., p. 4. 


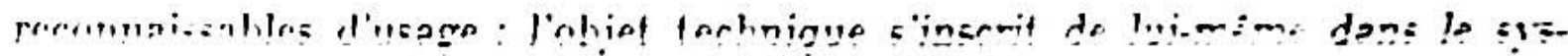
leme: righe drs échanges de valeur et dans une chaine de fonctions qui euglobe les produclions et less hommes. Isa finalilé immédiale de la technique semble la résorber dans une instrumentalité de manipulation. Actualisée dans telle fonction, dans tel disposilif, dans telle configuration, la lechnique les dépasse comme manifeslalion d'une activité originaire el irréductible. C'est l'acle luimeme qui est constitutif, outre les buts particuliers qu'il poursuit. Instruite par un savoir, la technique ne peut pas se ramener à sa simple application. Elle consiste dans un déploiement du lemps selon le mode élémentaire du rapport projul-réalisation, et assimile le monde à l'environnemenl immédiat du corps (1). Si le monde grec aux représenlations closes el achevées n'inclinail pas avec forec à la l.ransformalion de la nature, l'influx de la pensée judéo-chrélienne, halilée par le travail de la Genèse et l'enjeu de l'Incarnation, propose une rialisalion progressive du monde el juslifie sa lransformation possible par l'efforl, la tâche et même le sacrifice. La doctrine chrétienne ouvre devant l'homme un espace à remplir el finalement à organiser; en fondant la responsahilité cl. la solidarité, clle réfère l'ćchec au mal el pousse l'homme historique à traverser les ruines de ses efforts inaboutis.

Charque déconverte lechnique résulte d'un réseau antérieur découpant et arlieulant la nalure, que l'inventeur achève en réalisant un parcours parliculier. Toule découverte peut avoir des effets multiplicalcurs, ramifiants, créant des fins qui lranscendent le savoir et la prévision. Elle recule les limiles de l'espace possible. Ensemble des organes el des fonctions colleclifs, la technique issume la totalité toujours provisoire, mais nécessaire, de la reproduction des actos vilaux. En réalisant des buts particuliers, c'est l'homme qu'elle réalise : par une hisloricité transparenle des actes et des objets, toujours récupérables dans leur intelligibilité (sauf pour les objets techniques à finalité magique), mais aussi par une intégration fonclionnelle dans l'organisme social, garanl de l'efficacité et de la survic.

Deux mouvements déterminent la destinèe historique de la lechnique; l'un, conscrvatif, lrouve son modèle dans la reproduclion vitale, son régime dans l'imitation, et son crilère dans l'économie de répélition. L'autre tendance cocfliciente est accidentelle de nature, c'est l'invention qui vient enrichir et perlurber une communaulé d'habiletés, el se réalise dans la rigure de l'essai, donl la permanente image anceslrale est la liberté de la main ustensile. On comprend dès lors que la technique, quels que soient les raffinements intellecluels qui contribuent à ses récentes manifestations, ne se développe que comme

(1) La main s'arrête à l'objet qu'elle fail el use. Dans la Iransformation du monde, c'est l'jdéce d'une lotalité organique jamais réalisée, loujours approchée et à relaire, qui permel di: remplir l'espace technique. Cette appréhension du monde informe le phantasme d'un Diderol imagrinant une unité manufacturière, ouvriers, outils el machines, comme un seul Qtre vivant: "Que serail-ce qu'un métier de la manufacture de Lyon, si l'ouvrier et la lireuse faistient un tout sensible avec la trame, la chaine, le sample gavassine ? Ce serait un animal semblable à l'araignée qui pense, qui veut, qui se nourrit, se reproduit et ourdit sa toile. Elémenls de physiologie, CEuures, éd. Assézal, t. 9, p. 268. 
un accroissement défini des pouvoirs gestuels el une dilalalion de limane du corps.

Historiquement, la lechnique a douné lieu à divers types de: disenurs; los uns proprement scientifiques, sont l'explication mème des ol,jels techuiqures de leur structure, et de leur labrication ; d'autres, d'essence politique, prenurnt pour objet le règlement de l'activilé lechnique dans la sociélé. Ce sont les discours technologiques. D'aul.res portent enfin sur l'image de l'olijel lirehniqür. dans la collectivilé sociale et, recucillent, en particulier, les prestiges archaïjurs de la puissance.

Parmi les discours technologitues, certains insislent surtoul sur le I railement des matériaux naturels cl visent, à definir lo meilleur parcours lechni in.". de leurs transformations; d'aulres privilégient l'aspecl économiegur da la production et du travail; il en est cnfin qui se donnent pour objel l'étude. ethnologique ol la critique philosophique de l'activité technique (1). Cela constilue, a proprement parler, le champ de la technologie. Co qui exclul ivirlemment le sens anglo-saxon de technolog!l qui esl identifiable a la leclunipur "u général et aux énoncés de la science appliquéc.

Dans sa première malurité, la technologic élait directement liée par son objet aux procéclés de fobrication, aux arts el, aux manufaclures, à l'industrie. Son élaboration était également normative ; la technologic apparait alors comme une discipline destinée à informer ccux qui sont appelés à faire des chojix économiques. Procédés et pratiques étaient intégrés dans une vision économique globale de la société, si bien que la technologie devient le discours ral ionalisant les procédés techniques dans une organisation politique du travail.

Celle technologie s'est formulée dans le milieu universitaire germanityue. Elle y a reçu l'emprcinte des exigenees de classification el de systémalisal ion propres à un enseignement. traditionnel. L'élévation au rang académique tr. la théoric des activités artisanales correspond en pays allemand à un liesoin dr thématisation qui s'est exprimé en France dans la description et. la eriliyul. des opérations des arls. De part et d'autre du Rhin, les préoccupations lechnologiques sont nées dans des contexles politico-économiques comparahles, sous des pouvoirs de lype absolutiste inclinćs au dirigisme économique. Pour une large mesure, la réflexion technologique est une réponse ì la révélation de: l'avance économique de la Grande-Bretagne et au désir d'imiler sa puissance industrielle. Or, en pays anglo-saxons où se créent plus tôt qu'ailleurs les struclures de production modernes, les motifs technologiques ne donnent d'abord pas lieu à des inilialives aussi clairement marquées; c'est que la découvrrte: les procédés d'industrie, leur perfectionnement el leur développement. daient. l'objet d'une activilé diffuse que soutenail, il esi vrai, un syslime de palentes

(1) Pour Espinas, ln technologic rlésigne a des groupes do rigles praliques, Jes arts ou

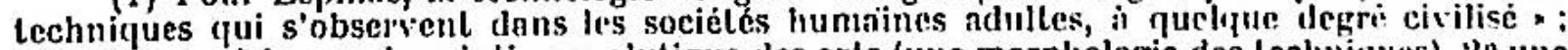
elle comprend $1^{\circ}$ une description analytique des arts (unc morphologie des lechnipues), 2" mins recherche des conditions el des lois de leur efficacilé pratique, $3^{\circ}$ une étude de leur dèvelnpemenl. Les origincs de la lechnologie, Paris, 1897, p. 8-9. 
forl incien, el que protégeront souvent des initialives parlementaires. Le progrès leclinique étail à la fois une affaire de praticiens directement engagés et III phénomène qui altirait les soins de propriétaires et d'amaleurs dont la réunion évoquait davantage des clubs que des académies. Peu à peu se formera au $\times{ }^{\prime}{ }^{e}$ siècle une classe d'ingénieurs civils donl le Lalent spécial ne devra pas grand chose aux universités qui ne créent que bien tardivement un enseignement lourné vers la pratique industrielle. Le coneept de technologie, son usage étendu el son organisation en discipline ne s'affirmeront que dans le premier tiers du $\mathrm{xIX}^{\mathrm{e}}$ siècle (1). Mais cette émergence lardive charge le concepl d'un nouveau contenu; il sera fixé dans la dénomination des institulions d'enseignement el, de recherche qui donneront au terme sa généralité et son prestige (2). La technologic se développe alors comme une mise en ordre systématique des sciences appliquécs dans un contexte économique capitaliste : elle est une scirnce des processus de produclion, lecls qu'ils sont, réalisés dans la grande industrie et exigent une application systématique des sciences (3).

Sur le continent, au fur el a mesure que l'induslrie se développe et embrasse Ies productions de plus en plus diverses, la techmologie, rui présidail à son installation, perd progressivement du terrain pour disparaile presque complèt.ement, à la fin du $\mathrm{xIX}^{\mathrm{e}}$ siècle. Dans la langue française, le terme est plutôt rare après 1860. En Allemagne, son historien Karmarsch devienl en mème temps son dernier grand représentant. La diffusion de l'enseignement technique et la conversion de la société vers le type bourgeois libéral cantonnent. la technologie au sens beckmanien dans des limites étroites (4), en position loul à fait marginale; l'explosion industrielle à la fin du $\mathrm{x}_{\mathrm{x}} \mathrm{x}^{\mathrm{e}}$ siècle dont le développement est régr par la concurrence et tend à échapper aux possibilités d'intervention de l'Etat, rend superflue une discipline qui relève du dirigisme économique et qui n'a pas encorc rompu son application à l'ancien univers artisanal. La technologie est une discipline contemporaine de la transformation de la sociélé artisanale et manufacturière en sociélé industrielle moderne.

Ce n'esl peut-être pas un hasard si elle réapparait de nos jours, au déclin du libéralisme classique, à une époque où l'Etat entend exercer une influence déterminante sur les choix économiques, oủ la planification s'élend non seulement à

(1) Un des premiers ouvrages imporlants de langue anglaise oi le mol apparail dans le Litre est celui de J. Bigerow, Eiements of Technolog!, Boston, 1829.

(2) La polytechnique américaine sera nommée Massachuscls Instilule of Teclnology. - Une bifurention de sens due à la fixation de moments historiques distincts marquern désorntais le concept. Tout en gardant une référence implicite nux aspects économiques des techniques, lechnology désigne essentiellement les procédés techniq̨ues cux-mêmes.

(3) Les grants trailés d'économic manufaclurière de Ch. BABnsaE (A treatise on the reonomy of machines and manu/aclures, London, 1832), de $\mathrm{A}$. Une (The philosaphy of manufarlure, London, 1835) ef de E. BAINes (History of collon manufaclure in Enylund, London, 18:35) sunl en fait des descriptions teclinologiques de la période avance de la révolution indestrielle. C'est en s'appuyant sur leurs analyses du travail industriel que Marx parlera de la a science toute moderne de ln technologie $n$.

(1) Dans le monde soviélique et en Europe de l'Est, le terme garde un sens précis, inclus dans l'ensemble de l'nctivité technique : il désigne un segment déterminć dans la suile des opérations de la production, mais il a perdu sa connolation économique. 


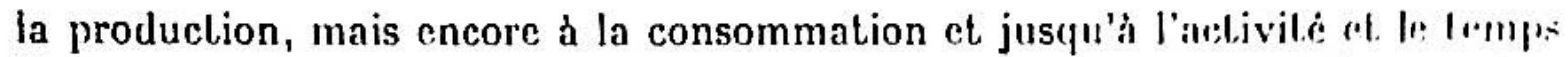
libre que le travail social laisse aux hommes; it une éporpur aussi de lraturerrmation de l'industrie par l'aulomalion, appelée sans doute i susciler une mulation de la structure sociale aussi profonde que la constilution de la grand. industrie au $\mathrm{xIx}^{\mathrm{e}}$ siècle.

Les mots sont en proic à des aventures dont il est parfois difficile d. mil s:1cer la trajectoire. Les avalars sémantiques de lechnologie doivent c̀tre rapjurtion i) la liaison précaire de préoccupations historiquement, varialbles de: l'homm.n. a l'égard du travail des autres.

Mais, indépendamment de l'aventure historirue de la discipline inlilulè.

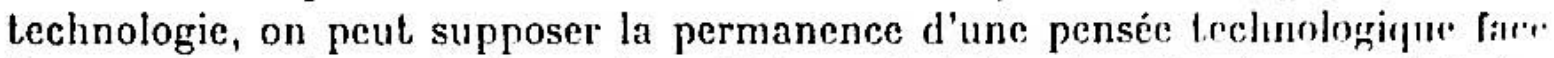

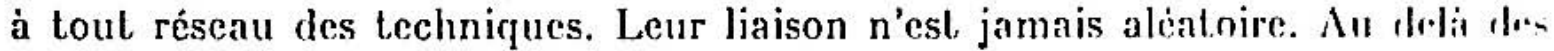
réticulations transitoires dans l'ensemble rles transformations maliriellies. au delà de toul ajustement des rapports de produclion, il est. tent:ant. de relur. cher s'il existe des molifs permanents. Sans aucunement. prétendere is les defi nir lous, du moins pouvons-nous esquisser quelques linéaments de celtu configuration supposéc.

La pensée technologigue se déploie comme un champ d'opréralions. l'illui celles-ci, on peul noter la volonté de constituer une nomenclature des malijirr. des instruments de transformation, des procédés de prorluction. Colle lir-he. jamais achevée de définitions de la langue des arts va de la deseription rapron dique des métiers a la notation systématique et normalisée des élements de lit production ; elle ne peut alteindre sa maturité que par application milhediqu. de concepts scientifiques. La définition des opérations techuir|urs sup juse latur réduclion finale à des expressions numériques de grandeurs physigues. Ciest lit raison pourguoi il n'ćtait pas question d'imaginer une technologie arlulla atial la segmentation précise du temps des opérations. Cependanl, cette langure i elle ne peut se constituer sûrement hors des concepts physico-chimiyums du $\mathrm{xix}^{\mathrm{c}}$ siecle, doit utiliser en outre une terminologie propre, reflet, de la sl.rw: $1 \ldots$. socio-culturelle constituéc par la totalisation ordonnće des organes Irchnirpund'un groupe humain. Le tecluologue qui légifère sur les raljports de I'homm. avec sa production, use done d'une langue qui lui permet de comprendre at 1 . suggérer les transferts de schémas opératoires entre activités différenles. C"rol la normalisation des opérations et des productions qui permet leur comlintaism" dans un ensemble économique complexe. La transparence de la langue d. l'ingénieur permel les transferts de compétence el la communical ion entre liimaginations techniques. Celte réduction des opérations it un mode conmun de programmation entrainc une contagiosilé de la pensée lechnologicune. II n'esl que de songer au deslin du colonialisme qui s'achive par une rxporlalint des procédés d'exploitation, quelles que soient les molivalions invorpureCette contagiosité détermine par diverses voies une unificalion des modiss d. production à l'échelle planétaire. Cependant qu'elle déploie sur le grkhe sim réseau d'organisation lechnique, qu'elle fait, comme le disait dẹji D. IIolzman! en 1784, "de la terre qui consislait auparavant d'innombrables parlies isulie. 
une lotalité conncxen (1), elle unifie aussi les structures d'accueil de l'image fle la réussile professionnelle et aspire à homogénéiser la temporalité vécue. La pensée technologique procède comme si clle se donnait pour but de traiter des groupes sociaux de plus en plus vastes en unilés machinales; elle transporte dans l'organisme social les concepts el les méthodes de la production de série. Les seuls obstacles radicaux, mais peut-être provisoires, à son déploiement, tiennent à la difficulté de définir les faits sociologiques el à obtenir, instantanémenl el incessamment, toutes les informalions nécessaires aux décisions. Nourrie de raisons scientifiques, la penséc technologique est tenue encore à conjecturer sur les nécessités vagues qui animent les groupes sociaux. Le « technologue n lui-mème ne peut se déprendre de toutes sortes de déterminalions mythiques, il est en [ermé dans ses désirs, muré dans ses propres artifices. La pensée t.echnologicue n'est pas neutre ; mais en s'appuyanl sur une expression unifiantc des valeurs, en réduisanl le déploiement des diversités individuelles à des tabulations symboliques, elle crée un univers factice dans lequel demeureronl sans loute des disparités, mais que l'impérialisme des codifications tendra á homogénéiser sous le manteau colleclif des mélonymies du désir.

J. Guillenme,

Chef de travaux d la Facullè

de médecine de Besançon,

Instilul d'IIisloire des Sciences.
J. SEBESTIK,

Allache de recherches au C.N.R.S., Inslitul d'histoire des sciences.

(I) [L'art de mowemenl] * ordonne les pierres difformes en temples qui seraient dignes de la majesté de Dieu qui les labite, si les choses finies pouvaient être dignes d'un atre infini ; il cunstruil des palais dont la vue impose le respect pour ses habitants ; on lui est. obligé de ce yue les pays, séparćs par des océans, peuvent échanger leurs produits naturels et ceux de l'art, augmenter leurs richesses, rendre plus florissant leur commerce; il a fail de la terre qui consislait auparavant d'innombrables parties isolées pour ainsi dire une tolalilé connexe : car il a construil les navires dans lesquels le marin léméraire enserre le globe ; cet art nous relie avec les pays les plus lointains par les liens irréfragables de l'utilité et des inlérêts :. Donat Iolzuan,, Ersle Vorlesung vom wesentlichen Ein/luss der Maschinenlehre au/ dic qargerliche Gesellscha/l, Vienne, 1784. 
Errata

p. 51, note 1: L'Encyclopédie d'Alsted a paru pour la première fois en 1630 à Herbron (rééd. à Stuttgart-Bad Cannstatt, 1989-1990). 1609 est la date de la parution du Clavis artis Lullianae. L'encyclopédisme de Comenius vient d'Alsted qui fut son maître à l'université de Herbron.

p. 59, avant-dernière ligne du texte : lire pédagogie au lieu de pédagodie.

p. 74, ligne 7: lire notions au lieu de motions.

p. 87, ligne 1: lire pour la première fois dans un texte de 1769, ensuite en 1772 (1); ajouter à la note (1): Grundsätze der teutschen Landwirtschaft (1769), Vorrede.

p. 109, ligne 15: lire matière au lieu de manière. 